\title{
A Study of Demographic, Situational, and Motivational Factors Affecting Restraint Usage in Automobiles
}

\author{
J. M. B. Mayas \\ N. K. Boyd \\ M. A. Collins \\ B. I. Harris
}

Lawrence Johnson \& Associates, Inc.

4545 42nd Street, N.W.

Suite 103

Washington, D.C. 20016

Contract No. DTNH-80-C-17278

Contract Amount \$195,258

This document is available to the U.S. public through the National Technical Information Service, Springfield, Virginia 22161 
This document 18 alsseminated under the sponsiorship of the Department of Transportation in the interest of Information exchange. The Unlted States Government assumes no liability for 1 ts contents or use thereof. 


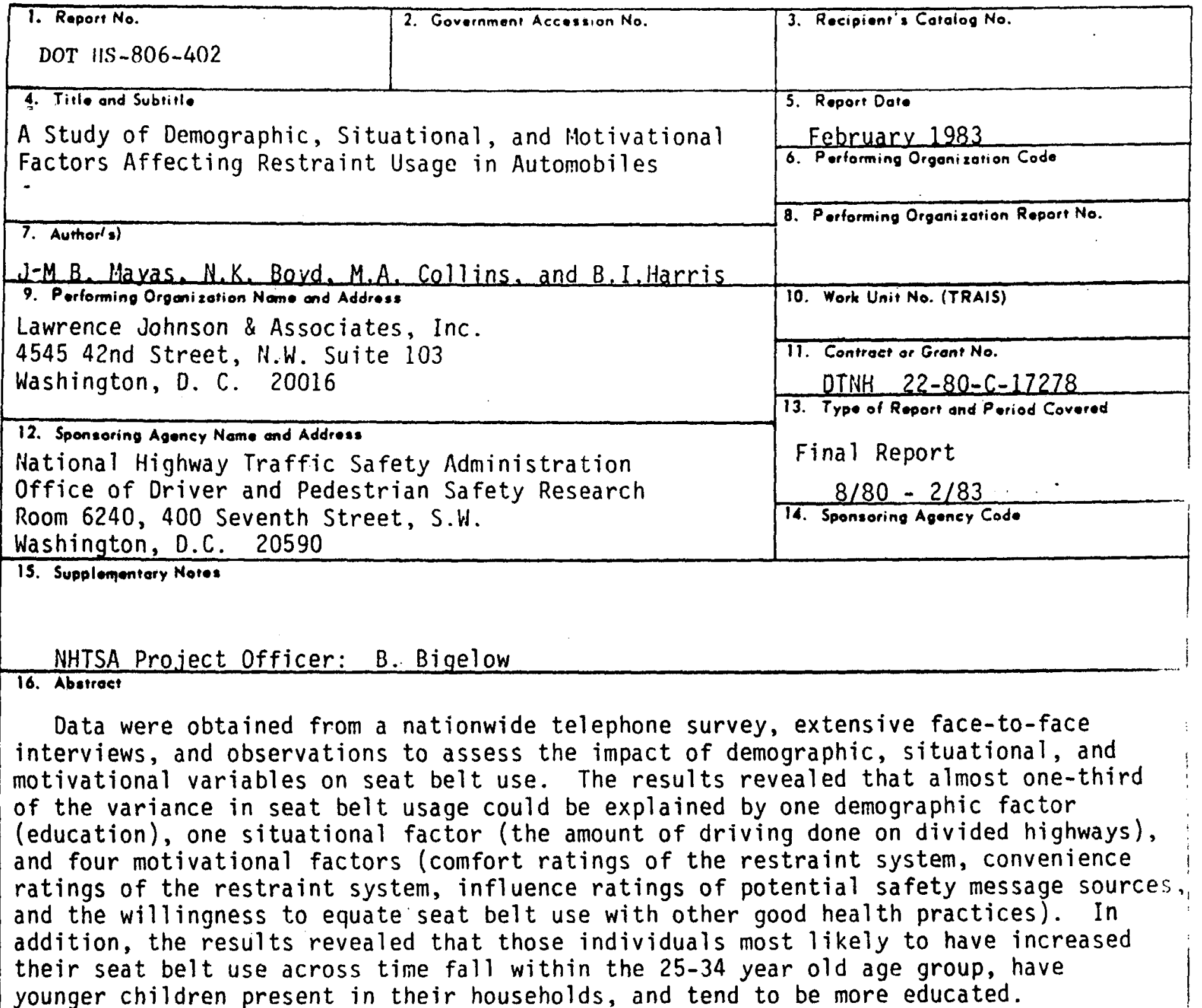

Despite a significant correlation between self-reported and observed measures of seat belt use, the results indicated that self-reported usage figures are somewhat inflated. In over $90 \%$ of the observed cases, seat belts were not being worn.

The data are useful in helping to design campaigns aimed at increasing restraint system use for both automobile drivers and passengers.

\begin{tabular}{|c|c|c|c|c|}
\hline \multicolumn{2}{|l|}{ 17. Koy Words } & \multicolumn{3}{|c|}{ 18. Distribution Stotement } \\
\hline $\begin{array}{l}\text { Seat belts; car rest } \\
\text { safety }\end{array}$ & automobile & $\begin{array}{l}\text { No restric } \\
\text { to the pub } \\
\text { Information } \\
22161\end{array}$ & $\begin{array}{l}\text { This documen } \\
\text { ugh the Nati } \\
\text { e, Springfie }\end{array}$ & $\begin{array}{l}\text { is available } \\
\text { nal Technical } \\
\text { d, Virginia }\end{array}$ \\
\hline $\begin{array}{l}\text { 19. Security Classif. (of this roport) } \\
\text { Unclassified }\end{array}$ & \multicolumn{2}{|c|}{ 20. Security Classif. (of this page) } & $\begin{array}{l}\text { 21. No. of Poges } \\
160\end{array}$ & 22. Price \\
\hline
\end{tabular}


METRIC CONVERSION FACTORS

Apareximate Conversiens to Motrie Alessures

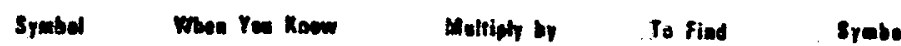

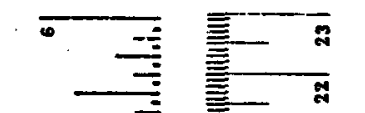

Approsiments Conversions from Motrie Mustures

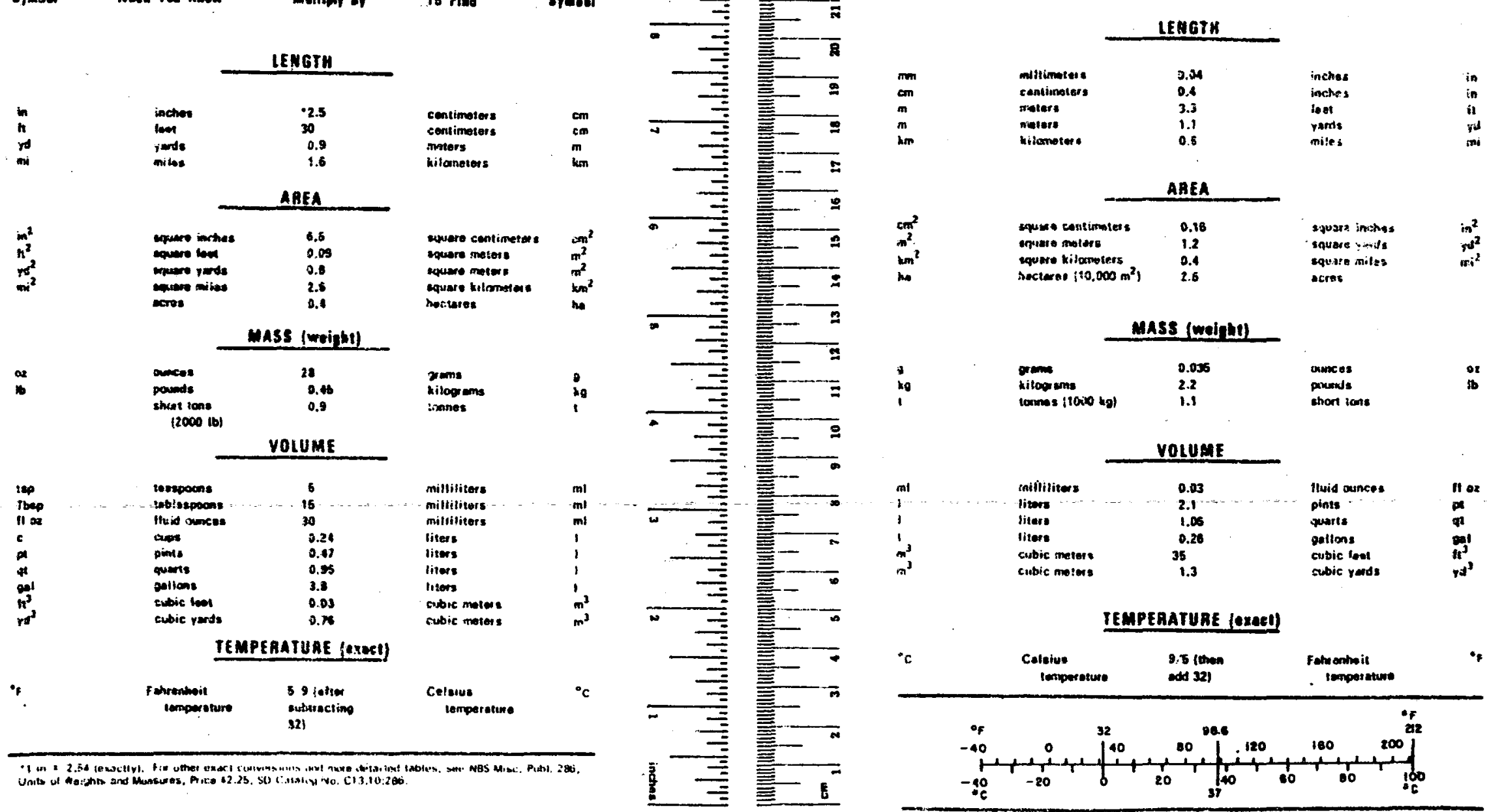




\section{FOREWORD}

This report presents the findings of telephone and face-to-face interview surveys of the demographic, situational, and motivational factors associated with seat belt usage. It is intended for use by the transportation research community.

The report is for distribution to the National Highway Traffic Safety Administration and to other transportation planners at NHTSA's discretion. 


\section{TABLE OF CONTENTS}

Page

Chapter I Background and Purpose...$\ldots \ldots \ldots \ldots \ldots \ldots \ldots \ldots \ldots \ldots$. 1

Project Role Within the NHTSA Driver and

Pedestrian Safety Program................................ 1

The Need for a Study of Factors

Related to Restraint Usage ................................ 1

Vol untary Use of Acti ve Systems

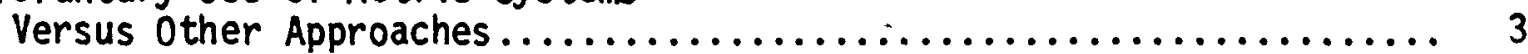

Goals of the Present Project.................................... 3

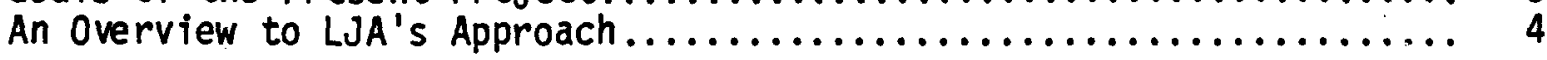

Chapter II Literature Review................................. 6

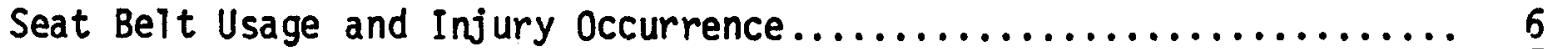

Seat Belt Usage Rates in the United States...................... 7

Seat Belt Usage in Foreign Countries:

Canada as an Example...................................... 10

Demographic and Situationa? Factors

Affecting Seat Belt Usage ............................... 12

Summary of Demographic and Situational

Factors Affecting Seat Belt Usage........................... 14

Motivational Characteristics of Seat Belt

Users and Non-users..................................... 14

Surmary of Moti vational Studi es $\ldots \ldots \ldots \ldots \ldots \ldots \ldots \ldots \ldots \ldots \ldots \ldots, 17$

The Fhaner and Hane Studies:

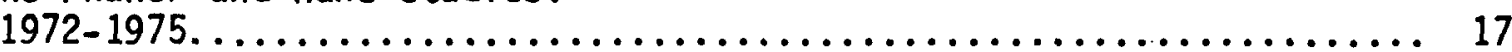

Surmary of Fhaner and Hane Studi es $\ldots \ldots \ldots \ldots \ldots \ldots \ldots \ldots \ldots \ldots, 19$

The Market Opinion Research (MOR) Study......................... 20

Surmary Regarding the MOR Study ................................. 23

"Samebody Needs You" Media Campaign............................. 23

Surmary and Conclusions Regarding the Literature Review............ 24

Chapter III Methodology....................................... 25

General Overview........................................... 25

Consideration and Selection of Methods......................... 25

Consideration and Selection of Samples........................... 26

Description of Ins truments $\ldots \ldots \ldots \ldots \ldots \ldots \ldots \ldots \ldots \ldots, \ldots \ldots \ldots, \quad 32$

Tests of Procedures and Methods ................................. 33

Methods to Maximize Response Rates $\ldots \ldots \ldots \ldots \ldots \ldots \ldots \ldots \ldots \ldots \ldots \ldots, 33$

Development of Research Questions $\ldots \ldots \ldots \ldots \ldots \ldots \ldots \ldots \ldots \ldots \ldots, 34$

Chapter IV Resuits....................................... 40

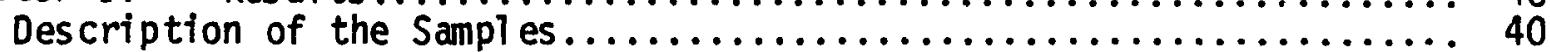

Results of the Telephone Survey.............................. 40

Results of the Face-to-Face Survey................................. 82

Observationa1 Data........................................... 105 
TABLE OF CONTENTS CONT'D

Chapter $v \quad$ Summary and Concl usions........................... 112

Seat Belt Usage ................................................ 112

Demographic Factors............................................. 113

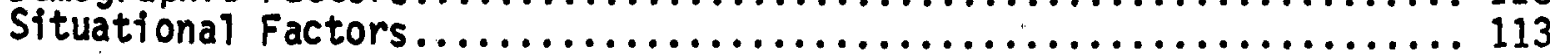

Moti vational Factors............................................ 114

References......................................... 117

Appendix A Telephone Intervi ew.................................. 121

Appendix $B \quad$ Face-to-Face Interview................................... 137

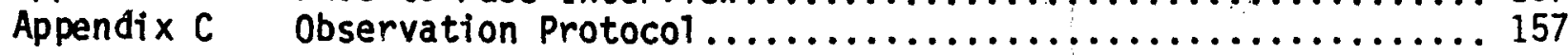


Project Role Within the NHTSA Driver and Pedestrian Safety Program

It has been established that a high percentage (as much as $85 \%$ ) of reported highway accidents are due to driver errors. Thus, one of the major program objectives of the National Highway Traffic Safety Administration (NHTSA) of the Department of Transportation (DOT) is to reduce the human element as a factor in motor vehicle and pedestrian accidents and their consequences through:

- better understanding of road user and pedestrian behavior in relation to accident causes,

- development and evaluation of effective countermeasures involving road users, and

- development of improvements in driver qualification, certification, and regulation systems.

To support the NHTSA goal of reducing accidents due to road user errors and rel ated accident-generating factors, one objective of highway safety research is to:

- survey and increase usage and acceptance of "automatic" and "manual" safety belts (or other restraints), both by improving belt system design and by developing new, more effective approaches, including public information and education programs and other positive motivational influences.

In this regard, NHTSA has been conducting research: to determine safety belt usage levels and trends, along with associated factors; to assess educational approaches to increase use of belts; to evaluate comfort and convenience of most belt restraints; and to develop specifications to improve these characteristics of both automatic and manual belts (or other restraints, such as those used for children under four years of agel.

The Need for A Study of Factors Related to Restraint Usage

Vol untary use of safety belts or child restraints is a non-typical human bellavior generally ranging from about $5 \%$ to $10 \%$ for child restraints up to about $10 \%$ to $20 \%$ for adult seat belt usage (e.g., ORC, 1980). This rate of usage varies somewhat with demographic characteristics (e.g., gender, SES, age, and rural versus urban drivers), situational factors (e.g., short versus long trips, passengers versus no passengers, and use of drugs or alcohol while driving), and motivational factors (e.g., "convinced" of the value of rês traints or not, or gamblers versus non-gamblers). However, in many cases there apparently is very strong resistence or aversion to restraint usage, often despite apparent knowledge of the efficacy of child restraints and safety belts. This situation suggests the following questions which are in need of study. 
Why are some people consistent users, while most others are only sometimes users or consistent non-users?

- What are the social characteristics (demographics) of people who tend more often to use car restraints and what are the demographics of people who are most open to persuasion toward greater use?

- What situational factors are rel ated to a greater tendency for restraint use and what circumstances are most promising for educational efforts toward greater use?

- What psychological factors motivate some people to be committed non-users, who resist appeals for seat belt and child restraint use, while some others are committed users or part-time users?

o. What approaches based on knowledge of social, psychological, or situational factors seem most promising for persuading: more committed non-users to become committed users, or at least to become part-time users; more part-time users to become committed users, or at least to become more frequent users; and committed users to continue their use and not revert to part-time or non-use?

In the case of adults and older children, it has been well established that the use of seat belts and other restraint systems substantially reduces the likelihood of death as a result of an automobile accident. On the average, studies (e.g., Bigelow, 1979) estimate that universal use of seat belts in the United States would reduce traffic fatalities by about $60 \%$ or about 20,000 or more per year. Studies also indicate that the severity of injury in non-fatal accidents also is substantially reduced in general by the use of car restraints (e.g., Phil pot, Perry, Hughs, Wyrick, Culler, Lo, Trent, \& Geiss, 1979). In addition to the social benefits associated with reduced fatalities and less catastrophic injuries as a result of seat belt usage, obviously millions of dollars in medical care, insurance, disability, litigation, and other costs associated with deaths and injuries resuiting from automobile accidents could be saved. For example, a recent study sponsored by the Insurance Institute for Highway Safety (Smart, Hartunian, \& Thompson, 1980) estimates the direct and indirect yearly costs attributable to motor vehicle injury to be $\$ 14.4$ billion (second only to cancer among major causes of death). Thus, even if only an additional $10 \%$ of the population of the nation could be persuaded to use seat belts regularly, about 2,000 (or more) lives could be saved each year, many more than this number would have lesser injuries than otherwi se each year, and many millions of dollars of injury and death related costs would be saved each year. Using the Insurance Institute estimate, even a mere $1 \%$ increase of non-users to users could save close to $\$ 100$ milition in death and injury costs yearly.

In the case of infants and young children, perhaps the most dramatic way to point to the value of greater use of infant and child restraints is to indicate that after the critical early weeks of life for the newborn baby automobile accidents are the number one cause of death and injuries among young children. About 4,000 children under the age of fourteen die each year in automobile accidents and tens of thousands are seriously injured (e.g., Claybrook, 1979). The evidence is (e.g., Scherz, 1978) that the correct use 
of well designed infant and child restraints is an effective preventative - measure (perhaps as high as $91 \%$ ) for decreasing fatalities and the severity of injuries as the result of automobile accidents.

\section{- Voluntary Use of Active Systems Versus Other Approaches}

There is clear evidence from studies in Canada and other countries that legislation coupled with strong enforcement doubles pre-law levels (e.g., Knapper, Cropley, and Moore, 1975) of seat belts use (even in countries such as France where the people often strongly resist government mandates). Also, in the one state having had a child restraint 1 aw for some time, Tennessee, there is evidence for significant increase in usage le.g., Philpot et al., 1979). Neverthel ess, for various reasons it is currently considered politically infeasibie to implement national legislation mandating the use of active restraint systems; nor, with the exception of a few states seriously considering child restraint legislation, is mandated use of active restraint systems considered feasible at the state level. Recent efforts have concentrated on mandating passive systems (e.g., air bags and automatic seat belts) and implementation of a national requirement was scheduled to begin with small cars in model year 1982 . However, given recent postponements due to manufacturer resistance, the reversal in priorities of initial implementation from large to small cars first, at the bequest of American manufacturers (despite their previous insistence of the initially reversed priority), arguments for a "choice", and a change in executive administration, the actual implementation has been somewhat problematic.

Whether or not passive restraint systems soon become standard on new car models, there are a number of good reasons for continued efforts towards increasing the usage of active restraints. During the at least ten year transition from active to passive restraints, many thousands of deaths and injuries could still be substantially reduced with an increase in usage of active restraint systems. Also, the continued installation and use of active systems will afford greater protection for adults and children as, for example, in the case of a side collision or a second collision in an air bag car. Thirdly, passive systems are designed mainly for adult usage and they simpiy do not sufficientiy protect young children or infants. Finally, continued efforts to study the reasons for non-use of car restraints may help ascertain the reasons why some individuals deliberately have defeated certain restraint systems in the past. This type of information will help mitigate against efforts to do the same with the passive systems.

Goals of the Present Project

A study in 1971, by National Analysts, Inc., entitled "Motivating Factors in the Use of Restraint Systems" (\#FH-11-7610), identified a variety of factors associated with restraint usage which helped direct many of the educational activities of NHTSA in subsequent years. Since that study was conducted ten years ago, some of the findings may be out of date, while others are probably as relevant as ever. Thus, there is a need for a new study to update knowledge about demographic, situational, and motivational factors affecting restraint usage to direct new or continuing NHTSA sponsored educational programs. 
Numerous studies have been conducted since 1971 which augment NHTSA's knowledge about circumstances related to restraint usage and non-usage and about the successfulness of educational approaches: While useful in guiding the research design for the present study, none of these studies is sufficiently comprehensive or definitive to meet the purposes for which the present study was contracted, namely to:

- identify all valid spectra of demographic, situational and motivational factors which may identify groups, circumstances or values which are associated with use of safety belts or child restraints.

\section{An Overview to LJA's Approach}

In this regard, LJA undertook a Phase I research design effort to develop an implementation plan for Phase II, including:

- review of relevant iiterature,

0 identification of factors and development of a conceptual framework,

0 development of an information gathering plan, and

- development of a data analysis plan.

While Phase II was designed to provide useable information to aid NHTSA in the development of education influence strategies as a resuit of the efforts proposed, the pian was developed in the context of presupposing a continued program of research (i.e., a Phase III and perhaps beyond) which would further build upon Phase II and provide additional refinement and validation.

Building on Previous Studies. The study approach builds upon the extensive research efforts of others detailed in LJA's review of the literature related to restraint usage. The first use of this literature review was to aid in a conceptualization that wou?d provide the theoretical framework for the study. A second use of this literature review was to aid in prioritizing variables likely to be most related to selat belt usage and to point to gaps in the literature. A third use of the literature review was to evaluate different methodologies utilized in other studies for their potential applicability to the study design and to point to areas fon improvement in methodology. A fourth use of the literature was to evaluate different data analytic techniques for the ir potential utility in Phase II, to point to areas of analytic weakness in previous studies, and to develop a stronger multivariate approach than previousiy utilized. Some of the ways these uses of the literature review came to fruition are summarized in the subsections which follow and are elaborated on in subsequent chapters.

Development of a Conceptual Framework. Substantial effort went into the deve Topment of a conceptual framework to organize and guide the research strategy for Phase II. Th is effort involved the development of more precise definitions and distinctions among the three types of study variables, developing sub-sets and subcategories, and, in some cases, placing particular variables into different categories than have other studies. This process was 
undertaken with the expectation that greater conceptual clarity and interpretability would thereby result. Specifying the conceptual models underlying the research plan al so greatly aided the development of appropriate methodologies and appropriate analyses.

Multi-Method Approach to the Data Gathering Plan. A major feature of the Phase II plan was to utiTize a mutti-method approach which builds on the complementary strengths and miti gates complementary weaknesses inherent in each single method approach. Part of this multi-method approach invol ved a representative national telephone survey component and a regional study component involving multi-site, multi-sample observations coupled with extensive follow-up face-to-face interviews. The first approach is stronger in regard to external validity (generalizability) and the second approach is stronger in regard to internal validity $(\mathrm{cl}$ arity and depth of understanding of the relationships among the variables studied).

Data Analysis Plan. The analysis plan called for the use of a broad range of analytic techniques, again to take advantage of the strengths of each technique and to mitigate the weaknesses. This approach assures a failsafe set of alternatives to achieve the research goals of Phase II. For example, there are three approaches toward infering causal relations and likely points of potential influence (change): inferences from group differences, from causal models, and inferences from change measures. The use of different analytic techniques was anticipated to achieve the maximal utility from the data in regard to comprehensiveness, clarity of understanding, efficient data reduction, and prioritizing optimal influence strategies.

The following chapters present a review of literature (Chapter II), a description of the projects' methodology (Chapter III), the results of the observations and surveys (Chapter IV), and conclusions and recommendations based on the findings (Chapter $V$ ). The observation protocol and survey instruments appear in the appendices. 


\section{CHAPTER II. LITERATURE REVIEW}

As part of this literature review, LJA utilized bibliographies or computer searches in the areas of adult restraint usage, child restraint usage, and driver behavior (Bi gel ow, 1979; NTIS, 1979; NHTSA, 1979a, 1979b; IIHS, 1980). These sources were supplemented by articles provided through informed sources and LJA library-research. In total, approximately 200 studies were considered in the literature review process. While all these studies in a sense bear on this project, only those most immediately germane to the discussion of factors affecting restraint usage are directly cited and referenced in this chapter.

In addition to literature directly bearing on restraint usage or driver behaviors, LJA consulted the general psychological and sociological literatures rel ated to demographic, motivational, and situational variables. Again, only those general 1 iterature studies or articles most explicitly tied to the study are directly cited and referenced in this document.

Seat Belt Usage and Injury Occurrence

There have been numerous studies related to the efficacy for seat belts to deter or minimize injuries due to motor vehicular accidents. For example, Campbe 11, 0'Neil1, and Tingley (1974) studied the comparative injuries to belted and unbelted drivers for a mix of car sizes. Their data base was one-half million accidents reported through official 1 aw enforcement auspices in North Carolina. Differentiating three injury cl asses--all injuries, .serious injuries plus fatalities, and fatalities-- the analyses indicated that for each car size regardless of injury class "belted drivers fare (d) better than unbelted drivers." It also appeared that with an increase in accident severity there is a corresponding increase in seat belt effectiveness. The Campbell et al. analyses indicated that with seat belt usage there is a reduction of death probability ranging fran $80 \%$ with 1 arger cars to $33 \%$ with smal1 import cars.

Comparable results have been found in foreign countries where seat belt usage has been pramul gated. In an Australian study, Foldvary and Lane (1974) studied data collected by the Commonwealth and states' statistical offices regarding motor vehicle traffic fatalities and the non-fatally injured. Their analyses indicated that for metropolitan areas, mandatory usage 1 aws contributed to a significant reduction in fatalities of about $21 \%$, and in both metropolitan and non-metropolitan areas the laws contributed significantly to a $13 \%$ reduction in non-fatal injuries.

Despite these examples of studies demonstrating seat belt effectiveness, there is still some controversy regarding the relation between seat belt usage and injury due to accident occurrence. On the one hand, Campbel1 (1969) showed that people who habitually use seat belts were more likely not to be injured in an accident; seat belt usage was virtually absent among drivers killed from accidents according to his study. Morris (1977), however, found that in some instances seat belts themselves contributed to injury occurrence in accidents. Studying nine models of 1976 automobiles subjected to the FMSS No. 301 compliance test, Morris found that certain structural deficits within the seat belt system contributed to injury in accident occurrence. 
Aside from some evidence that seat belts mav occasionally lend themseives to contributing to injury in acciderits, there are myths that the driving public voices suggesting that seat beits noi only contribute to, but cause serious injury and death. One popular myth, for example, is about the confining nature of seat belts, inhibiting a driver's or passenger's ability to be thrown clear of an accident and thus avoiding an injury in certain type of accidents (e.g., Sweeter, 1976). It is clear that this belief is properly labeled as a myth from a study conducted by Miller and Stark (1968). Their analyses of data regarding 800 accidents where occupants were ejected indicated the necessity of using seat beits and other restraining devices to minimize the deleterious effects of ejection.

Myths aside, the positive effects of seat belt usage far outweigh their negative potential (e.g. , Sabey, Grant, \& Hobbs, 1977). Therefore, it is quite clearly in the interest of the health and well being of the nation's drivers and passengers to use seat belts habitually. Seat belt usage in the United States has been and is currently low despite seat belt availability and the many efforts over the past twenty years to increase usage. The next two sections explore the seat belt usage levels for the United States and for selected foreign countries. There is a brief discussion of some methodological artifacts that may have significance for interpreting results of studies related to usage levels in the United States.

Seat Belt Usage Rates in the United States

Fhaner and Hane (1973a), in a comprehensive literature review, indicated that icat belt usage levels for the United States and foreign countries without mandatory seat belts laws ranged from $25 \%$ to $35 \%$. A review of more current seiected studies, summarized in Table II-1, suggests that that range may have $t c$ ise adjusted downwards. The data summarized in Table II-1 are for general seat belts usage patterns; there are some significant differences for usage patterns with select sub-groups. Those data are addressed in this chauter in the section on "Factors Affecting Seat Belt Usage."

In the summarized studies, there are a variety of methods which have been used to derive the usage levels reported which appear to have an impact on the reported usage levels. And while it is clear that the usage level ranges from no more than four-tenths down to approximately one-tenth (for the United States and foreign countries without mandatory usage laws), th is wide variation may have to do with how the usage behavior is defined and studied as we 77 as with the behavior itself. To interpret these studies better and to be able to generalize appropriately from their results, five methodological

comparatives will be discussed to account for the varying perspectives of seat belt usage behavior: 1) verbal versus observed reports; 2) single versus multiple observations; 3 ) item constructionwusage percentage versus cued response; 4) mailed versus telephone or face-to-face interviewing; and 5) truck observation versus on -the-street observation. (Because these comparatives are important to both the United States and the foreign countries studies, examples will be given irrespective of study origin.)

Waller and Barry (1969) did a study to assess differences in reported and observed seat belt usage. By observing seat belt usage in North Caroina and then sending questionnaires to the owners of the cars, Waller and Barry were 
Table 11-7. Selected Studies Reporting Restraint Usage: 1969-1980 Usage Percentages and Methodology used to Collect Data

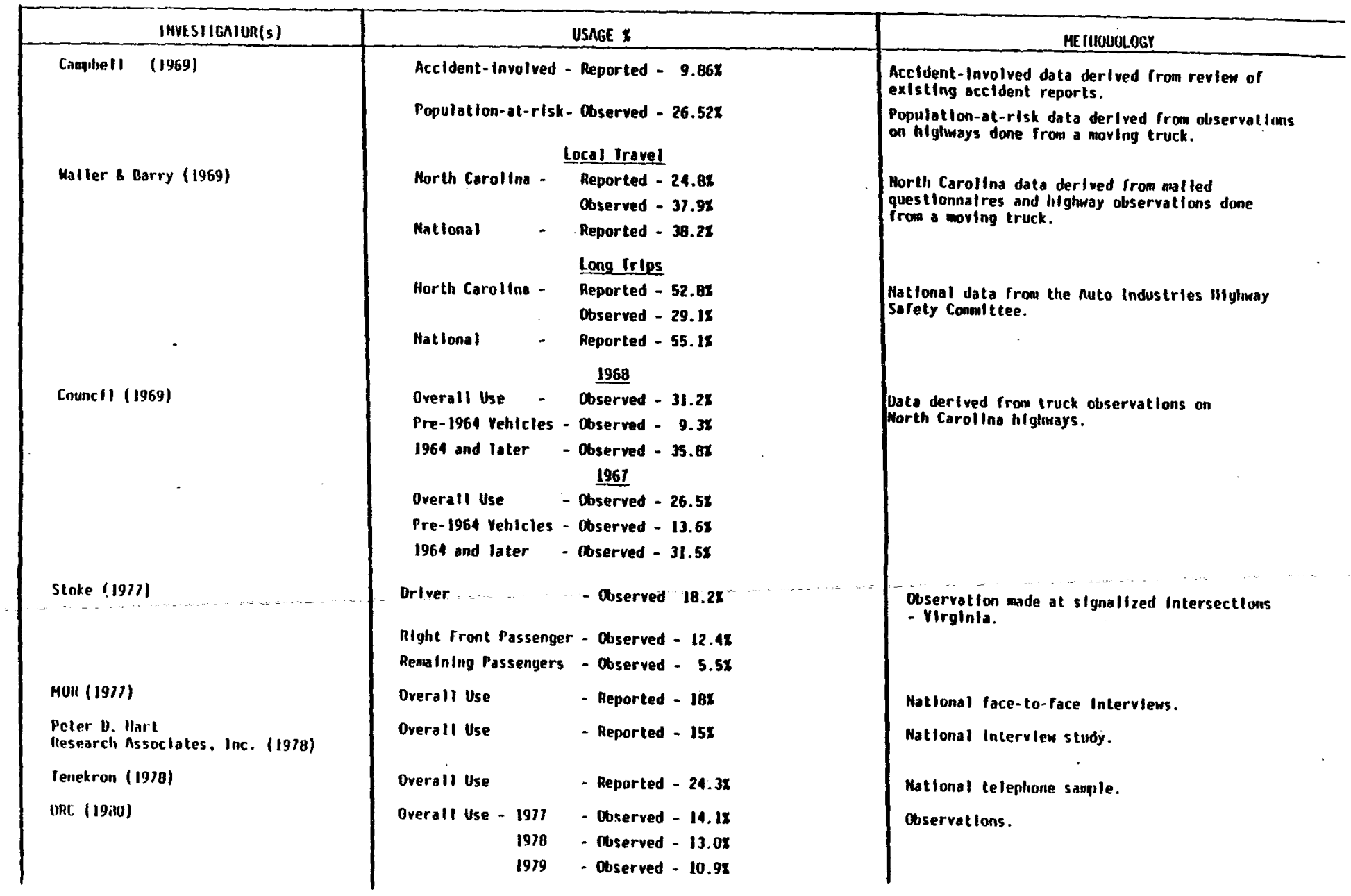


able to compare the reported and observed usage for $10 c a 1$ and 1 ong trips. Although the local trips sample was small $(n=29)$, making its results suspect, the long trip sample $(n=134)$ was 1 arger and seemingly more reliable. It appeared that there was a large portion of drivers on long trips whose behavior belied their verbal reports of seat belt usage. The data indicate that $23 \%$ accurately reported their usage behavior, $43 \%$ accurately reported their non-usage behavior, and $6 \%$ were observed using seat belts when they had reported variable usage (a consistent finding); however, $28 \%$ reported always using seat belts when in fact they had been observed not so doing. These significant findings suggest that a large portion of the driving population tend to misstate their seat belt usage. This behavior suggests that any verbal report of usage wi thout accompanying verifying observations may be subject to inflation. It does not, however, necessarily extrapolate to the position that assumptions and research done using verba? reports of seat belt usage as the dependent variable will be of suspect use (cf., in the Fhaner and Hane section of this report).

Fhaner and Hane (1974a), in a study to be discussed further 1 ater in this report, conducted multiple observations of driver seat belt usage. By doing a number of observations from a consistent site they were able to define a sample of "belt users" as drivers observed using seat belts five times or more. Non-users were defined as having a minimum of eight non-use observations. Considering that 87 out of the $105(83 \%)$ drivers in the final sample were observed using seat belts at least once and that the "belt user" subsample was reduced to $30(29 \%)$ when the five-or-more criterion was used, it convincingly suggests that studies using only one observation as their criterion for defining their belt user population are not assessing a homogeneous group with respect to usage behavior. This calls into question the generalization and interpretation of some study results (e.g., Robertson, 1977 .

Market Opinion Research (MOR, 1977) discussed the differences in respondent frame of reference that differentially constructed items can provide for drivers responding to questionnaires on seat belt usage. Their study assessed differences between a five alternative item on seat belt usage --always, most of the time, some of the time, very seldom, and never--and an item requesting the respondent to estimate their seat belt use in percentage of time $(0-100 \%)$. While MOR found that the degree of relation between these measures was good, there were deviations in estimates for the moderate and low range of usage behavior (those indicating 11-89\% usage). Differences with the variable usage groups suggests that researchers must be cognizant of the effects that the type of measure has on the classification of user groups. This caution should, of course, be extended to comparing the results of studies using different scales as measures of belt usage. These differentiations and how they divide the driving population are crucial for interpreting the study results.

Differences in response rate between mail, telephone, and face-to-face techniques have been noted that suggest potential bias. Fhaner \& Hane (1973a) in their literature review indicate that the response rate on mail questionnaires had been remarkediy 1 ow, sometimes bel ow $50 \%$. They suggest that "this self-selected sample might be biased along factors significant and relevant to the behaviors in question." It is less clear whether this error 
bias is due to this reason or the inadequate methodology under which most mail surveys prior to 1972 were conducted. Survey techniques in the seat belt study area have more recently concentrated on face-to-face (MOR, 1977) or telephone interviewing (Tenekron, 1978).

While most studies have conducted their observations of seat belt usage by placing people alongside of an intersection, either city street or highway ramp, researchers from the University of North Carolina Highway Safety Research Center have consistently used panel trucks driving along on city streets or highways when making their observations. Council's (1969) work represents the Center's approach. As evident from Table II-1, his observations show the highest usage rates among all studies reported. And, while his work occurred within North Carolina, there are no compelling reasons to believe that North Carolina drivers are so different from the rest of the country in their usage. It is suggested that the Center's use of panel trucks for single observations of seat belt usage might make for better vantage in deriving usage levels than does the person-on-the-street approach. This methodology would not be appropriate for deriving multiple observations of a sample; the person-on-the-street approach is seemingly the most effective in that regard. Again, however, this necessitates consideration when interpreting and generalizing from these reports. A key methodological implication is that whatever observational method is used, it should be consistent across types of observational settings if comparisons of usage rates are to be meaningfully interpreted.

Seat Belt Usage in Foreign Countries: Canada as an Example

As suggested previously the range of seat belt usage in the United States and foreign countries without mandatory usage 1 aws is $25 \%$ to $35 \%$ (Fhaner \& Hane, 1973a), with many recent studies showing even lower rates. Some foreign countries, such as Australia, France, and Canada, have instituted 1 aws requiring seat be1t usage for the populace. To assess the impact of 1 aws on seat belt usage, this section will use Canada as representative of countries with mandatory usage 1 aws. Also, since Canada is closer in distance and in cultural perspective to the United States and as Canada's seat belt usage before the 1 aws were instituted was comparable, Canada seems to be a particularly good model for drawing potential inferences for the United States.

Knapper, Cropley, and Moore (1975), as part of a study to assess attitudinal factors related to non-usage of seat belts, asked drivers in Saskatchewan about their usage behavior. At that time, there were no mandatory usage 1 aws in any Canadian province. In results comparable to American studies, $8.6 \%$ of their sample said that they always used seat belts on city streets ard $23.0 \%$ indicated that they always used seat belts when driving on the highway. These results compare well to the studies displayed in Table II- 1 .

In 1975, Ontario adopted a mandatory seat belt usage 1 aw that came into effect January 1, 1976. Robertson (1978) conducted a before-and-after-the-1 aw observational study to determine if the 1 aw had any measureable effect on usage. Observations conducted during December, 1975, indicated that the usage 1 evel was 21\%; this was one month before the 1 aws effective start date and generally the rates are comparable to the Knapper, Cropley, and Moore (1975) 
rates. Two months after the law became effective (February, 1976), observations were done and a dramatic increase to $71 \%$ usage was recorded. Six months after the law became effective (June, 1976), the rate had lessened to $48 \%$. In August of 1976, another set of observations were done and the usage rate obtained was identical to that recorded two months earlier. Robertson concluded from this that the June/August rate was probably sustainable.

Williams and Robertson (1979) conducted a similar type of study assessing the effects of a law which mandated daytime seat belt usage in Vancouver. Observations taken two and one-half years before the law was to take effect (March, 1975) showed a usage rate of $32 \%$. Observations that the authors conducted one week before the law's enactment (September, 1977) recorded a user rate of $50 \%$ and observations recorded a week after the law's enactment (October, 1977) showed a user rate of 79\%. Six months afterwards (Apri1, 1978), observations indicated that the rate had fallen to $67 \%$ and observations in the ninth month (July, 1978) showed only a drop of one percentage point $(66 \%)$.

These studies indicate clearly that mandated seat belt usage at least doubles previous seat belt usage: in the Ontario study, the pre-law rate was $21 \%$ and the time-eroded rate was $48 \%$, and in the Vancouver study, the pre-law rate was $32 \%$ and the time-eroded rate was $66 \%$. Assuredly, while this was not full compliance, the rates in sustained usage (after eight and nine months) are encouraging. It is conceivable that with effective and consistent reinforcement and with complementary media campaigns and educational programs, these rates can not only be sustained, but raised to even higher levels than the initial user compliance levels of $71 \%$ and $79 \%$ (Williams \& Robertson, 1979).

The experience of foreign countries promulgating mandatory seat belt usage suggests that driver user levels can be raised dramatically and, while slippage will occur, the effect of the law still will double previous user levels. However, it has also been the experience of foreign countries that this promulgation is a long, tedious process involving as much as ten to fifteen years of active persuasion and legislating before any serious action is undertaken. As the United States is currently politically very far from actively considering any federal or state adult seat belt law of this stature, it is unlikely that in the foreseeable future that compulsory use will be mandated here other than for child restraints in some states. Thus, persuasion, rather than forced compliance, must be used to effect a change in seat belt behavior. To persuade the populace to change their driving habits will require an understanding of the factors that affect seat belt and other automobile restraint usage. The rest of this chapter will explore: the factors that influence seat belt behavior, focusing on the demographic and situational factors; the characteristics of seat belt users and non-users; a series of important studies conducted by Fhaner and Hane on seat belt usage; an embracing study conducted by Market Opinion Research on identifing crucial factors related to seat belt usage; an example representative of media studies--the "Somebody Needs You" campaign; and a summary discussion about what implications these data have to regarding subsequent research. 
This section explores the effects that demographic and situational factors have on seat belt usage. The backbone of this section is derived from a literature review conducted by Fhaner and Hane (1973a). As this literature is to some degree dated, if newer studies efther extend or make obsolete the results of the Fhaner and Hane review, then these studies are noted to update the review information.

The demographic factors, as defined by Fhaner and Hane, include: age, sex, education, socio-economic status, marital status, urban-rural, annual car mileage, car age and structure, and accident history. Situational factors include: highway versus city driving, distance and speed, weather conditions, and time of day and week. A major discussant of many of these variables, the MOR study, will not be presented here in depth as attention is paid to it in a separate section.

Age. Fhaner and Hane report that some studies show a positive relationship between seat belt usage and age: older drivers tend to use seat belts more of ten than younger driyers. They indicate, however, that some studies show no relationship. Recent studies tend to support this 1 ater finding (ORC, 1980; Beitel et al., 1974). The MOR (1977) study suggests that while there may be a relationship between age and seat belt usage, it may not be linear, and, as such, is less than "clearcut."

Sex. Fhaner and Hane indicate that most studies indicate no gender differences in usage. More current studies tend to support that finding (e.g., ORC, 1980).

Education. Almost all studies (Fhaner \& Hane and others) indicate that the more educated tend to use seat belts more often. This effect is the strongest and most consistent of all demographic variables.

Socio-Economic Status (SES). As measured either by occupation and income (Fhaner \& Hane) or by just income (Beitel et al., 1974), socio-economic status is a positive predictor of seat belt usage. The reader should bear in mind the strong positive relationship between socio-economic status and education, as it appears that the variance of education accounts for much of the socio-economic status relation with seat belt usage (MOR, 1977).

Marital Status. The literature suggests that married people as compared to single people tend to be seat belt users. The MOR study, while confirming the above finding, found, however, that there was a negative relationship between usage and children in the household.

Urban-Rural. Fhaner and Hane's review indicated that people in urban areas tend to use seat belts more than people in rural areas. Recent studies (e.g., ORC, 1980) confin that conclusion.

Annual Car Mileage. Fhaner and Hane's review is inconclusive regarding seat belt usage and the number of miles driven within a given year. Some studies show a positive relation, some a negative relation, and one reports an inverted " $U$ " relation, with increase usage up to a certain mileage point and 
then a decrease in use thereafter. Recent studies (e.g., Beitel et al., 1974) indicate that there is no relation between the variables. In the Fhaner and Hane review, the Americans studies were very old (1963, 1964) and they were the only studies to show any positive relationship; thus, it might have been a temporal artifact that caused those results. The American studies occurred before compulsory installation of seat belts was mandated, and studies since then in America and foreign countries have not replicated those earlier findings .

Car Age and Structure. Fhaner and Hane and more recent studies seem to indicate that new cars owners are more likely to use seat belts than owners of older cars (taking care to include in the older car range only those cars from years after mandatory seat belt installation). Studies such as ORC (1980) indicate that owners of smaller foreign cars tend to use seat belts more than owners of the 1 arger American cars. A cursory look at these data seems to indicate that both variables (small versus 1 arge cars and foreign versus domestic cars) may be independently rel ated to usage rates.

Accident History. Suprisingly, accident history has been found to be unrelated to seat belt usage in virtually all studies (Fhaner \& Hane 1973a; Beitel et a1., 1974; MOR, 1977).

Highway Versus City Driving. A most consistent situational effect las consistently found as the effect of education) is the difference in seat bel $t$ use for city and highway driving. Fhaner and Hane and current studies included in this review find that there is a higher usage reported for highway driving than for city driving. There are, however, some real differences in the observed behavior for some persons and the verbal reports of their seat belt usage (e.g., Wallace \& Barry, 1969); for the most part, though, verbal reports and observations are closely related in this regard.

Distance and Speed. These variables seem to replicate the highway finding for most drivers. With the perception of a long trip at high speeds, Fhaner and Hane and others have found that drivers report a disposition towards seat belt usage.

Weather Conditions. Fhaner and Hane indicate that verbal reports of usage tend to indicate higher restraint usage rates for driving in bad weather compared with good weather. However, observations of drivers in dry and wet weather situations do not show significant differences in usage (OCR, 1980).

Time of Day and Week. The results regarding the influence of time of day on seat belt usage are inconclusive. Fhaner and Hane found that while some verbal reports indicate higher usage at night, an observational study found no such trend. The ORC (1980) study reinforces the no difference finding of the observational study. The same type of result is found regarding time of week. While studies soliciting verbal reports indicate that seat belt usage is more likely to occur on weekends, observational studies do not confirm this (Fhaner \& Hane 1974b; ORC, 1980). Beital et al. (1974) did an observational study and found differences between weekday versus weekend driving and seat belt usage, -but their observations were specifically for night driving. 
Summary of Demographic and Situational Factors Affecting Seat Belt Usage

Exhibit II-1 summarizes the demographic and situational factor effects on seat belt usage as reported in the literature.

For demographic factors, a profile of a seat belt user based on the literature would suggest a well educated, higher status, married, urban dweller with a newer, smaller, foreign car. For situational factors, a profile would suggest that driving on the highway at high speeds and longer distances would have an effect on seat belt usage. For the demographic profile, education, and for the situational profile, highway driving, seem to be the most significant, consistent, and effective predictors of seat belt usage. Discussion of these profiles will be augmented in the sections discussing the MOR study and the 1 ater Fhaner and Hane studies.

Motivational Characteristics of Seat Belt Users and Non-users

The previous section presented research profiling the demographic and situational effects on seat belt usage. This section surveys studies detailing the psychological characteristics of seat belt users. The purpose is to determine the motivations of seat belt users, variable users, and non-users. It is assumed that cognizance of the different motivations for these three groups aids in the ability to design efforts to inf? uence behavior.

This section discusses four studies: Sweeter (1967); Dobson (1971); Marzoni (1971); and Helsing and Constock (1977). Two studies that also present user profiles, Fhaner and Hane (1974a) and MOR (1977), are discussed in their respective sections. The contextual frameworks of the latter two studies dictate separate considerations that will aid in understanding the work presented in both this and the previous sections.

Sweeter (1967) conducted interviews in the metropolitan Boston area on a "purposive" sample of 197 drivers divided equally into three groups: male commuters, female commuters, and mothers with cars. (The above purposive. sampling is in quotes because the author, aside from stating such, gives no other indication about how or from where the sample was derived.) The author had the subjects in these samples respond to a nine item attitude scale regarding seat belt effectiveness and safety, scored on a four point Likert-style basis: agree strongly, agree somewhat, disagree somewhat, and disagree strongly. Responses to these nine items were subjected to a factor analysis out of which three scales were derived: a good equipment scale (GE), a safe to use scale SU, and a peace of mind scale (PM). (While LJA has some research concerns regarding the validity of doing factor analysis with such a small item base, we have more concerns with the author's development of the PM scale. While the data show that the GE and SU scales were clearly loaded on the two different factors produced from the factor analysis, the PM scale items were equally loaded on both factors. Creating a scale with these items seems to viol ate the statistical interpretation of factor analysis and it is not clear how and by what analytic extrapolation this scale was created. Its subsample correl ations presented below do little to allay our serious methodological and analytic concerns.) 
Exhibit II-1. Summary of Demographic and Situational Relationships with Seat Beit Usage.

- Demographic Variables

Age

Sex

Education

Socio-Economic Status

Marital Status

Urban/Rural

Annual Car Mileage

Car Age and Structure

Accident History

Situational Variables

Highway versus City Driving

Distance and Speed

Weather Condi tions

Time of Day and Week $t=$ studies indicate positive relation
Relation with Seat Belt Usage

$+/-$ (inconclusive)

no relation

+ (more education, more use)

+ (higher status, more use)

+ (married, more use)

+ (urban, more use)

no relation

+ (new car, more use)

+ (smaller/foreign, more use; larger/American, less use)

no relation

+ (highway driving, more use)

+ (more distance/speed, more use )

$+1-$ (inconclusive)

$+/-$ (inconclusive)
$-=$ studies indicate negative relation
$+1-=$ both positive and negative relation- ships


Sweeter correl ated these factors with the different subgroups of seat belt users. For male users, the GE scale was the only significant predictor of their usage. For female users, while the GE scale was a significant indicator of usage, the SU scale was a more salient predictor. For mothers, while al? the scales significantly predicted their usage, the PM scale was clearly the more meaningful. These results suggest that there are characteristics and dispositions or attitudes that should be considered and emphasized when appealing to different subsamples of the population to increase their restraint usage.

Dobson (197.0) reports on a campaign by the E.I. du Pont de Nemours \& Co., Inc., at its plant in Martinsville, Virginia, to educate its employees about seat belts and to promote increased usage. Although the details of this report are sketchy, it is apparent that 500 employees were interviewed by telephone and 500 were interviewed by mail. Both methods had a $90 \%$ return or contact rate. These surveys were designed to determine the effects of the safety and educational campaigns. The results suggested to du Pont that the campaigns were successful.

To contribute to the development of the campaign, du Pont hired Dr. Pau? Fine to determine fron the survey what motivational factors regarding safety and seat belt usage he could unearth. Fine suggested that there appeared to be three distinguishable groups: innovaters, traditionalists, and the majority. Innovaters tended to be seat belt users. Their perspective suggested that cars were not perfect instruments, but that there was potential for a driver to control some aspects of the driving situation and using seat bel ts would be one way to do so. Traditionlists tended to be non-users. For this group, the car was considered a "fortress" in which they felt protected from danger and their security feelings contribute to a non-usage pattern. The innovators and traditionalists were smaller groups than the majority. The majority group used seat belts variably and their orientation was somewhere between the other two groups: They realized the car's danger potential, but still identified it as a security item.

Marzoni (1971) conducted interviews on a national probability sample of 1,500 licensed drivers, aged 16 to 64 , who had seat belts on their personal cars. This sample was supplemented by 250 interviews with drivers whose seat belt usage was observed when coming into gasoline stations. By doing a factor analysis on responses to 55 statements regarding seat be1t attitudes, Marzoni was able to categorize virtually all of his saniple into five distinct 0 factor segments: "convinced (43\%), gambling (7\%), pholic $(22 \%)$, impatient $(6 \%)$, and skeptical (16\%); $6 \%$ were unclassifiable. The itatement that best identifies the "convinced" group is: "wearing belt is physically very comfortable." The statement, "whenever I feel uneasy about driving I put on the belt," best identifies the "gambling" group. The "phobic" group is best identified with the statement: "panicked at thought of being tied and trapped." The statement, "silly to put on when going only a few blocks," best identifies those in the "impatient" group. The statement that best identifies those in the "skeptical" group is "seat belts can do you as much harm as good."

Marzoni also asked the sample whether they always, sometimes, or never used seat belts. While there were none of the $Q$ factors that could account for or differentiate completely the three usage groups, those who were 
identified as members of the "convinced" and of the "gambling" groups tended .to have higher percentages of seat belt usage; members of the "skeptical" group were more often non-users; members of the "phobic" and of the "impatient" groups tended to be variable users.

Helsing and canstock (1977) studied the relation of a number of psycho-social variables, smoking, drinking, alienation, belongingness, norml essness, powerlessness, agression and others, along with demographic, behavorial, and socio-economic variables, with seat bel $t$ non-usage. They studied 1,009 respondents from Washington County, Maryl and, with family cars equipped with seat belts. They found that the most significant psycho-social behavioral variables predicting non-usage were the powerlessness scale (high scores are related to non-usage) and the cantrill ladder of life (low level pl acement is related to non-usage).

Sumary of Moti vational Studies

These studies indicate that there are some relationships between attitudes and other psychological constructs and seat belt usage. The studies have typically studied psychological variables in isolation from demographic and situational variabies, which probably accounts for the inability of their psychological (motivational) profiles to account adequately for more than just. modest percentages of the behavior of seat belt user groups. The MOR study is a good example of a study that tries to rectify this situation.

The Fhaner and Hane Studies: 1972-75

Gunilla Fhaner and Monica Hane were associated with the Psychology Department at the Uni versity of Uppsala, Sweden, during the early 1970s, where they conducted a series of studies that constitute an important contribution towards understanding seat belts usage. By researching contextual factors and biasing of reports on usage, the situational effects on usage, the relationship among beliefs, attitudes, and usage, and the effect of changing beliefs on changing usage, Fhaner and Hane provide an information base that is extended by the MOR study reported on next. This section presents in sequential detail results of the Fhaner and Hane studies.

Fhaner and Hane (1974b) conducted a study to determine if the discrepancy often reported between verbal accounts and observations of seat belt usage was due to a social desirability response set. In other words, they studied if inflated reports of usage were due to respondents' desires to present the "correct" response rather than an accurate representation of usage. To make this determination, seat belt usage of 257 drivers was observed in running traffic. These drivers were subsequently interviewed by telephone to determine their seat belt use habits and their opinions on a seat belt use $1 \mathrm{aw}$. One-half of the sample was told that their seat belt usage had been observed, while the other half was not so informed. This procedure created a situation where bias in reporting usage could be determined. Results from the many analysis of variance tests conducted suggested that a social desirability response set does not affect reports on seat belt usage. Given that result, Fhaner and Hane suggest that researchers who rely on verbal reports of seat belt usage in the conduct of a study designed to interpret attitudes regarding seat belt usage might be in a sounder position than previousiy supposed. 
Fhaner and Hane (1973b) conducted one of a series of two-part studles to determine the influence of situational factors on usage. (These two-part studies usually involved combinations of methodologies: the first part of a study would be based on verbal reports about an issue, while the second part would attempt to validate the verbal reports through some observational assessments.) Via previous literature, Fhaner and Hane determined a number of factors that might have some effect on seat belt usage: city vs. highway travel, distance of trip, speed, weather conditions, road conditions, vehicle density, time of day, time of year, passengers, belt accessibility, clothing, purpose of trip, familiarity of road, state of hurry, mood, and actual accident risk.

Devising a questionnaire with at least two questions for each of these variables, differentially specified for highway and city driving, culminated in the development of an 83-item two-part questionnaire: 40 city driving questions and 43 questions oriented towards highway driving. These questionnaires were used to conduct face-to-face interviews with 75 persons randomly selected from vehicle registration lists for Uppsala, Sweden. The data indicated that, while there were apparent differences in reaction to the cues of highway and city driving, within those cue frames there was iittle variation. Analysis of variance and other statistical tests on the data suggested that inter-individual variation was more significant than the effects of situational factors.

The second part of this study was designed to validate through observations the results derived from the verbal reports. Eschewing a complete validation of all questionnaire items as unreasonable and infeasible, Fhaner and Hane narrowed their concern to issues that could be assessed given a repeatedly observed sample in a uni-dimensional situation. Observing a sample of 105 drivers during "the morning hours $(6: 30$ am to 8:05 am) a certain number of times," the sample was divided into two groups regarding seat belt usage: 25 users were observed using belts at least five times and 80 non-users were observed not using belts at least eight times. Persons in these groups were identified and their responses were solicited by interviewers asking them about nine items from the highway part and eight items from the city part of the questionnaire. As this sample was not randomly selected, the results were presented with some caution. The results of the analyses done on the data from this observational part of the study confimed the findings obtained in the section based on verbal reports.

Since this study indicated that inter-individual differences accounted more significantiy for variation in seat belt usage than did situational factors, Fhaner and Hane were led to conduct another two-part study regarding the relationship between beliefs, attitudes, and seat belt usage (Fhaner \& Hane, 1974a). Fhaner and Hane constructed a questionnaire based on a model relating attitudes to behavior. This questionnaire was mailed to 545 private car owners randomly selected from registration lists of orebro county, Sweden. "A final sample of 368 (68\%) respondents was finally procured. Assuming that there would be substantial correl ations among factors, an oblique factor analysis was done on the questionnaire items. Examining the items within the five factors obtained, the labels "discomfort," "worry," "risk," "effect," and "inconvenience" were given. The discomfort (D) and effect (E) factors combined to give the best correlation with verbal reports 
of usage behavior. The effectiveness of this two factor relation was then validated during the second part of this study using an observation sample-described in the previously discussed study (Fhaner \& Hane, 1973b). The correl ational analyses al so indicated that the users/non-users categories were differentiated significantly by items extracted from the questionnaire representing the two factors. These results led Fhaner and Hane to posit a model of seat belt usage based on the factors: "discomfort" of belt usage and "effect" of belts in an accident. These were rel ated to a general attitude regarding seat belt usage which in turn was predictive of usage itself.

To determine whether this model would be useful in changing attitudes and actual use, Fhaner and Hane (1975) studied the effects of various educational efforts to change the beliefs and behavior of seat belt non-users. By viewing drivers who were workers at a steel company every morning and evening for a nine-day period, a sample of 154 persons was obtained who met the following criteria.

- They were observed on at least 9 out of the 18 occasions .

$0 \quad$ They had not worn a seat belt on any of the occasions.

0 They were willing to be involved in a research project.

0 They had the time and ability to come to the educational sessions.

This sample was randomly assigned to one of the six treatment groups. The pretest was a measure assessing seat belt beliefs. The posttest and follow-up instruments were the same as the pretest instrument except that the wording and numbering of the questions were different. Treatment 1 was an education session offering verbal information relevant to seat belt usage; Treatment 2 was a practice session on seat belt usage; and Treatment 3 was a session with verbal non-relevant information. The posttests were administered at the end of the group settings. The follow-up questionnaires were mailed to the respondents' homes 1 ater. Follow-up observations were al so done to determine if there were any changes in usage behavior as a result of the interventions.

The multiple analyses generally indicated that Groups 1, 2, and 3 had significantly different belief patterns and significantiy different short term usage patterns as a result of the treatment as compared to the non-experimental groups (Groups 4, 5, and 6). The analyses were interpreted to suggest support for the $D+E$ model and support for the specific effect of the discomfort factor. The effect factor by itseif seemed to have more support for influencing short-term rather than long-term belief change.

Summary of Fhaner and Hane Studies

The Fhaner and Hane studies (1973b; 1974a; 1974b; 1975) are important contributions to understanding seat beit usage behavior. These studies indicate that: 1) drivers tend not to respond with a social desirability response set to queries regarding seat belt usage; 2) aside from the different settings of city and highway driving, other situational variables have much less explanatory power than inter-individual variables regarding the variation in explaining seat belt usage; 3 ) in seat belt usage, two factors, discomfort 
and effect, are very important; and 4) an education program designed to change beliefs oriented around a model with the discomfort and effect factors as exogenous variables would have a positive effect in influencing seat belt usage.

The Market Opinion Research (MOR) Study

Market Opinion Research (MOR, 1977) was contracted by the General Motors Corporation to conduct a study entitled "An Analysi's of the Factors Affecting Seat Belt Use." This comprehensive effort studied many of the factors, their interaction, and relative effects that the literature had determined to have a relation to seat belt usage. Fhaner and Hane (1973a) in their literature review remark that while many variables have been studied and related to seat belt usage, these variables were typically studied in isol ation of each other and their relative effects had not been assessed. To make this assessment, the MOR study fielded a varied questionnaire.

The MOR report addressed the following objectives.

- to specify those factors most closely related to current seat belt use (or non-use)

- to assess the relative strength of those factors against one another, and to rank order their importance

0 : to array the interrelationship among factors and evaluate their direct and indirect impact on seat belt use

- to draw conclusions from this evidence as to optimal methods or strategies to increase seat belt use

To address these objectives, MOR conducted door-to-door interviews on 1667 drivers, aged 15 years and up, selected via a "probability-proportionateto-size multi-stage clustered sample of occupied dwellings based on the 1970 Census" and yearly updates. The sample was asked to rate their percentage of seat belt usage, which was then tricohtomized: $45 \%$ the sample were 1 abeled non-users ( $0 \%-10 \%$ seat belt use); $20 \%$ of the sample were labeled moderate users (11\%-89\% seat belt use); and $18 \%$ of the sample were 1 abeled confirmed users $(90 \%-100 \%$ seat belt use $)$.

The remainder of this summary of the MOR report is discussed and is organized by the four objectives previously noted.

- To specify those factors most closely related to current seat belt use (or non-use)

An extensive literature review indicated that there were six identifiable sets of variables that would be predictive of seat belt usage. The six sets are:

1) demographic characteristics including age, education, family income, occupation, number of years driving and others; 
2) Structural characteristics of vehicles and restraint systems including type of seat belts, make and size of car, type of warning systems;

3) perceptions of vehicles and restraint systems including feelings of comfort and convenience, and the safety of vehicles;

4) attitudes about driving and seat belts;

5) interactions among drivers and passengers in vehicles; and

6) events (such as driver's training) and conditions (such as adverse weather).

Measures assessing the specific variables within these predictor sets comprised the basis of the questionnaires.

- To assess the relative strength of those factors against one another, and to rank order their importance

To determine which of the specific measures within each predictor set was most rel ated to seat belt usage, while controlling for the variance accountable to the other sets, multiple classification analyses (MCA) were conducted. Aside from the MCA giving those specific measures most rel ated to seat belt usage, it also gives an indication of the amount of variance lagain, holding the effects of other sets constant) that the measures from that set take into account. This relative percent of the variance for which that set can account is presented in Table II-2 for each predictor set alongside of those measures which define the predictor, differentiated into two groups: one that appeared to be more predictive and another that appeared to be less predictive.

It is apparent that attitudes, social interaction factors and perceptual factors are strong predictors. These results clearly extend the work reported in the Fhaner and Hane section. The MOR study replicates the minor contributions of demographic and situational factors (represented by the demographic and events predictor sets) that Fhaner and Hane (1973a, 1974b) found and tends to emphasize inter-individual variation as a more prominent concern. The Fhaner and Hane studies indicated that discomfort and effect factors were related to seat belt usage. The MOR study notes similar findings given the strength of the components of the attitude set and the perceptual set. The MOR extends the range of contributing effects in its inclusion of social interaction, a variable set not taken into account by Fhaner and Hane.

To provide an assessment regarding which of the specific measures was most accountable for the seat belt usage of the total sample and the three usage groups, a summary analysis was done using the component measures within each

- set that had proven to be viable predictors. The result of the summary analysis is in Table II-2. The results indicated the importance of the social interaction, events, attitudes and perceptual component measures for the total sample. For the comfirmed and nonuser group, the event, social interaction, and structural predictor sets were the most important. For the moderate user group, social interaction and attitudes were apparently the strongest predictor sets. 
Table II-2.

Results of the MCA (MOR, 1977)

Predictor Group and $\%$ of Variance

Accountable

Demograph ic- $2 \%$

Structura $1-11 \%$

Perceptual-32\%

Attitudes-48\%

Social Interaction $-40 \%$

Events $9 \%$
Less Predictive

--occupation

- sex

--we ight

--height

-- income

--number of years driving

- marriage

- year of car

-- inter lock system/ disconnect interlock

--type of warning system

-- if belts are in the back

- -safety of the vehicle --discomf ort

--best and worst safety feature

--careful driving

--worry about accidents

--fear of major accidents

--concern about specific types of accidents

--amount of encouragement and advice from others

--friends and relatives interacting with driver

--city/suburban driving

--marriage

- -having a child

--knowledge of personal experience with an accident
More Predictive

--education

--age

- number of cars

- urban/rura 1 .

--type of belt system

--type of vehicle (size)

--make of vehicle (manufacturer)

-- inertia mechanism

-- if the buzzer was defeated.

--comfort

-- inconvenience

--important safety feature

--seat belt effect

--entrapment

--driver interacting with teen-ager and adults

--total passenger interacting with driver

--driver to children under 5

--message discrimination

- -new car

- -we ather

--highway driving

--driver's training

--propensity to use seat be $7 t s$ 
To array the interrel ationships among factors and evaluate their direct and indirect impact on seat belt use

Using the measures that were determined to be related to seat belt usage, MOR constructed a model of usage. Their complicated model was assessed using path analysis; the three measure effects determined to be significant were: 1) a general affective attitude; 2) interactions of driver with adult and teenage passengers regarding belt usage, and 3 ) the propensity to use seat belts.

- To draw conclusions from this evidence as to optional methods or strategies to increase seat bett use

The MOR report suggests the following six prioritized program activities that, if coordinated, would likely lead to increased seat belt usage.

1) Establish a seat belt information center.

2) Get seat belt information to new car buyers.

3) Support media campaigns and other information di ssemination activities which emphasize interaction themes.

4) Identify and implement positive reinforcement devices as part of the design of passive and nonpassive restraint systems.

5) Support educational specialists and other professionals who have some responsibility in promoting seat belt use.

6) Lobby for materials on vehicle safety features and their use to become standard features of all relicensing examinations and procedures.

Sumnary Regarding the MOR Study

Although there are some methodological and theoretical concerns that LJA has about the MOR study, they do not detract from the major and extensive contributions of the study. Clearly the study represents a progression and extension of research knowledge regarding seat belt usage upon which other research designs can build.

"Somebody Needs You" Media Campaign

of all the media campaigns that are noted in the 1iterature, the "Somebody Needs You" campaign is potentially the most clearly supported by literature findings, the best designed campaign, and the most studied. It al so seems to have generated a fair amount of controversy regarding its impact that appears to have been out of proportion with the import of the campaign.

The Motor Vehicle Manufacturers' Association in 1.976 commissioned a national study from Yankelovich, Skelly, and White regarding the use of restraint systems. With the results of that study, the automobile industry formed a non-profit corporation called Motorists Information, Inc. (MII) whose task was "to evaluate the monitoring public about the value of safety belts" 
(MII, 1978). In 1977, based upon a model of attitude change, MII solicited the Ross Roy, Inc. advertising agency.

The Ross Roy agency designed a media campaign on the concept of "Somebody . Needs You." The parallels between this approach and the third suggestion mentioned under Issue 4 in the MOR section of this review are striking. In fact, the MOR report specifically mentions this campaign as the type of effort needed (a) though MOR would have inverted the concept to "you need others," MOR, 1977, p. 268). Under this theme, television and radio spots were developed.

The "Somebody Needs You" campaign was piloted in the Grand Rapids area and the results from a before/after telephone survey of residents indicated that the campaign had made a positive impact on attitudes and knowledge regarding seat belt efficacy. Buoyed by these results, a southeastern Michi gan project was designed to assess the advertising campaign's effects on seat belt behavior. Lincorp Research, Inc. was contracted to develop the assessment study which called for before/after observations conducted at 224

randomiy-selected intersections that were representative of traffic throughout southeast Michigan. The same procedures used in the before part were replicated for the after part of the study. At the study's end, more than 42,000 cars. were observed. The data indicated that there was an overall usage increase from 12.4\% to 16.8\%. Different city areas, different car year cohorts, and different times of the day registered different rates of usage. The campaign was more successful in upper and upper-middle class neighborhoods than in others and for the better educated (college graduates). The report concluded that the campaign was worthwhile and that it could have a significant effect on driver belt usage.

Summary and Conclusions Regarding the Literature Revi ew

The literature on seat belt usage has developed and progressed over the past twenty years. Early studies painted the profile of a seat belt user by assessing uni-dimensional or isolatediy-viewed variables. Later studies have tried to create collages which represent the seat belt user's behavior as resulting from a complex interaction of variables. The methodological progressions and theoretical extrapolations and developments clearly point out some state of the art conclusions that will naturally have an impact on the present study. 
CHAPTER III. METHODOLOGY

General Overview

There are three key features to LJA's data gathering $p l a n$. One feature is the utilization of a mul ti-method approach which builds on the strengths of complementary methods and miti gates weaknesses in each. The second feature invol ves obtaining steady-state (e.g., comparison of group differences) data, as well as dynamic (e.g., change) data for optimal utility in aiding the development of educational influence strategies. The third feature is for this effort to be considered as a major step in a program of research; while achieving certain goals in its own right, it paves the way for follow-on efforts.

\section{Consideration and Selection of Methods}

Experimental Versus Correl ational Methods. From the perspective of achieving the highest possible internal validity regarding causal factors in restraint usage, an experimental approach would be the ideal. However, several factors argue against the use of an experimental approach. Although the short time frame precludes more than a cursory effort toward systematic experimental methods, this is not the key reason for postponing an experimental approach to a 1 ater phase of research. A more important reason is that while some well designed research has been done related to demographic, motivational, and situational factors in restraint usage, no study has been comprehensive and systematic enough to point definitively to the most profitable relationships for experimental verification. Thus, a relatively broad-based correlational data approach is seen as most appropriate for this stage of research.

A comprehensive steady-state variable data set is expected to provide:

- a sense of the key vartables in restraint usage and the interaction among variables,

- a basis for data reduction (e.g., combining attitude items into attitude scales),

- development of causal inferences via non-experimental techniques, and

- a basis for prioritizing influence strategles uttlizing experimental or quasi-experimental designs.

Survey Versus Focus Group Approach. A focus group approach was utilized to elicit personal and professional views rel ated to factors in restraint usage from a diverse and mul ti-disciplinary group of LJA staff. While a focus group approach has many merits, these merits are primarily in the realm of method development, rather than for rigorous data collection per se. LJA's usage of the focus group to suggest direction along with usage of the existing jiterature in the area of restraint usage facilitated the development of instruments, selection of methods, and development of research questions. 
A Two-Pronged Survey and Observation Approach. Based upon the focus group and on the literature review which enabled us to build on the efforts of others, LJA developed a two-pronged approach. One component is based on a national survey of a random sample of licensed drivers. The other component is based on a regional survey of selected samples coupled with observations in selected settings.

The national survey of 1 icensed drivers was intended to provide an approach emphasizing external validity (generalizability) over internal validity (clarity of relationships within the data, including causal rel ationships). Within the resources for Phase II, a telephone national survey was feasible, but not a face-to-face survey nor associated observations. Furthermore, sub-sample stratifications had to be kept within reasonable limits. To obtain a high response rate and to be more assured of full responses within the study time period, a telephone survey approach was selected over a mail survey approach. A reasonable number of response items can be included within a twenty minute period (the typical maximum length of a telephone survey); it was necessary, however, to be selective among all the potential items that could be incorporated into a survey. While the emphasis was toward well established measures, a few innovative or exploratory measures were al so incl uded.

The second component involved a study wi thin a selected regional area, the Bal timore, Maryl and SMSA. This component invol ved observations and follow-up face-to-face interviews. The observations provide a behavioral index of restraint usage of selected samples in selected settings, including mul tiple observations. This regional study component emphasized internal over external validity. A study concentrated in one local region made it feasible to undertake both observations and face-to-face interviews. Face-to-face interviews allowed for a longer ques tionnaire (about 40 minutes) so that more innovative and exploratory items could be included. A longer questionnaire al so provided a 7 arger data set with greater potential for productive data reduction and other data analyses.

Consideration and Selection of Samples

Regional Study

This component included the observation of driver behavior in the Bal timore, Maryl and SMSA followed by face-to-face interviews with drivers on whose cars multiple observations were made. This section describes the observation component, which was the first to be executed.

Site Selection. The selection of observation sites was the initial task in this component. The Bal timore, Maryl and SMSA was selected as a typical metropolitan area in terms of demographic characteristics and for its convenient location. The SMSA includes the city of Bal timore, and Bat timore, Howard, Carroll, and Anne Arundel Counties. Three general types of observation settings were selected: 
o work-related setting,

- a limited-access residential area, and

- day care or school setting.

Examples of each of these types of observations settings were selected in three diverse geographic sites within the SMSA:

- urban (Baltimore),

- suburban (Towson), and

- small town/rural (Westminster).

LJA staff members examined potential sites in a variety of urban, suburban and rural locations. In addition, suggestions were solicited from NHTSA and from observers who lifved in the Baitimore area. Final sites were selected on the basis of location, accessibility, and traffic flow.

Observation Protocol. An observation protocol was developed for use in this component (Appendix $C$ ). It was designed to allow the accurate recording of information as rapidiy as possible. The protocol included a space for the license number; descriptors of the driver (age, sex, race) and car (size, age); whether the driver wore a restraint; whether passengers were present; and whether a child, if any, was restrained.

Staff Selection and Training. The observers were temporary staff member's who resided in the Baltimore area. They were senior undergraduates or graduate students, recruited and screened by a faculty member at Morgan state University in Baltimore.

The training session took place in Baltimore. The observers were informed of the scope and purpose of the study in general and of the observation component in particular. The schedule and procedure for conducting observations were presented. The observation protocol was discussed in detail.

Finally, all observers conducted observations with project staff members present to answer questions which arose. This practice session was followed by a debriefing.

Field Observations. Observations were conducted on weekdays over a three-week period from August 3 through 21, 1981. Two observers monitored each site at times selected for arrivals and departures from work sites and day care centers. At residential sites, both rush-hour and mid-day traffic were observed.

- Observers were provided with orange safety vests, LJA business cards and a letter explaining the purpose of the study. Individuals with questions about the study were referred to the LJA offices. 
During the course of conducting field observations, two types of problems were encountered. The first involved objections to the observations themsel ves, and the second involved the influence of observers upon the subjects.

At a small number of locations, all of them work sites, there were objections to the observers' presence, even when the purpose of the study and it's sponsorship had been explained. objections included statements that the observers were on private property and their presence was an invasion, concern over legal liability in case of accident, and fear of what one person referred to as "nefarious purposes." Generally, these problems were solved, but in two cases alternative sites were used to avoid loss of observation time.

At one site observers reported that their presence appeared to have a small effect on the behavior of some drivers as the observation period progressed. A few drivers were seen to pull their seat belts over and hold them as if they were fastened. Others would actually fasten their belts when thiey saw the observers. These individuals were recorded as not wearing their seat belts when such behavior was observed.

Sample Resulting from Observations. The specific numbers for the regional sample coutd not be precisety predicted because they were largely dependent on observation opportunity and because this particular ad hoc approach had not been utilized by researchers previously.

A total of 449 cases were observed four or more times during the observation period. Of these, 337 were observed five or more times. Residential areas contributed the largest number of cases with 248. Work sites contributed 147 cases to the sample. The smallest number of cases was from day care centers with 54 mul tiple observations. The total number of observations over the three-week period was 11,135. The multiple observation cases (449) represent about one-fourth of the total observations recorded.

Sample Identification. A list of licenses upon which multiple observations were made was provided to the Maryland Motor Vehicie Administration (MVA) for identification. A special computer run was conducted by MVA which produced a list of registrations for each iicense on a si te-by-site basis.

MVA output indicated that, of the original 449 cases, 31 were registered to business or leasing campanies. These were deleted from the sample, since company vehicles are often driven by a number of people, or clearance by the company may be needed for an interview. An additional 27 cases were reported as having no record of Maryl and registration.

The registrations which were provided show that a small number of households are duplicated in the sample. That is, two cars registered at the same household were observed at least four times. In these cases, LJA determined the most appropriate person to be interviewed. Thus, the final sample of usable cases was 389.

Preparation for Interviews. Upon clearance of the survey by the office of Management and Budget, the sample was contacted by mail. A letter over the 
signature of the Administrator of the MVA described the study and encouraged participation. An additional letter from $L J A$ was enclosed which provided

- further information. Each sample member was contacted by telephone to establish an interview appointment.

RDD Sampling*

National Sample. The requirements for this sample were that it be nationally representative of licensed drivers and sufficiently large for major sub-group comparisons of interest. A sample size of 1,000 to 1,500 respondents was determined to meet both these requirements. Oversamp les of 100 cases each in Seattle and Dallas were added to study typical usage behavior in those areas. Respondents were reached via telephone and identified through a random-digit-dialing sampling frame.

The sample frame used for ROD samples includes a current file of over 30,000 telephone exchanges. For each exchange, a full working bank profile is maintained. Additionally, each exchange is coded for membership in a county, state, SMSA and census region. For every county in the nation, the total number of households, Black households, Hispanic households, and median income has been recorded. While a national probability samp le is maintained (described below), a considerable variety of sample designs are readily avajlable. Any county-based stratif ication scheme can be implemented at a national, regional, or state level. The design detailed below is routinely used for national probability samples of telephone households and has many distinct advantages.

First, the design provides the ability to make independent estimates for 18 sampling strata (nine regions by Metropolitan and non-Metropolitan with in each). Second, the design provides for a self-weighting sample of households with in each of the sampling strata. Third, the stratification provides the ability to vary the sampling rates efficiently from each of the strata, or any combination of them. This enables the oversampling of various regions, or if desired, the elimination of any stratum, or strata, without introducing bias in to the estimates themselves. Fourth, depending on the sample respondent se lection criteria for the particular study, the appropriate third stage probabilities of respondent selection are automatically included in the data record facilitating the calculation of the final estimates.

And $f$ ifth, since the sample is self-we ighting with in each stratum, simple ratio estimates based on number of househoids provide unbiased estimates of household data. And, if the estimates are related to population data, a simple ratio estimate based on population can be applied.

Overall, the sample design provides the simplicity, flexibility, representativeness, precision, and ease of estimation required of a high quality national, regional, state or local consumer survey system.

*The section describing RDD sampling techniques is provided by chilton Research Services (CRS) from whom the sample was obtained. 
Definition of the Sample Universe. The actual definition of the universe will vary from survey to survey. However, a consistent definition of the sample population is that the ultimate respondent will reside within a telephone household and be an adult 18 years of age or older. In other words, the first and second stages of sample selection remain constant.

Specifically, these are sample central offices and sample househol ds, respectively. The final stage of sample selection represents the variable sampling frame. In this study, the final level is the selection of a licenced driver.

Sample Selection. The actual sample selection is accomplished in three distinct stages. In technical terms this sample can be described as a stratified three-stage cluster sample. Briefly, the three stages are defined as follows.

\section{Stage I: Selection of Sample Central Offices}

Stage II: Selection of Sample Households

Stage III: Selection of Eligible Respondent.

The following sections detail the sampling procedures involved with each of the three stages of sample selection. It should be emphasized that the procedures described provide for unbiased selection of sampling units at each successive stage and their designation is accompl ished independently of interviewers, clerks, etc. The entire selective process, at all stages, is based on the strict application of accepted sampling procedures and variance reduction methods.

Exchanges A telephone central office is an integral communication, service and business unit of the telephone communication network. A telephone subscriber's number consists of a ten-digit number. The first three digits identify the area code; the second three digits identify the central office or telephone exchange; and the last four digits identify the telephone subscriber household.

CRS maintains and constantly updates a Master Telephone Exchange Fi? e which contains a listing for each of the approximately 30,000 telephone exchanges (or central of fices) currently in use in the continental United States. Each telephone exchange is identified by the following parameters: (1) major population center served -- city, town, etc.; (2) county in which the population center is located; (3) SMSA in which the county is located, if applicable; (4) state in which the county is located; and finally, (5) the region which contains the state and county. By employing the above parameters each telephone exchange is uniquely assigned to one and only one of the 18 sampling strata.

Within each regional and metropolitan/non-metropolitan stratum the master file is sorted by state and then by median income for the county. When the entire file has been stratified and then sorted wi thin each strata, a systematic (or nth) selection of the desired number of exchanges is made. These techniques assure the representativenesss of the final sample across the following dimensions:

(1) 9 census regions;

(i) States within region; 
Metropolitan/non-metropolitan within state; (4) and finally by media income of the county. That is, the sample of exchanges will be distributed in direct proportion to the distribution of the full master file along these dimensions.

The result is a known equal probability of selection for each and every central office selected. The selection process will yield approximately 1,050 central offices, distributed among the various strata in proportion to the number of central offices contained in each. Each of the central offices, both in the sampling frame itself and in the sample, are uniquely identified with one and only one stratum.

Telephone exchanges are in actuality clusters of telephone households. These clusters, in addition, are of varying size. In order to achieve a self-weighting sample of households the selection of sample households must be accomplished in proportion to the number of households served by each telephone exchange.

It should also be noted that prior to interviewing, a large proportion of the non-working and non-household numbers in each telephone exchange are identified. This indentification is based on the first two digits of the four-digit suffix. These first two digits are termed "banks," and contain 100 numbers each. Thus, there are 100 possible "banks" in each tel ephone exchange that may contain assigned residential numbers.

The "banks" containing working residential numbers are designed prior to the sample generation. When the computer program generates them, random four-digit suffixes, it matches each against the known "working banks," for the appropriate telephone exchange, and rejects those falling outside of the "working banks." By this process, approximateiy 80 percent of the nonworking and nonhousehold numbers can be eliminated prior to interviewing. The banks included for sampling purposes are those containing any number assigned to residences. Thus, the excluded banks contain no residential telephone numbers.

In summary, it has been demonstrated that the sampling procedures provide an unbiased representative sample of all telephone househol ds, and that the procedures rely on strict probability sampting methods. The use of randomi $y$ generated four-digit suffixes also provides an unbiased sample of nonlisted or nonpublished residential numbers in their correct proportions. The result is that househol ds which have recently moved, as well as those househol ds possessing nonpublished telephone numbers, are included in the sample in their correct proportions. Thus, this system is superior to methods based on published telephone number samplings, e.g., telephone book samples, "+1" sampling, etc., in which these groups are not and cannot be included in their correct proportions.

When using the "Survey Processor System", the interviewer elicits from the sample household a description of all eligible respondents residing therein. These eligible respondents are automoticaily assigned numbers, $1,2,3$ and so on. The interviewer then consults a randan number table to identify the correct respondent. At this point, two pieces of sample data become a permanent part of the data record for the sample household: (1) the total number of eligible respondents; and (2) the particular respondent which was randomly designated by the computer. Whether the interviewer is able to 
complete the interview at that time, or if a callback must be scheduled for a future time and date, the above information is carried with the data record, eliminating the possibility of respondent substitution.

Description of Instruments

To assess the demographic, situational, and moti vational variables suggested by NHTSA; to determine the effects of the various change factors, driving behavior, and media influence variables identified in the conceptual framework; and to survey appropriately the different samples required by the two methodologies (telephone and face-to-face interviews), two questionnaires were developed. The prototype was the face-to-face interview of which the telephone instrument represents an abbreviated, modified version. The telephone instrument has some questions altered from the prototype and others not included, but the majority of items are held in common. Following is a discussion on general questionnaire design and item construction issues.

Face-to-face and telephone interviews hold in common the need to be orally delivered in a manner that facilitates comprehension and accurate responses. Item 1 anguage, as such, tends to be dictated by this need. For illustration: 1 anguage on a mail questionnaire may present detalled lead-ins for an item, aiding in respondent comprehension; conversely, long constructions tend to hinder comprehension of orally delivered items. While mail questionnaires may be thorough, thus elaborate, orally delivered questionnaires must be precise and quick to elicit the appropriate response. Telephone questionnaires have an added burden of required preciseness since the telephone interviewer has none of the advantage of the face-to-face interviewer's ability to observe the respondent's behavioral cues to determine whether an item has been understood or whether it needs to be repeated or clarified. LJA constructed the face-to-face and telephone questionnaires to circumvent the above concerns. LJA also pretested the questionnaires, using their appropriately corresponding methodologies, to aid in the item development process. The pretest proved invaluable in deriving item clarity. The pretest also assured that administration times would be within the decided lengths.

The methodologies of face-to-face and telephone interviewing bring concerns to the questionnaire design and $i$ tem construction, al so. The optimal length of a telephone questionnaire is approximately twenty mi nutes whereas a well constructed face-to-face questionnaire can be between forty-five minutes to an hour. The conceptual framework dictates a consideration of core variables that must be accounted for within each questionnaire. To construct the questionnaires, LJA, based on the conceptual framework, determined the universe of variable types even tangentially related to the focus of this study. Items representing these variable types were constructed and formatted to provide maximum respondent comprehension and compliance. These items form the face-to-face questionnaire. This protocol was vetted to identify core variables necessary for both questionnaires and the corresponding items were isol ated to comprise the telephone survey instrument. Where the original structure of an item could be preserved, it was; where the item length was at issue, its alternatives were modified and reduced; where the item construction was less conducive for telephone delivery, it was reformatted to preserve the variable type in concern and to provide conceptual comparability during the analysis process. 
Concern for the appropriate item structure necessitates much consideration regarding the end product of the study and the context in which the study is conducted. Analogousiy and as mentioned previousiy, this study does not consider the focus group methodology as the most appropriate primary vehicle " for deriving study information; focus groups are best used when there is a lack of information or during the early phase of a research project. As there has been much functional research conducted wi thin the restraint usage area, LJA was able, appropriately, to suggest that the open-ended focus group approach would be less profitable than a more rigorous research design. The logic extends well to the task of item construction.

Open-ended items are needed to elicit information where the investigator is unclear of the uni verse of responses that may be obtained. The literature in the restraint usage area, however, allows for much anticipation regarding the responses that may be received and, as such, item al ternatives were designed to categorize responses and, where appropriate, allow for a standard meas ure of response intensity. This minimized the need for open-ended items and enabled the investigators to apply more fruitful and productive statistics offering a more usable end-product. Where open-ended items appear it is because the universe of responses is either not known or so vast as to not be feasible to put it on the ques tionnaire. For some items where categories of responses are provided, the "other" category allows for a response to be embraced that might not have been considered.

The content and format of all items developed for the interview instruments appear in the appendices. Appendix A consists of the telephone questionnaire as administered and Appendix B consists of the face-to-face ques tionnaire.

Tests of Procedures and Methods

LJA pretested both the telephone and face-to-face interviews. Individual items were tried out on staff members and generally revised mul tiple times to obtain optimal clarity and appropriate responses. Thus, individual items often went through as many as a dozen or more revisions before being tried in final form; of course items derived from other sources, and thus previousiy tested by other researchers, generally required little if any revision. In addition, to further aid revision for item $\mathrm{clarity}$, the pretests assured that the administration times would be within desired lengths and provide the basis for es timating response burden.

Training procedures for interviewers included a small pretrial field sample. Thus, an additional field test of the procedures and methodology occurred before actual implementation. This assured quality of data and minimized the burden to the public by ensuring an efficient, smooth flowing interview process for both the telephone and face-to-face interviews.

Methods to Maximi ze Response Rates

To maximize response rates for the telephone interviews, at least two call backs were instituted if no answer was obtained. Call backs were initiated in the early evening, if no response was obtained during a daytime attempt. If no answer was obtained in the early evening, a call was initiated 1 ater in the 
evening. Call backs were at least one day apart to increase the probability of finding a prospective respondent at hame.

If an answer was obtained on a call, but the person answering was not a qual ified respondent ( $i$.e., not a licensed driver), screener questions ascertained if a licensed driver was available. If a 1 icensed driver was not immediately available, but one resided at the dwelling reached, infomation was obtained regarding optimal time for a successful call back. If no licensed driver resided at the number reached, the call was not considered in computing the response rate, since persons there would not be in the universe of interest.

Face-to-face interviews were grouped according to geographic proximity to reduce travel time for interviewers. This also facilitated a call back 1 ater in the day or evening, if nobody was home at the time of the first call or if the driver of interest (i.e., the person observed during the field observations) was not available at that time. If the driver of interest was not home during the first follow-up call back, a standard note was left letting the resident(s) know that a survey attempt was made and that a telephone follow-up would ensue to establish a convenient time for the interview. At least two attempts would then be made via telephone to set-up a time for the call back interview or to establish that the driver of interest was either not available or refused to be interviewed.

Another technique for maximizing response rate was to check that interviewers' appearance or telephone communication conveyed non-threatening professionalism. This was accomplished during interviewer training. Interviewers who did not convey these characteristics after training were to be dismissed, although this did not turn out to be necessary.

\section{Development of Research Questions}

A number of research questions were developed which link the three different components of the conceptual framework, focussing on demographic, situational, and motivational factors associated wi th seat belt usage, with specific variables or groups of variables measured in the survey instruments. The data analysis plan was designed to assess systematically the impact each one of these factors has on restraint use. In addition, a set of predominantly dependent (i.e., usage) variables which measure different types of restraint system usage were identified. The research questions to be addressed by examining these usage variables include the following.

o How often are seat belts used during different types of trips and under certain weather conditions?

- How often do individuals use their seat belts as a driver versus as a passenger?

o How consistent is the restraint system usage across time?

o How often are child restraints used?

- How often have people disconnected their seat belt systems? 
The specific variables measured in the survey instruments which are designed to answer the above research questions are 1 isted below.

$$
\text { List of Restraint Usage Variables }
$$

1. How of ten used on roads which are wet, or snow and ice covered

2. How often used on long trips

3. How often used on short trips around town

4. How often used as passenger

5. How often used as driver

6. How often child care restraints are used

7. Used same now as always

8. Changed use since period when used most of the time

The three central components of the conceptual framework $\mathrm{cl}$ assify groups of predominantly independent variables thought to be associated with restraint system usage. As previously identified, these three variable groupings characterize certain demographic, situational and motivational factors suggested by previous studies and expert opinion. Specific research questions which relate to the demographic characteristics of drivers include the following.

- What are the primary demographic characteristics which distinguish seat belt users from non-users?

- What are the primary demographic characteristics which distinguish seat belt users who have changed their behavior?

- What are the profiles of individuals concentrated in certain low use and high use geographic locations (e.g., Dall as, Texas and Seattle, Washington )?

- Do people with families, particularly small children, tend to use restraint systems more often and encourage or require that other household members do the same?

- Is seat belt usage more frequent among individuals who have had more experience driving and have been exposed to the potential or actual dangers of hazardous driving behavior and conditions?

- Is how much a person drives associated with seat belt usage?

- Which is more influential regarding restraint usage, initial encouragement and training when learning to dri ve or subsequent experience regarding traffic safety?

- o Does height influence seat belt use? 
The particular demographic variables measured in the survey instruments which were designed to answer the above research questions are listed below. They are subdivided into three general categories. Ascribed social characteristics are those which do not change over a lifetime, acquired social. characteristics are those which can change over a lifetime, and proximal socialization characteristics are those which are most transitory.

List of Demograpic Variables

I. Ascribed Social Characteristics

1. Ethn ic group membersh ip

2. Gender

3. Regional origin

II. Acquired Social Characteristics

1. Children in household four years old or younger

2. Age

3. Household income

4. Education

5. Residence (urban/suburban/rural)

6. He ight

7. Body size

8. Church attendance

III. Proximal Socialization Characteristics

1. Miles driven per average work day

2. Driver education

3. Accident record/exper ience

4. Demonstration on how to use child safety seats

The following research questions involve situational variables which may be associated with seat belt. usage.

- Under what kinds of driving conditions does seat be it usage tend to increase or decrease for sometimes users?

0 Do seat belt users and non-users vary in the type of travel undertaken?

- Do users and non-users vary in the type of car driven and/or restraint system installed?

0 To what extent is seat belt usage required by employers when driving on company business?

- Do people tend to respond to others' admonitions to use seat belts?

- Is alcohol or drug impairment related to variable safety belt usage?

- What effect does exposure to injury due to a car accident have upon seat belt usage and for how long? 
The above research questions are addressed in the survey instruments in terms of a variety of situational variables. As listed bel ow, most of these variables represent either physical or social envirorments.

\section{List of Situational Variables}

I. Vehicle As The Behavior Setting

A. Physical Envirorment

1. Size/structure of vehicle

2. Age of vehicle

3. Restraint system characteristics: type, knowledge of use, working condition

4. Foreign or domestic vehicle

5. Work vs. personal travel

6. Type of road

7. Weather conditions

8. Length of trip

9. Time of week

10. Time of day

11. Holidays

12. Rush hour

13. Mul ti-stop trips

14. Smaller car than typically driven

15. Street familiarity

16. Restraint jamming, etc.

17. Where car serviced

B. Social Enviroment

1. Usage required by business

2. User as driver vs. passenger

3. Passenger request to use belt

4. Driving alone vs. with children

5. Al cohol impaiment

6. Drug impairment

7. Exposure to near accident

8. Driver requests to use belts

9. Car radio use

10. Used more or less after recent accident

11. Used as often now as immediately following accident

II. Non-Vehicle Behavior Settings

1. Hone

2. Work

3. Day Care

The remaining component of the conceptual framework consists of various motivational factors thought to be associated with the use of restraint systems. The following research questions were designed to assess the motivational as pects of drivers' usage behavior. 
- Are people who tend to be internally motivated in making decisions more likely to take personal safety precautions, including the use of seat belts, than people who often rely upon others to define their actions?

- To what extent is a driver's use of seat belts associated with fears or concerns regarding driving safety?

0 Are the convenience and comfort of restraint systems associated with the frequency of seat belt usage?

- What are people's predominant opinions on how to get others to use their seat belts?

- Do individuals who take precautions regarding their personal health and well being (not associated with driving) and avoid other risk-taking behavior also tend to take precautions regarding driving safety?

- What appear to be the most influential sources of persuasion regarding the use of safety belts? Do users and nonusers agree on the most influential sources?

- Do people who perceive more potential accident hazards and adverse driving conditions tend to use seat belts as a precautionary measure more than those who pay less attention to possible dangerous situations?

The 1 ist below specifies the particular motivational variables of interest to be used in assessing the above research questions .

I. Personality Dimensions

1. Susceptibility to influence of others

2. Internal-external locus of control

II. Drives/Needs

1. Fear of injury

2. Concern over car's handling ability

3. Fear of entrapment

4. Concern over driving ability in bad weather

5. Fear of other drivers

6. Concern driving with others

III. Opinions and Perceptions

A. Opinions

1. Reason others find belts inconvenient/uncomfortable

2. Didn't wear belts when thought should

3. Took off belt during trip

4. Opinion of how to get others to use belts

5. Similarity of seat belt usage and good health practices 


\section{B. Perceptions}

1. Comfort of seat belt system

2. Convenience of seat belt system

3. Driving safety under various conditions

IV. Behavioral Dispositions

1. Likelihood of paying attention to different safety message/media

2. Smoker vs. non-smoker

3. Frequency of visiting dentist

4. Constant exercise or not

5. Heaith maintenance behavior

6. Gambler vs. non-gambler

The preceding outl ine of research questions and associated variables serves as a guide for conducting data analysis. Thus, the plan for analysis includes both a means for answering specific questions which have been posed regarding seat belt usage and a capability for more extensive data manipulation to uncover meaningful patterns of usage behavior as well as strategies likely to be influential in seat belt usage campaigns. The ensuing chapter discusses the results of data analysis. 


\section{RESULTS}

This chapter summarizes the basic findings of the study. Following a brief description of the samples, the results are presented sequentialiy for the telephone survey and then for the face-to-face survey. The research questions of primary interest provide the format for discussing the study findings. The singular results for each questionnaire item are presented in the appendices.

\section{Description of the Samples}

The national telephone survey was based on a random digit dialing (RDD) process aimed at contacting 1200 respondents, including oversamples of 100 each in selected high seat belt use (Seattle) and low seat belt use (Dall as/Fort Worth) areas. The obtained sample consisted of 1020 individuals randomly selected nationwi de pl us 109 individuals living in Seattle and 99 individuals living in Dallas. This sample thus met original projections and can be considered sufficient to make generalizations regarding seat belt usage throughout the country.

The second survey component focused on a selected regional area in the Maryl and SMSA and was based both upon observations of actual seat belt usage and follow-up face-to-face interviews. A total of 449 cases were observed four or more times during the observation period. After discounting 60 cases which were not private passenger cars with Maryl and 1 icense plates and others which could not be located for interviews, the sample was narrowed to 197 respondents who completed the face-to-face interview questionnaire.

Results of the Telephone Survey

Because of the myriad of different items comprising the telephone questionnaire, the respective results for each item will not be presented in a sequential manner in this chapter. The item-by-item results can be found in Appendix A. Only the singul ar findings for variables of primary focus are presented and discussed below. These findings provide answers to a number of research questions raised which links the three different components of the conceptual framework, that is, demographic, situational, and moti vational factors, with seat belt usage.

In the analyses that follow, the first series of research questions presented are those associated with general seat belt usage variables. These are followed in order by research questions addressing demographic, situational, and motivational variables. In each case, results obtained from the national sample will be discussed, followed by data obtained from the over-sampled areas (Seattle and Dallas), where appropriate .

Because of the large sample size, a probability level of $p<.01$ was chosen as the cutoff for defining statistically significant differences. Thus, the chance is 1 in 100 (or greater) that a reported difference among group means, for instance, is due to sampling error rather than a true difference in the population. The rationale behind choosing the .01 level as the cutoff (rather than the more traditional .051 evel) is to be conservative when reporting that 
true differences exist in the population and to guard against reporting small differences among groups which may be statisically significant, but

psychologically or realistically meaningless. Only those results that reach the .0I cutoff are presented below. Differences which are not statistically reliable will not be discussed, unless they address specific research questions.

Seat Belt Usage Variables. Five research questions address general seat belt usage variables.

o How often are seat belts used under certain weather conditions and during different types of trips?

As can be seen in Table IV-l, people tend to wear the ir seat belts slightly more often when driving on long trips than they do when driving under poor weather conditions. Seat belt usage declines, however, on short trips. A similar pattern of results was found for the Seattle and Dallas respondents.

0 How often do individuals use their seat belts as a passenger versus as a driver?

Table IV-2 presents the data relevant to this research question. An inspection of the percentages reveals that a majority of the people never or somet imes wear the ir seat belts. There is some tendency for people to wear their seat belts more often when they are driving compared to when they are passengers in an automobile. Seattle and Dallas respondents report similar behavior.

$0 \quad$ How consistent is the restraint system usage across time?

As can be seen in Table IV-3, seat belt use is relatively consistent across time. Still, approximateiy one-third of the individuals have changed their seat belt behavior. A major ity of these individuals who changed wear the ir seat belts more now than in the past. Comparable results are found in Seattle and Dallas, although twice as many Seattle residents have increased the ir seat belt use compared to the Dallas residents.

o How often are child restraints used?

Only 193 people reported that they had children 4 years of age or under in the ir households, of these, 131 (70\%) said they had at least one child car seat. For these respondents with child car seats, $80 \%$ always use them, $16 \%$ use them sometimes, and $4 \%$ never use them. Too few cases of child car seats exist in the Seattle and Dallas samples for the results to be presented.

o How often have people disconnected their seat belt systems?

A total of 127 people (12\%) have disconnected their seat belt systems. The vast majority of these $(71 \%)$ did so because the buzzer was annoying (when seat belts were not fastened). Similar results are found in Seattle and Dallas. Fifteen percent of the Seattle respondents disconnected the ir seat belt system and 93\% said the buzzer was annoying. In Dallas, 17\% of the respondents disconnected their seat belt system and $81 \%$ claimed that the buzzer was annoying. 
TABLE IV-1

Percent of Seat Belt Usage Under Certain Weather Conditions and During Different Types of Trips.

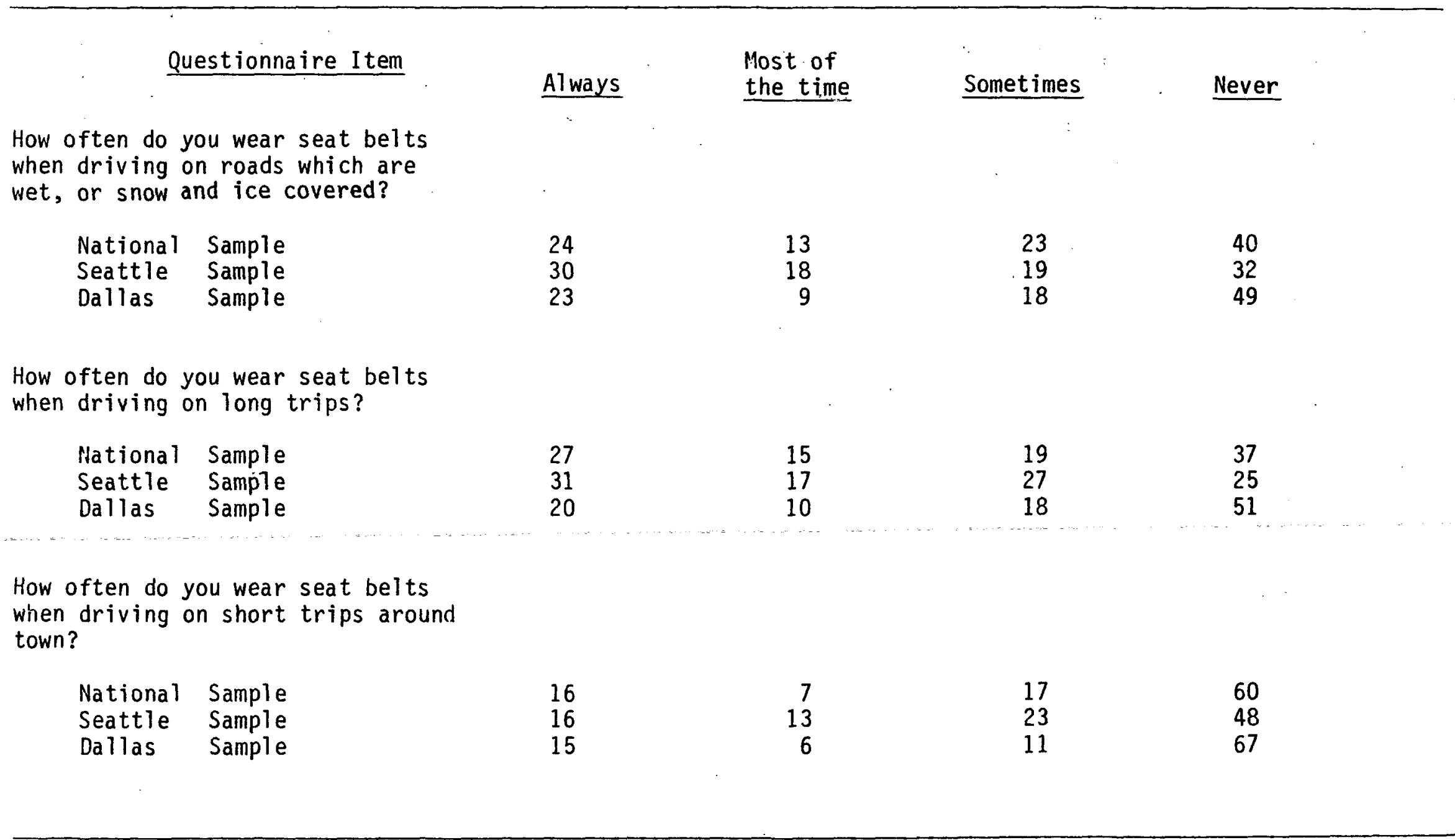

(Note: In this table and all subsequent tables row and column percentages not summing correctly and those not summing to 100 are due to rounding error.)

" " 
TABLE IV-2

Percent of Seat Belt Usage As A Function of Being

A Passenger or Driver

\section{Questionnaire Item}

In general, when you are a passenger

in someone else's car, how much of

$\begin{array}{ll}\text { Always } & \begin{array}{l}\text { Most of } \\ \text { the time }\end{array}\end{array}$

Never?

the time do you use seat belts?

$$
\begin{array}{ll}
\text { National } & \text { Sample } \\
\text { Seattle } & \text { Sample } \\
\text { Dallas } & \text { Sample }
\end{array}
$$

12
17
8

15

20

31

Sometimes

Total

How much of the time do you use them when you are driving?

National Sample
Seattle Sample
Dallas Sample


TABLE IV-3

Percent of Individuals Reporting Consistency of Seat Belt Use Across Time

\section{Questionnaire Item}

Is your use of seat belts today

the same as its always been?

$\begin{array}{lll}\text { National } & \text { Sample } & 68 \\ \text { Seattle } & \text { Sample } & 59 \\ \text { Dallas } & \text { Sample } & 71\end{array}$

Yes No, less No,more

$11 \quad \cdot 21$

9

$71 \quad 13 \quad 15$


Before turning to the research questions addressing the demographic factors influencing restraint system usage, it should be noted that the respondents were classified into three distinct seat belt user categories based on their responses to the questions regarding seat belt use under poor weather conditions, during long trips, and during short trips. That is, respondents were identified as frequent seat belt users, sometimes users, and infrequent users based on their summed scores to the following three questionnaire items

a) How often do you wear seat belts when driving on roads which are wet, or snow and ice covered?

b) How often do you wear seat belts when driving on long trips?

c) How often do you wear seat belts when driving on short trips around town?

Following summation across these items, where " 1 " = always, " 2 " = most of the time, "3" = sometimes, and "4" = never, individuals were classified as "frequent users" if their score was from "3" to " 6 ", "sometimes users" if their score was from "7" to "10", and "infrequent users" if their score was "11" or "12".

Table IV-4 presents the frequency breakdown of the three user groups. siightly less than one-third of the people are classified as frequent seat belt users and a little less than one-third as sometimes users of seat belts . The remaining $41 \%$ of the individuals rarely or never use their seat bel ts and are classified as infrequent users. As expected, there is a significant difference between Seattle and Dall as residents in their frequency of buckling seat belts $\left(X^{2}(2)=10.20, p<.007\right)$. Seattle residents are more likely than Dall as respondents to be frequent and sometimes users. More than half (54\%) of the Dall as residents are infrequent seat belt users compared with $32 \%$ of the Seattle residents.

It should be noted that the three seat belt user groups differ in their usage behavior across time $\left(x f_{4}\right)=185.39$, p (.0001). Most $(86 \%)$ of the infrequent users have al ways been infrequent users, whereas nearly half (43\%) of the frequent seat belt users have increased their seat belt use.

The analyses below generally involve the newly created user group variable in order to ascertain the demographic, situational, and motivational factors associated with seat belt usage.

Demographic Variables. Eight research questions relate to the demographic characteristics of drivers and their use of seat belts.

- What are the primary demographic characteristics which distinguish seat belt users fran non-users?

Two variables, age and education, are the most important demographic characteristics which distinguish seat belt users from non-users. As can be seen in Table IV-5, younger drivers, aged 15-24, and those in the 35-49 year old age group tend to be infrequent users of seat belts. 01 der drivers, aged 50 and above, are equally likely to be frequent as infrequent users. 
TABLE IV-4

Percent of Frequent, Sometimes, And Infrequent Seat Belt Users

\begin{tabular}{lcccc}
\hline & & Frequent users & Sometimes users & Infrequent users \\
National & Sample & 29 & 30 & 41 \\
Seattle & Sample & 34 & 34 & 32 \\
Dallas & Sample & 22 & 23 & 54 \\
\hline
\end{tabular}


TABLE IV -5

Percent of Frequent, Sometimes, And Infrequent

Seat Belt Users As A Function of Age

$(n=987)$

\begin{tabular}{|c|c|c|c|c|c|c|c|}
\hline User Type & \multicolumn{7}{|c|}{ Age } \\
\hline Frequent Users & 0.5 & 2.6 & 7.4 & 6.8 & 7.0 & 4.4 & 28.7 \\
\hline Sometimes Users & 0.7 & 3.1 & 9.6 & 8.4 & 5.5 & 2.9 & 30.2 \\
\hline
\end{tabular}

$\chi^{2}(10)=30.46, p<.0007$ 
Tabie IV- 6 presents the percentage of seat belt use as a function of education. Generally, higher educated individuals (i.e., some college, graduated college, post graduate work) are more likely to be frequent users than infrequent users compared with lower educated individuals.

- What are the primary demographic characteristics which distinguish seat beit users who have changed their behavior?

Table IV-3 shows the percentage of individuals who have changed their seat belt usage over time. Four variables, the presence of children 4 years of age or under in the household, age, education, and exposure to driver education distinguish those drivers who have altered their seat belt use.

Individuals who have increased their seat belt usage are more likely than individuals whose seat belt use has decreased or remained the same to have a child 4 years of age or under living in their household (see Table IV-7).

The greatest percentage of individuals who have increased their seat belt use fall within the 25-34 year old age category, as seen in Table IV-8. Table IV-9 also indicates that people who have increased their seat belt usage tend to be more educated, that is, they have had at least some college.

The remaining variable distinguishing people who have changed their seat belt behavior is exposure to a school or comercial driver education program. The data reveal that more than half of the people who have changed their seat belt usage (either increased or decreased) have been exposed to a driver education program. Less than $50 \%$ of the consistent seat belt users received their initial drivers training from a driver education program (see Table IV-10).

The preceding information concerning the presence of children 4 years of age or under in the household, age, and education suggests that the more responsible an individual's position in life becomes, the more likely he/she will increase seat belt usage. This is evidenced by greater education, presence of a child to care for, and simply growing up. It will be remembered that the 15-24 year ol ds tend to be infrequent users. As an individual matures into the 25-34 year old age group, the 7 ikelihood is highest that his/her seat belt usage will increase. The role of driver education programs on changed seat belt behavior is not clear.

- What are the profiles of individuals concentrated in certain low and high use geographic locations le.g., Dallas, Texas and Seattle, Washington)?

Consistent with the finding that age is a distinguishing variable among frequent, scmetimes, and infrequent seat belt users, the data reveal that the high use seattle sample is older than their low use Dallas counterparts. Table IV- 11 reveals this difference and 111 ustrates the greater number of 18-24 year olds in the Dallas sample. Similarly, there was a significant difference between Seattle and Dall as residents for the year they first received their drivers' 1 icenses. This finding parallels the preceding data concerning differences in age. On the average, Seattle residents first received their drivers' 1 icenses around 1958 compared to 1964 for Dallas 


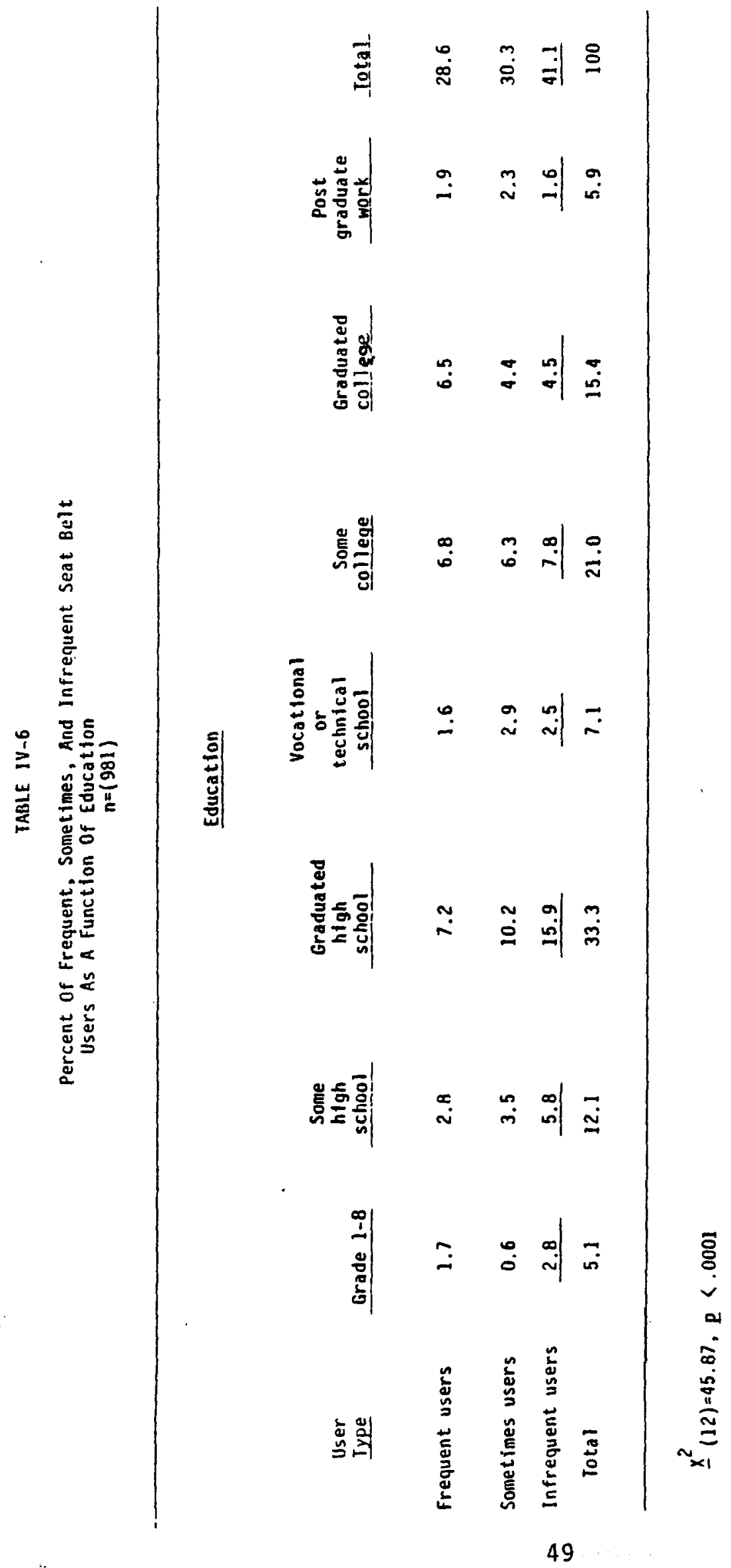


TABLE IV-7

Percent of Individuals Whose Seat Belt Usage Has Changed

By The Presence/Absence of Children In The Household $(n=951)$

Seat belt use across time

Consistent

Decreased

Increased

Total

\footnotetext{
$\underline{x}^{2}(2)=21.89, p<.0001$

$\underline{x}^{2}(2)=21.89, p<.0001$

II
}

Number of children 4 years of age or under in the household

\begin{tabular}{rcr} 
None & One or More & Total \\
\cline { 2 - 3 } 57 & 11 & 68 \\
9 & 2 & 11 \\
$\frac{15}{81}$ & $\frac{6}{19}$ & $\frac{21}{100}$
\end{tabular}


TABLE IV-8

Percent of Individuals whose Seat Belt Usage Has Changed By Age

$(n=952)$

Seat belt use across time

\begin{tabular}{|c|c|c|c|c|c|c|c|}
\hline & $15-17$ & $\underline{18-24}$ & $23-34$ & $35-49$ & $50-64$ & $\underline{65 t}$ & Total \\
\hline Consistent & 1.9 & 9.6 & 15.8 & 17.2 & 14.8 & 8.4 & 67.8 \\
\hline Decreased & 0.2 & 1.9 & 2.9 & 2.9 & 2.1 & 1.2 & 10.9 \\
\hline Increased & 0.3 & 1.8 & $\approx 8.5$ & 6.3 & 3.3 & 1.2 & 21.3 \\
\hline Total & 2.4 & 13.2 & 27.0 & 26.5 & 20.1 & 10.7 & 100 \\
\hline
\end{tabular}


TABLE IV-9

Percent of Individuals Whose Seat Usage Has Changed

By Education

$(n=946)$

\section{Education}

\begin{tabular}{|c|c|c|c|c|c|c|c|c|}
\hline $\begin{array}{l}\text { Seat } \\
\text { belt use } \\
\text { across } \\
\text { time }\end{array}$ & Grade 1-8 & $\begin{array}{c}\text { Some } \\
\text { high } \\
\text { school }\end{array}$ & $\begin{array}{l}\text { Graduated } \\
\text { high } \\
\text { school }\end{array}$ & $\begin{array}{c}\text { Vocational } \\
\text { or } \\
\text { technical } \\
\text { school }\end{array}$ & $\begin{array}{c}\text { Some } \\
\text { college }\end{array}$ & $\begin{array}{l}\text { Graduated } \\
\text { college }\end{array}$ & $\begin{array}{c}\text { Post } \\
\text { graduate } \\
\text { wark }\end{array}$ & Iotal \\
\hline onsistent & 4.5 & 9.0 & 25.4 & 4.2 & 12.3 & 9.3 & 3.3 & 68.0 \\
\hline ecreased & 0.1 & 1.7 & 3.3 & 0.7 & 1.9 & 1.9 & 1.2 & 10.8 \\
\hline ncreased & 0.3 & 1.4 & 4.6 & 1.9 & 2.2 & 4.1 & 1.7 & 21.2 \\
\hline Total & 5.0 & 12.0 & 33.3 & 6.9 & 21.3 & 15.3 & 6.1 & 100 \\
\hline
\end{tabular}


TABLE IV -10

Percent of Individuals Whose Seat Belt Usage Has Changed As A Function of Exposure To A Driver Education Program $(n=974)$

Seat belt use across time

Consistent

Decreased

Increased

Total

\section{Exposure to school or commercial}

driver education program

\begin{tabular}{ccc} 
Yes & No & Total \\
\cline { 2 - 3 } 30 & 38 & 68 \\
6 & 5 & 11 \\
12 & $\frac{9}{52}$ & $\frac{21}{100}$
\end{tabular}

$\underline{x}^{2}(2)=15: 05, \underline{p<: 0005}$ 
respondents $(F(1,203)=8.69, p<.004)$. Thus, the onty demographic variable which distingüishes the high use Seattle area fram the low use Dallas area is age .

o Do people with families, particulary small children, tend to use restraint systems more often and encourage or require that other household members do the same?

There is no difference between frequent, sometimes, and infrequent seat belt users regarding the number of children 4 years of age and under in their households. Approximately $20 \%$ of the frequent, sametimes, and infrequent users have young children in their homes. Similarly, the presence/absence of young children has no influence on whether or not individuals request others to wear safety belts. Approximately half of the individuals with young children present in the household and half of those without children request others to buckle up.

- Is seat belt usage more frequent among individuals who have had more experience driving and have been exposed to the potential or actual dangers of hazardous driving behavior and conditions?

As previously mentioned, age is a factor in determining seat belt usage. However, there is no statistical difference between frequent $(\bar{X}=1958)$, sometimes $(\bar{X}=1960)$, and infrequent $(\bar{X}=1961)$ seat belt users concerning the year in which they first received their drivers' licenses.

- Is how much a person drives associated with seat belt usage?

Frequent seat belt users $(\bar{X}=33$ miles $)$, sometimes seat belt users $(\bar{X}=33$ miles), and infrequent seat belt users ( $\bar{X}=32$ miles) all drive approximately the same amount of miles on an average work day.

o Which is more influential regarding restraint usage, initial encouragement and training when learning to drive or subsequent experience regarding traffic safety?

Initial encouragement to use safety belts and initial training when learning to drive are two distinct variables. The first, initial encouragement to use seat belts before learning to drive, has an impact on subsequent seat belt usage. Of the 540 individuals for whom seat belts were in existence before they learned how to drive an automobile, the majority (75\%) did not receive encouragement to wear safety belts. As Table IV-12 reveals, however, the greatest percentage of the remaining $25 \%$ of the individuals who did receive encouragement to wear safety belts are now frequent seat belt wearers.

The second variable, initial training when learning to drive, is not - influential regarding restraint usage. Forty-six percent of the frequent users, $51 \%$ of the sometimes users, and $46 \%$ of the infrequent users were exposed to a school or commercial driver education program. These small - differences do not approach statistical significance. 
TABLE IV -12

Percent of Frequent, Sometimes, And Infrequent Seat Belt Users

As A Function of Initial Encouragement To Use Seat Belts

$$
(n=540)
$$

User Type

Frequent users

Sometimes users

Infrequent users

Total

\section{Initial Encouragement}

\begin{tabular}{|c|c|c|}
\hline Yes & No & Total \\
\hline 9 & 16 & 25 \\
\hline 9 & 22 & 31 \\
\hline 7 & 37 & 44 \\
\hline 25 & 75 & 100 \\
\hline
\end{tabular}

ต $x^{2}(2)=19.19, p<.0001$ 
Again, age is related to seat belt usage, but the year in which drivers -first received their 1 icenses did not have a reliable impact on restraint use. Thus, initial encouragement to use seat belts preceding the experience of learning to drive is an influential factor regarding 1 ater seat belt usage.

- Does height influence seat belt use?

There is no statistically significant difference in height between frequent users of seat belts $(\bar{X}=68$ inches $)$, sometimes users of seat bel ts $(\bar{X}$ $=67$ inches $)$, and infrequent seat belt users $(\bar{X}=70$ inches $)$.

In conclusion, the data reveal that two demographic variables, age and education, have a reliable impact on restraint usage. Whereas younger drivers up to age 24 and drivers 35-49 years old are more likely to be infrequent than frequent seat belt users, those drivers 50 years of age and above are just as likely to be frequent users of seat belts as infrequent users .

The data also reveal that individuals with at least some exposure to a college education and those with more educational experience are more 1ikely to be frequent than infrequent seat belt users compared with their less educated counterparts. This result is consistent with the finding that the people most likely to have changed their behavior and increase their seat belt use over time are the more educated, maturing individuals facing new responsibilities, such as raising a family.

One demographic variable, age, distinguishes between the respondents of Seattle and Dall as. Individuals sampled from Seattle, where seat belt usage is generally high, tend to be older than those contacted from Dallas, a city characterized by generally low seat belt use.

Situational Variables. Seven research questions guide the analyses involving the previousty defined situational variables which may influence a person's decision to wear safety belts.

- Under what kinds of driving conditions does seat belt usage tend to increase or decrease for sometimes users?

As can be seen in Table IV-13, the situation in which sometimes users are most likely to increase their seat belt usage is when they are driving in poor weather, followed by having nearly been in an accident and driving with children. It should be noted that the only situation where sometimes users report that their seat belt use decreases is when they are driving alone.

- Do seat belt users and nonusers vary in the type of travel undertaken?

Frequent seat belt users tend to spend a greater percent $(\bar{X}=34 \%)$ of their total week1y travel on divided hi ghways compared with sametimes $(\bar{X}=$ $27 \%)$ users and infrequent $(\bar{X}=25 \%)$ users $(F(2,937)=6.64, \mathrm{pr} .002)$. This finding suggests that frequent users do a greater percentage of long trip, high speed travel as opposed to sometimes and infrequent seat belt users. 
Mean Response of Sometimes Seat Belt Users Ind icating When Their Use of Seat Belts Decreases, Stays The Same, Or Increases

\section{Situation}

When the weather is poor like rain, snow or fog

After having been in or nearly in an accident

When driving with children in the car

On a holiday

After taking drugs or prescribed medication

When in a car smaller than the one typically driven

During rush hours

During weekends

On a trip with more than one stop along the way

When driving alone
Mean

2.68

2.64

2.51

2.49

2.39

2.36

2.33

2.17

2.05

1.93

Note: Responses were scored: "1"= seat belt use decreases in that situation $" 2 "=$ seat belt use stays the same in that situation "3"= seat belt use increases in that situation 

restraint system installed?

Individuals who drive foreign cars are more likely to be frequent seat belt users compared with individuals who drive domestic cars (see Table IV-14). The impact of comfort/convenience ratings of restraint systems on seat belt usage is discussed in the following section. It should be noted, however, that people rate the restraint systems more comfortable and more convenient in foreign imports compared with the restraint systems in domestic cars (see Table IV-15).

The type of restraint system is also an important factor in determining seat belt use. Table IV-16 reveals that infrequent users are more 11kely than frequent and sometimes users to have a separated seat belt and shoulder strap. restraint system. In addition, the separated seat belt and shoulder system $(\bar{x}$ $=2.16)$ is rated more inconvenient than the combined seat belt and shoulder strap system $(\bar{X}=2.40)(\underline{t}(7.56)=-4.10, \underline{p}<.0001)$.

A few other variables related to the restraint systems show differences among the user groups. For instance, infrequent users are more 1 ikely to have been told how to put on a seat belt campared with frequent and sometimes users (see Table IV-17). And, approximately half of the frequent and infrequent users agree with the statement, "I don't think seat belts work properly when they feel loose around me after I fasten them," compared to approximately one-third of the sometimes users (see Table IV-18).

Finally, on occasions when seat belts become tangled or get stuck behind the seat, frequent users are more likely than sometimes and infrequent users to work at the problem until it is resolved. As can be seen in Table IV-19, most (76\%) of the infrequent users respond that they never use their seat belts, and, hence, the question becomes meaningless to them.

Respondents from the high seat belt use area of Seattle differ from their low seat belt use counterparts in Dallas regarding the type of automobiles they drive. Consistent with the national sample, Seattle residents tend to drive 1 ess domestic and more foreign cars than Dallas respondents (see Table IV-20). Also, the average year of the car driven by Seattle respondents is 1975 compared to the 1977 model cars driven by Dall as residents $(t(203)=$ $3.53, p(.0006)$.

As was the case for infrequent seat belt users in the national sample, Dall as residents are more 11 kely than Seattle residents to respond that they never use their seat belts when asked what is done when seat bel ts become tangled or stuck behind seats (see Table IV-21).

o To what extent is seat belt usage required by employers when driving on company business?

For the approximately $60 \%$ of the individuals to which this question is applicable, 11\% of the employers require seat bel ts to be worn. Thus, the practice is not wi des pread. 


\section{TABLE IV-14}

Percent of Frequent; Sometimes And Infrequent Seat Belt Users By Type of Car

$$
(n=939)
$$

\begin{tabular}{|c|c|c|c|}
\hline \multirow[b]{2}{*}{ User Type } & \multicolumn{2}{|c|}{ Type of Car } & \multirow[b]{2}{*}{ Total } \\
\hline & Domestic & Foreign & \\
\hline Frequent user & 22 & 7 & 29 \\
\hline Sometime user & 25 & 5 & 30 \\
\hline $\begin{array}{l}\text { Infrequent user } \\
\text { Total }\end{array}$ & $\frac{36}{83}$ & $\frac{5}{17}$ & $\frac{41}{100}$ \\
\hline
\end{tabular}


Mean Ratings of Comfort And Convenience of Restraint Systems As A Function of Type of Car

\section{Adjective}

Comfort

$\underline{t}_{(864)}=-2.73, p<.007$

Convenience

$\underline{t}(882)=-3.01, p<.003$
Type of Car

$\frac{\text { Domestic }}{2.31} \quad \frac{\text { Foreign }}{2.49}$

2.26

2.47

Note: Scores ranged from " 1 " to " 3 ", with " 1 " being "uncomfortable" or "inconvenient" and " 3 " being "comfortable or "convenient". 
TABLE IV -16

Percent of Frequent, Sometimes And Infrequent Seat Belt

Users By Type of Restraint System

$(n=750)$

N

Type of Restraint System

User Type

Frequent users

Sometimes users

Infrequent

Tota 1

$\underline{x}^{2}(2)-12.37, p<.003$
Total

Separated Seat Belt Combined Seat Belt

21

29

11

22

33

16

35

38

100 
TABLE IV -17

Percent of Frequent, Sometimes, And Infrequent Seat Belt Users

As A Function of Having Been Told How To Operate A Seat Belt

$(n=917)$

\section{User Type}

Frequent users

Sometimes users

Infrequent users

Total
Operation of seat belt system demonstrated

8

10

15

33
Operation of seat belt system not demonstrated

Total

22

29

21

31

25

67

$\underline{x}^{2}$

$(2)=11.33, p<.004$ 


\section{TABLE IV-18}

Percent of Frequent, Sometimes, And Infrequent Seat Belt Users Who Agree/ Disagree With The Statement. "I Don't Think Seat Belts Work Properly When

They Feel Loose Around Me After I Fasten Them"

$(n=905)$

\begin{tabular}{lccc}
\hline User Type & Agree & Disagree & Total \\
Frequent users & 15 & 15 & 30 \\
Sometimes users & 11 & 20 & 31 \\
$\begin{array}{l}\text { Infrequent users } \\
\text { Total }\end{array}$ & $\frac{19}{45}$ & $\frac{20}{55}$ & $\frac{38}{100}$ \\
\hline$\underline{x}^{2}(2)=14.48, \underline{p}<.0008$ & & &
\end{tabular}


TABLE IV-19

Percent of Frequent, Sometimes, And Infrequent Seat Belt Users

As A Function of What They Would Do If Their Seat Belt Was

Tangled Or Stuck Behind A Seat

$$
(n=982)
$$

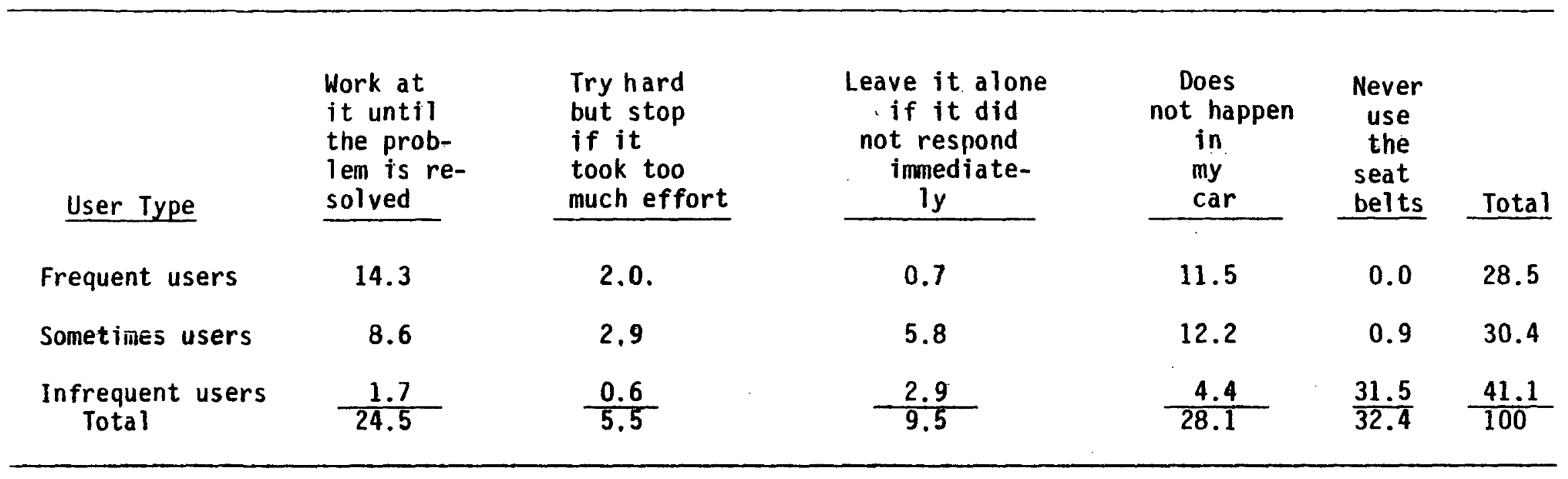

$\underline{x}_{(8)}^{2}=698.15, p<.0001$ 
TABLE IV-20 Percent of Seattle And Dallas Respondents Driving
Domestic And Foreign Automobiles

$(n=202)$

\begin{tabular}{|c|c|c|c|c|}
\hline & & \multicolumn{2}{|c|}{ Type of Automobile } & \multirow[b]{2}{*}{ Total } \\
\hline & & Domestic & Foreign & \\
\hline Seattle & Sample & 33 & 19 & 52 \\
\hline Dallas & Sample & 41 & 7 & 48 \\
\hline \multicolumn{2}{|c|}{$\because \quad$ Total } & 74 & 26 & $\overline{100}$ \\
\hline
\end{tabular}

g $\quad \underline{x}^{2}(1)=11.19, p<.0009$ 


\section{TABLE IV-21}

Percent of Seattle And Dallas Respondents As A Function of What They Would Do If Their Seat Belt Was Tangled Or Stuck Behind A Seat

$$
(n=207)
$$

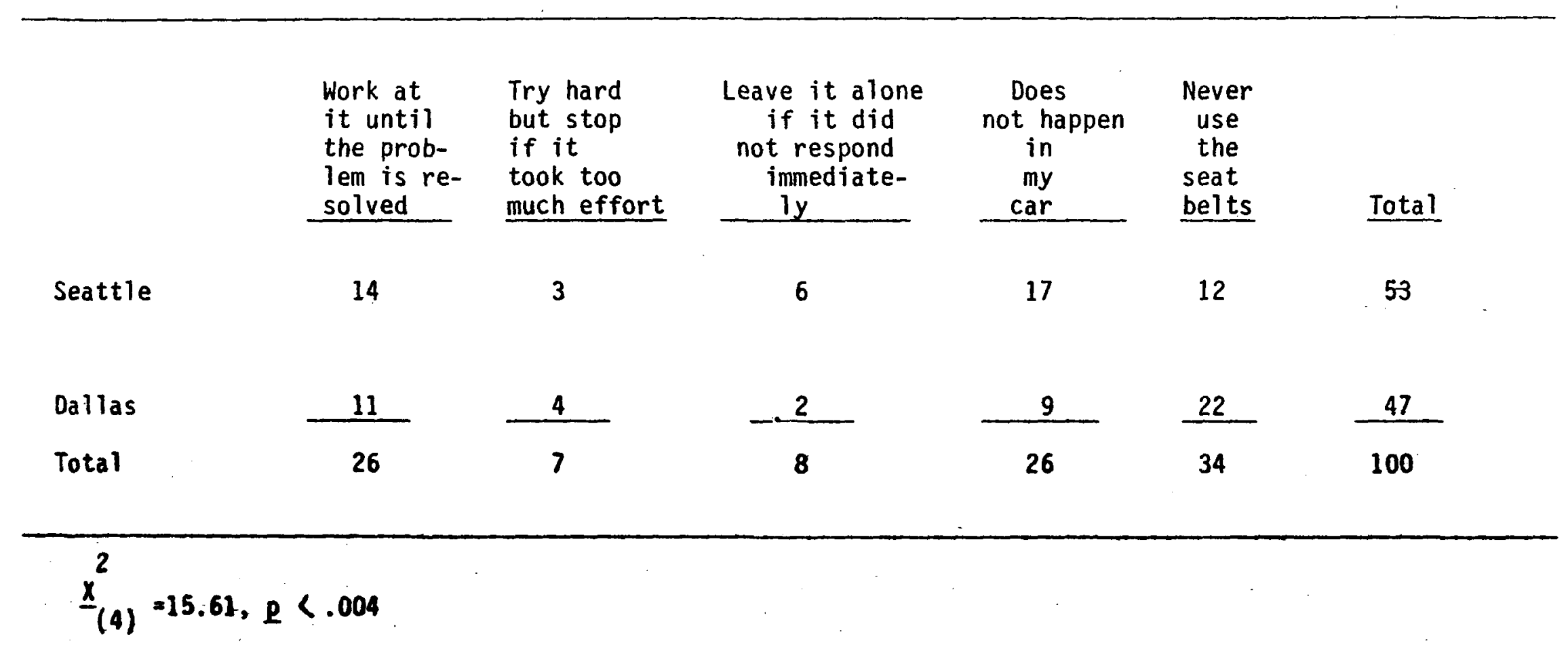


- Do people tend to respond to others admonitions to use seat belts?

The data reveal several interesting facts related to this research question. Fifty percent of the people have requested others in the car to buckle up. Table IV-22 reveals that infrequent users are the least likely user group to ask others to buckle their seat belts. Most people (94\%) complied with the request to buckle up, and it was generally believed that they did so out of courtesy (44\%) versus believing the request was honored because it was the right thing to do (28\%).

The majority of individuals $(64 \%)$ believe that if they buckled up other passengers would follow their lead and also fasten their belts without being asked. This is especially true of frequent and sometimes users as indicated in Table IV-23.

Forty percent of the individuals have been asked to buckle up their seat belts, most often $(86 \%)$ by the driver of the vehicle who was a friend $(64 \%)$ or relative $(36 \%)$. Sometimes users of seat belts were most frequently requested to buckle up (see Table IV-24) and $94 \%$ of all individuals asked to fasten their seat belts did so.: It should be noted that sometimes users were requested to fasten their seat belts more often than frequent users because presumably frequent users were already buckled up. It can be surmised that the greater frequency of requests made to sometimes users over infrequent users was due to the fact that sometimes users have been seen wearing seat belts in the past and perhaps simply needed a reminder to buckle up.

- Is alcohol or drug impairment related to variable safety belt usage?

Individuals, specifically sometimes users of seat belts, tend to increase their seat belt usage after taking drugs or prescribed medication, but not as much as under other situations (e.g., when the weather is poor) as previousiy noted.

- What effect does exposure to injury due to a car accident have upon seat belt usage and for how long?

Of the $19 \%$ of the people who were exposed to an accident, $19 \%$ used their seat belts more often and $6 \%$ used them less often immediately following the accident. Forty-eight percent were personally involved in the most recent accident and $65 \%$ of those were driving. Over time, $51 \%$ of the individuals continue to wear their seat belts as often as they did immediately following the accident.

The preceding data on situational variables reveal that various physical and social factors in the environment influence seat belt usage. Physical factors, such as the type of car driven, the type of restraint system

The alcohol issue was asked only of the face-to-face interviewees and will be addressed in the section dealing with the face-to-face items. 
Percent of Frequent, Sometimes, And Infrequent Seat Belt Users

Who Have Requested Others To Fasten Their Seat Belts

$(n=983)$

User Type

Frequent users

Sometimes users

Infrequent users Total
Requested Others

\begin{tabular}{|c|c|c|}
\hline Yes & No & Total \\
\hline 23 & 6 & 29 \\
\hline 20 & 10 & 30 \\
\hline$\frac{8}{51}$ & $\frac{33}{49}$ & $\frac{41}{100}$ \\
\hline
\end{tabular}

$\underline{x}^{2}(2)=276.96, p<.0001$ 
TABLE IV -23

Percent of Frequent, Sometimes, And Infrequent Seat Belt Users Who Believe

That If They Buckled Up Other Passengers Would Also Fasten Their Belts With-

Out Being Asked

$$
(n=937)
$$

\section{User Type}

Frequent users

Sometimes users

Infrequent users

Tota 1

$\check{o}$

Yes others would

buckle up

21

23

23

67
No others would not buckle up

Total

29

31

40

16

100

$$
\underline{x}^{2}(2)=19.17, p<.0001
$$




\section{TABLE IV-24}

Percent of Frequent, Sometimes, And Infrequent Seat Belt Users Who Have Been Asked By Others To Fasten Their Seat Belts

$$
(n=950)
$$

\section{User Type}

Frequent users

Sometimes users

Infrequent users

Total
Asked by others

to buckle up

$$
\begin{array}{r}
9 \\
17 \\
13 \\
\hline 40
\end{array}
$$

Have not been asked by others to buckle up

Total

\begin{tabular}{lr}
19 & 28 \\
14 & 31 \\
28 & 41 \\
\hline 60 & 100
\end{tabular}

$\Rightarrow \quad \underline{x}^{2}(2)=43.95, p<.0001$ 
installed in the car, the length of the trip, the type of road driven on, and weather conditions, all contribute to an individual's decision to wear safety belts.

Social factors, such as others' requests to use seat belts, perceptions of whether or not others would buckle up without being told if they saw the driver buckle up, and driving alone vs. with others, all play a role in affecting variable seat belt usage.

Consistent with the national sample, Seattle residents, who are more freqent users than the Dall as respondents, are more likely than their Dallas counterparts to drive foreign cars. Foreign imports, it will be remembered, are associated with greater seat belt use than American cars.

Motivational Variables. Seven research questions assess the impact of various motivational factors on seat belt usage. Two questions, one examining interral versus external locus of control and the other addressing perceptions of potential accident hazards, were asked of the face-to-face interviewees only. These data will be described in a later section dealing with the face-to-face survey. The results pertaining to the five remaining research questions are presented below.

- To what extent is a driver's use of seat belts associated with fears or concerns regarding driving safety?

Frequent users of seat belts show less concern than sometimes and infrequent users about being trapped in their cars following an accident (see Table IV-25). In addition, Table IV-25 reveals that frequent users show less concern than sometimes and infrequent users when driving with other people in the car.

Consistent with the preceding finding is the fact that Seattle respondents $(\bar{X}=1.94)$ show less concern than their Dall as counterparts $(\bar{X}=2.35)$ when driving with other people in the car $(\underline{t}(203)=-3.49, \underline{p}<.0006)$.

- Are the comfort and convenience of restraint systems associated with the frequency of seat belt usage?

As previously noted, the seat belt systems in foreign cars, where restraint usage exceeds that of domestic models, are rated more comfortable and convenient than systems found in American cars (see Table IV-15). In addition, separated seat belt and shoulder straps, characterized by low usage, are considered more inconvenient than combined seat belt and shoulder strap systems.

Ratings of seat belt comfort and convenience also differ among user groups. Frequent seat belt users rate their seat belt systems significantly more comfortable than sometimes users, who in turn rate their seat belt systems significantly more comfortable than infrequent users (see Table IV-26). Table IV-26 reveals the same pattern for ratings of convenience. Frequent users judge their seat belt systems more convenient than sometimes users, who judge their systems more convenient than infrequent users. Surprisingly, there were no differences on ratings of comfort or convenience 
TABLE IV-25

Mean Ratings of Concern With Regard To Safety While Oriving By Seat

Belt User Groups

\section{Concern}

Being trapped in the car following an accident

$E(2,933)=6.03, p<.003$

$\stackrel{w}{\omega}$

Driving with other people in the car

$E(2,933)=5.31, p<.006$

\section{Frequent users Sometimes users Infrequent users}

2.26

2.40

2.49

2.11

2.31

2.29

Note: Scores ranged from "1" to "3", with "1" being "little concern" and "3" being "much concern." 
Mean Ratings of Comfort And Convenience of Restraint Systems By Seat Belt User Groups

\section{User Groups}

Frequent users $\quad$ Sometimes users $\quad$ Infrequent users
$\underline{F}(2,879)=55.16, \mathrm{p}<.0001$
2.67
2.32
2.06

Convenience

$\checkmark \mathrm{F}(2,898)=77.32, \mathrm{p}<.0001$

2.71

2.31

1.97

Note: Scores ranged from "1" to "3", with "1" being uncomfortable" or "inconvenient" and "3" being "yricomfortable" or "convenient." 
between Seattle and Dallas residents. Clearly, however, perceptions of comfort and convenience of seat belt systems are important factors influencing seat belt usage.

- What are people's predominant opinions on how to get others to use their seat belts?

Of those giving responses, the most predominant opinion on how to get others to use their seat belts is to make a general coment regarding safety (42\%), that is, a message that states seat belts save lives, prevent injury, etc. The next most frequent opinion regarding the type of safety message is to show pictures of actual accidents where people did not use seat belts (24\%), followed by messages that tell statistics or show figures proving that seat belts are effective in saving 7 ives and preventing injuries (18\%). Infrequent users of seat belts are more likely than frequent and sanetimes users to respond that they do not believe in seat belts and would not try to convince people to use them (see Table IV-27).

- Do individuals who take precautions regarding their personal heal th and well being (not associated with driving) and avoid other risk taking behavior also tend to take precautions regarding driving safety?

Individuals who take precautions regarding their personal heal th $(\mathrm{e} . \mathrm{g}$. , do not smoke cigarettes, visit the dentist at least once a year, and engage in a constant exercise program such as jogging or swimming) are more 1 ikely to be frequent and sometimes seat belt users campared to infrequent users (see Table (Y -28$)$.

In addition to the preceding behavioral difference regarding personal health and seat belt usage, differential belt use exists as a function of attitudes about personal health and seat belts. For example, most people $(80 \%)$ agree with the statement, "Wearing seat belts is like other good health practices, such as brushing your teeth and having regular medical checkups." As. seen in Tabl ve IV-29, however, infrequent seat belt users (67\%) are less likely to agree with the statement compared to frequent users ( $94 \%$ ) and sometimes users (89\%).

No statistical difference was found between Dallas and Seattle respondents regarding their overall personal heal th precautions (al though Seattle residents visit their dentists more often than Dallas residents) nor their likelihood of agreeing/disagreeing with the "seat belts (are) like other good health practices" statement.

- What appear to be the most influential sources of persuasion regarding the use of safety belts? Do users and nonusers agree on the most influential sources?

Table IV-30 displays the mean ratings for each potential source. As can be seen in the table, the most influential sources of persuasion are driver .education instructors, followed by the police and family members or friends. Frequent, sometimes, and infrequent seat belt users all rate the driver education instructor as the most influential source of persuasion regarding 


\section{TABLE IV-27}

Percent of Frequent, Sometimes, And Infrequent Seat Belt Users' Opinions

Regarding How They Would Convince Other People To Use Seat Belits

$$
(n=835)
$$

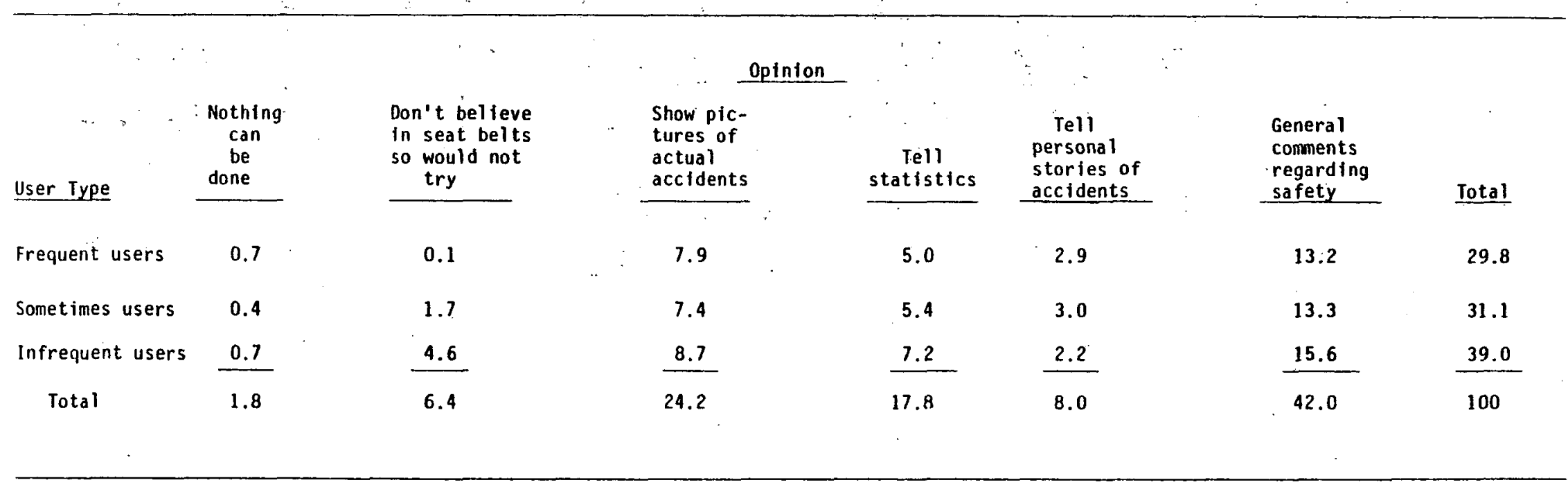

$$
\underline{x}_{(10)}^{2}=35.75, p<.0001
$$




\section{TABLE IV-28}

Percent of Frequent, Sometimes, And Infrequent Seat Belt Users As A

Function of Whether They Take Precautions Regarding Their Personal Health

$(n=658)$

User Type

Frequent users

Sometimes users

Infrequent users

Total

$\forall$

$\underline{x}^{2}(2)=11.71, p<.003$

\begin{tabular}{cc} 
Precautions not taken & Total \\
\hline 6 & 27 \\
9 & 31 \\
15 & 42 \\
29 & 100
\end{tabular}

Precautions taken

22

22

27

71
27

1

100 
TABLE IV -29

Percent of Frequent, Sometimes, And Infrequent Seat Belt Users Agreeing/Disagreeing With The Statement, "Wearing Seat Belts Is Like Other Good Health Practices, Such As Brushing Your Teeth And Having Regular Medical Checkups"

$$
(n-961)
$$

\section{User Type}

Frequent users

Sometimes users

Infrequent users

Total

\section{Agree with statement}

27

27

27

82

\section{Disagree with statement $\quad \underline{\text { Total }}$}

2

3

29

30

14

41

18 
TABLE IV -30

Mean Ratings of Potential Influence Sources

\begin{tabular}{ll}
\multicolumn{1}{c}{ Source } & Mean \\
Driver education instructor & 2.46 \\
Police & 2.34 \\
Family or friends & 2.32 \\
Professiunal race car driver & 2.30 \\
Automobile insurance agent & 2.26 \\
Federal government official & 2.12 \\
State or local government official & 2.09 \\
Priest, minister, or rabbi & 1.98 \\
Auto mechanic or serviceman & 1.79 \\
Nationally known sports figure or personality & 1.79 \\
Car dealer & 1.62
\end{tabular}

Note: Responses were scored from "1" (not influential) to "3" (influential) 
seat belt usage. Table IV-3I indicates that infrequent users rate all sources consistently less influential than frequent and sometimes users of seat belts, and the mean sum total influence score of infrequent users is significantly lower than that of frequent and sometimes users.

Television, cited by $53 \%$ of the people, is by far the most often mentioned media source likely to draw attention if automobile safety messages were presented. Television is followed by radio (18\%) and newspapers (12\%).

The data obtained regarding moti vational factors reveal several differences among the three user groups. First, people who wear seat belts sometimes or infrequently are more concerned about being trapped in their car following an accident compared with frequent users. This finding has ramifications for future safety messages. An effective safety message might dispel the myth that a fastened seat belt increases one's chances of becoming trapped in a car.

Second, the importance of the restraint system's comfort and convenience again surfaces. Frequent users rate their seat belt systems more comfortable and convenient that sometimes users, who in turn rate their seat beit systems more comfortable and convenient than infrequent users. One must be careful, however, not to assume that simply increasing the comfort of a seat bel $t$ system will result in an increase in seat belt use. Loose seat belts, which are designed for comfort, are viewed as ineffective by $45 \%$ of the people (see Table IV-18). If people perceive their seat belts to be ineffective, they probably will not use them, no matter how comfortable the seat belt feels.

It is somewhat surprising to find that Seattle respondents do not differ in their ratings of seat belt comfort and convenience from Dallas residents for two reasons. First, Seattle residents are more frequent users of seat belts than Dallas residents. Second, Seattle residents are more likely to dri ve foreign cars compared to Dall as residents (see Table IV-20), and it will be remembered that the seat belt systems in foreign cars are perceived to be more comfortable and convenient than systems found in domestic cars (see Table IV-15). Thus, the comfort and convenience of restraint systems is not an adequate explanation to account for the difference in seat belt use between Seattle and Dall as residents.

The data also indicate that persons who take precautions regarding their personal health are more likely to be users of seat belts (either frequent or sometimes) compared with infrequent users. However, personal heal th maintenance does not differentiate between Seattle and Dallas respondents.

Finally, the results obtained from the influence ratings of potential message sources suggest that infrequent users of seat belts may be a difficult group of people to influence. Infrequent users not only rate all potential sources as less influential than other user groups, they are also iess likely than others to try to convince people to wear seat belts. Thus, infrequent users may resent seat belt/safety messages aimed at them more than frequent and sometimes users. This finding suggests that indirect or subtle safety messages may be met with 1 ess resentment than direct advertisements about seat belts by infrequent seat belt users. 
TABLE IV-31

Mean Ratings of Potential Influence Sources By Seat Belt User Groups

\begin{tabular}{|c|c|c|c|}
\hline \multirow[b]{2}{*}{ Source } & \multicolumn{3}{|c|}{ User Type } \\
\hline & Frequent users & Sometimes users & Infrequent users \\
\hline Oriver education instructor & 2.65 & 2.64 & 2.19 \\
\hline Police & 2.45 & 2.46 & 2.17 \\
\hline Family or friends & 2.56 & 2.50 & 2.01 \\
\hline Professional race car driver & 2.52 & 2.46 & 2.03 \\
\hline Automobile insurance agent & 2.39 & 2.37 & 2.10 \\
\hline Federal government official & 2.17 & 2.27 & 1.95 \\
\hline State or local government official & 2.18 & 2.22 & 1.92 \\
\hline Priest, minister, or rabbi & 2.10 & 2.11 & 1.78 \\
\hline Auto mechanic or serviceman & 2.03 & 1.91 & 1.52 \\
\hline Nationally known sports figure or personality & 1.98 & 1.89 & 1.57 \\
\hline Car dealer & 1.85 & 1.72 & 1.39 \\
\hline mean sum total influence score & 24.76 & 24.65 & 20.53 \\
\hline$\underline{F}(2,901)=56.87, \mathrm{p}<.0001$ & & & \\
\hline
\end{tabular}

Note: Responses were scored from "1" (not influential) to "3" (influential).

Mean sum total influence scores were obtained by summing across all eleven sources. The higher the score, the more influential all eleven sources are seen. 
Additional Analyses. The foregoing analyses examined separately those demographic, situational, and motivational factors associated with seat be? use. In order to gain a better understanding of the interrelationship among these variables, correl ation matrices were calcul ated and examined. The data obtained from these correlations reveal that one demographic variable (education), one situational variable (driving on divided highways), and four motivational variables (comfort of seat belts, convenience of seat belts, disposition to be influenced by safety message sources, and feelings that seat belt usage can be equated to other health maintenance practices) are significantiy ${ }^{2}$ correlated with a general measure of seat belt usage (how often use seat belts when drivingl.

The preceding six variables were entered in a stepwi se multiple regression to determine the degree to which they are predictive of seat belt use. The partial coefficients generated by the multiple regression analysis reveal that each variable contributes significantly to understanding seat belt usage. The overall six variable model is significant $(F(6,855)=57.90, p<.0001)$ and accounts for approximately $29 \%\left(R^{2}=.29\right)$ of the variance in individuals' responses to how often they wear seat belts when driving an automobile. The analysis also reveals that the one variable best able to predict a general measure of seat belt usage is how convenient people judged their restraint systems to be $\left(R^{2}=.16\right)$.

Results of the Face-to-Face Survey

As was the case with the telephone survey, the length of the questionnaire precludes the sequential presentation of resuits for each item. The item-by-item results can be found in Appendix B.

In the analyses that follow, research questions associated with general seat belt usage variables are presented and answered. With two exceptions, specific research questions are not raised in the remaining sections addressing the impact of demographic, situational, and motivational factors on seat belt use. Rather, results that achieve statistical significance 3 are presented. In other words, in an effort to gain further insight into the previously described data obtained from the telephone survey, those demographic, situational, and motivational variables significantly affecting seat belt use are discussed.

Seat Belt Usage Variables. Because of their importance, the same five research questions regarding seat belt use raised in the telephone survey are considered below.

2 The significance level p<.0001 was used as the cutoff for defining significant correlations.

3 Because of the smaller sample size in the face-to-face survey, a probability level of $p<.05$ was chosen for defining statistically significant differencess. 
- How often are seat belts used under certain weather conditions and during different types of trips?

Table IV-32 reveals that people wear their seat belts most of ten on long trips, followed by driving in poor weather, and least often when driving on short trips. The same pattern of results was found for the national telephone sample.

- How often do individuals use their seat belts as a passenger versus as a dri ver?

As can be seen in Table IV-33, there is a slight tendency for people to wear their seat belts more often when driving as opposed to when they are a passenger in a car. However, individuals who fasten their seat belts always or most of the time are a distinct minority. This finding is consistent with the data obtained from the national sample.

- How consistent is the restraint system usage across time?

Forty-one percent of the people have changed their seat belt behavior over time and the remaining 59\% have been consistent users or nonusers. This figure (41\%) is slightiy higher than that found for the national sample. No assessment was made concerning whether or not the individuals who changed increased or decreased their seat belt use across time.

As was the case with the national sample, the user groups differ in their use of seat belts across time $\left.\left(x^{2} / 2\right)=10.45, p<.006\right)$. Fifty-two percent of the frequent seat belt users have changed their usage behavior, compared with $47 \%$ of the sometimes users and $26 \%$ of the infrequent users. 
TABLE IV-32

Percent of Seat Belt Usage Under Certain Weather Conditions And During Different Types of Trips.

\begin{abstract}
Questionnaire Item
How often do you wear seat

belts when driving on roads

which are wet, or snow and

ice covered?
\end{abstract}

How often do you wear seat belts when driving on long trips?

19

36

How often do you wear seat belts when driving on short trips around town?

Most of

25

38

$\underset{\infty}{\infty}$
32

14

the time

12

Always the time

25

14


TABLE IV-33

Percent of Seat Belt Usage As A Function of Being $A$ Passenger Or Driver

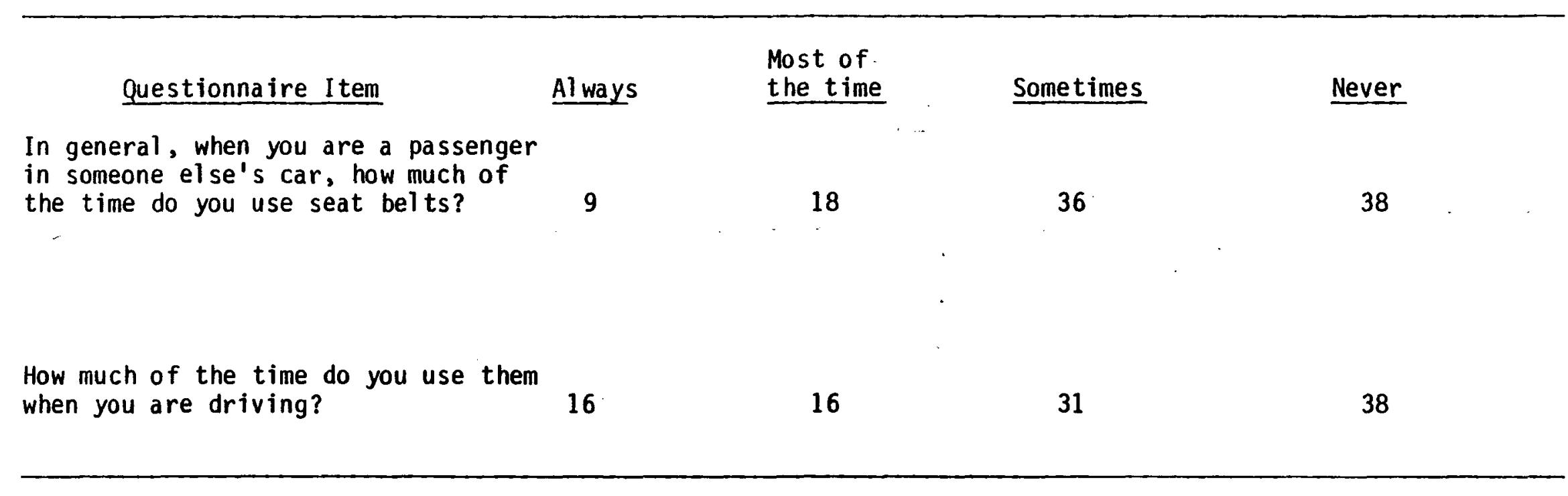


How often are child restraints used?

Forty-seven of the 197 respondents (24\%) reported that they had children 4 years of age or under in their households. Of these, $37(77 \%)$ said they owned at least one child car safety seat. For these respondents with child car seats, $61 \%$ always use them, $22 \%$ use them sometimes, and $17 \%$ never use them. There appears to be a somewhat higher percentage of parents in the face-to-face sample compared to the national sample who have young children and car safety seats, but who never use the seats.

\section{o How often have people disconnected their seat belt systems?}

Forty-seven peopte (24\%) have disconnected their seat belt systems, and half of them (50\%) did so because the buzzer was annoying when the seat belts were not fastened. In comparison to the national telephone survey, twice as many people in the face-to-face survey disconnected their seat belt systems, but fewer did so because the buzzer was annoying.

Respondents were classified into the three distinct seat belt user categories, frequent, sometimes, and infrequent users, by the same criterion as that employed in and previousiy described for the telephone survey. The breakdown is comparable to that found in the national sample. Slightly less than one-third of the people (30\%) are classified as frequent users and exactly one-third (33\%) are considered sametimes users of seat belts. The remaining $37 \%$ of the individuals rarely or never use their seat belts and are classified as infrequent users.

Although data obtained from the observational phase of the study are discussed in a later section, a camparison between self-reported seat belt use and observed seat belt use was made and is presented here.

A total of 127 observed individuals met the following requirements.

a) A same-sex driver was observed during 211 four observational periods.

b) Ratings of the driver's age, which were coded as "1" (adolescent), "2" (young adult), "3" (middle age), and "4" (elderly), had to be consistent, or not vary by more than one coded number, across all four observational periods.

c) The sex of the individual responding to the face-to-face questionnaire had to be the same as that of the driver observed lafter matching the observed license plate number with the identical license plate number from the face-to-face questionnaire).

d) No missing data existed.

A summed total seat belt score was calculated for the observational data. Notice was made whether the dri ver was wearing a seat belt (coded as "1") or not wearing a belt (coded as " 0 "). An individual received a summed total seat belt score of "4" if he/she was wearing a seat belt across all four observation periods, a " 3 " if the belt was not fastened on one of the four observation periods, a "2" if the belt was not fastened for two of the four 
observation periods, a " 1 " if the seat belt was fastened on one out of four occasions, and a " 0 " if the seat belt was never fastened during the four observational periods.

The above observed summed seat belt score was correlated with the responses to the self-report question, "How much of the time do you use (seat belts) when you are driving," where " 1 " = always, "2" = most of the time, "3" = sometimes, and "4" = never. The data reveal a significant correl ation between observed and se1f-reported seat belt use $(r=-.51, p<.0001)$. It should be pointed out that in $91 \%$ of the observed cases, drivers did not have their seat belts fastened. It will be remembered that $30 \%$ of the drivers report being frequent users of seat belts. Thus, instances of self-reported seat belt use appear somewhat inflated.

The analyses that follow generally involve the three distinct seat belt user categories (frequent, sometimes, and infrequent users) based on the self-report face-to-face survey. Despite the absence of specific research questions, the format, addressing the demographic, situational, and motivational factors influencing seat belt use, remains consistent.

Demographic Variables. One demographic factor, the type of 1 iving area, distinguishes between seat belt user groups. Table IV-34 presents the frequency distribution of user groups by living area. The table reveals that infrequent seat belt users are more likely than frequent and sometimes users to $l i v e$ in urban settings. Although this finding was not revealed in the telephone survey, it is consistent with the fact that seat belt usage declines on short trips. Urban settings seem less conducive for high speed, long trip traveling compared with other, more spread out living areas.

Situational Variables. Several situational variables, dealing with the seat belt system itself and response to others' admonitions to use seat belts, reveal significant differences among the user groups. Surprisingly, frequent seat belt users are more likely than sometimes and infrequent users to agree with the statement, "I don't think seat belts work properly when they feel loose around me after I fasten them" (see Table IV-35). As in the telephone survey, the data aga in reveal that nearly half $(47 \%)$ of the people bel ieve that seat belts do not work properly when they feel loose.

Frequent, sometimes, and infrequent users differ in their reactions to seat belts that become tangled or stuck behind the car seat. As can be seen in Table IV-36, frequent seat belt users are the most 7 ikely user group to work at the probiem until it is resolved. Infrequent users tend to respond that they never use seat belts, so the problem of a tangled or stuck seat belt is irrelevant. The same pattern of results is repeated for the telephone survey.

Slightly more than half (55\%) of the individuals have asked other people in their cars to fasten their seat belts. Table IV-37 indicates that infrequent users tend to be the least likely user group to ask others to buckle up. In addition, infrequent users are less likely than frequent and sometimes users to have their own seat belts fastened when they request others to buckle up (see Table IV-38). 
TABLE IV-34

Percent of Frequent, Sometimes, And Infrequent

Seat Belt Users By Living Area

$(n=189)$

\begin{tabular}{|c|c|c|c|c|}
\hline \multirow[b]{2}{*}{ User Type } & \multirow[b]{2}{*}{ Urban } & \multicolumn{2}{|c|}{ Living Area } & \multirow[b]{2}{*}{ Total } \\
\hline & & Suburban & Rural & \\
\hline Frequent users & 3 & 17 & 11 & 30 \\
\hline Sometimes users & 6 & 21 & 6 & 33 \\
\hline $\begin{array}{l}\text { Infrequent users } \\
\text { Total }\end{array}$ & $\frac{13}{22}$ & $\frac{15}{53}$ & $\frac{8}{25}$ & $\frac{37}{100}$ \\
\hline
\end{tabular}

$\underline{x}^{2}(4)=17.38, \underline{p}<.002$ 
Percent of Frequent, Sometimes, And Infrequent Seat Belt Users Who Agree/Disagree With The Statement, "I Don't

Think Seat Belts Work Properly When They Feel Loose

Around Me After I Fasten Them"

$(n=187)$

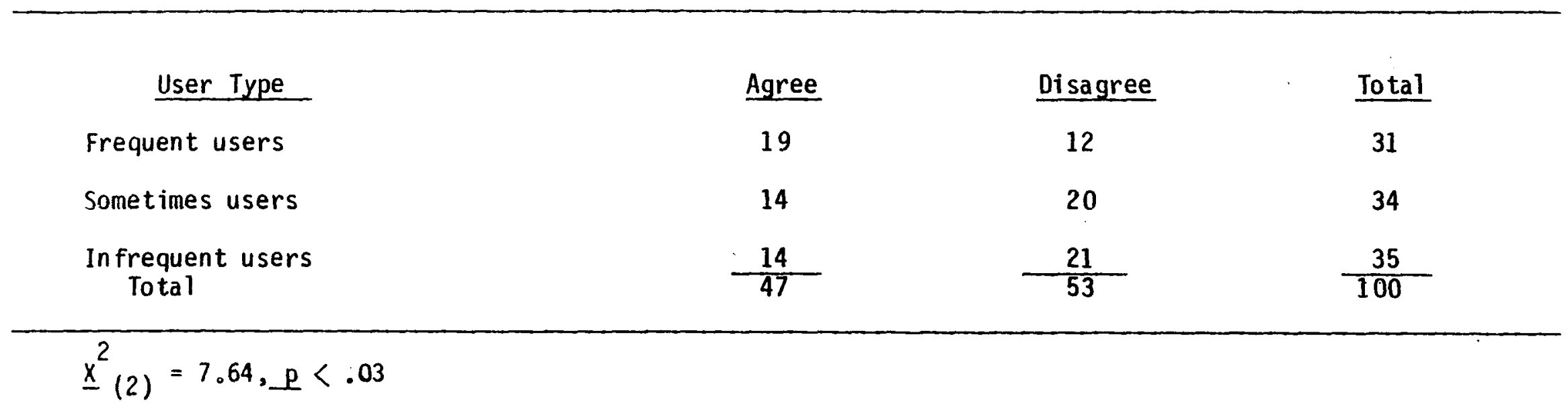


TABLE IV-36

Percent of Frequent, Sometimes, And Infrequent Seat Belt Users As A Function of What They Would Do If Their Seat Belt Were

Tangled Or Stuck Behind A Seat

$(n=194)$

\begin{tabular}{|c|c|c|c|c|c|c|}
\hline Frequent users & 15 & 3 & 1 & 10 & 0 & 30 \\
\hline Sometimes users & 10 & 5 & 6 & 12 & 0 & 33 \\
\hline Total & 30 & 9 & 9 & 25 & 27 & 100 \\
\hline
\end{tabular}


TABLE IV -37

Percent of Frequent, Sometimes, And Infrequent Seat Belt Users Who Have Requested 0thers To Fasten Their Seat Belts

$(n=194)$

\section{Requested 0thers}

User Type

Frequent users

Sometimes users

Infrequent users Total

$$
\underline{x}_{(2)}^{2}=23.21, \underline{p}<: 0001
$$

Total

30

32

38

\begin{tabular}{ccc} 
Yes & No & Total \\
\cline { 2 - 3 } 23 & 7 & 30 \\
19 & 13 & 32 \\
$\frac{13}{55}$ & $\frac{25}{45}$ & $\frac{38}{100}$
\end{tabular}




\section{TABLE IV -38}

Percent of Frequent, Sometimes, And Infrequent Seat Belt Users Who Were Wearing Seat Belts When Requesting Others To Buckle Up $(n=111)$

Oun seat belts fastened

\begin{tabular}{lcccc} 
User Type & Yes & No & Total \\
\cline { 2 - 5 } & 41 & 0 & 41 \\
Frequent users & 32 & 4 & 36 \\
Sometimes users & $\frac{4}{\pi 7}$ & $\frac{19}{23}$ & $\frac{23}{100}$ \\
$\begin{array}{c}\text { Infrequent users } \\
\text { Total }\end{array}$ & & &
\end{tabular}

$$
\underline{x}_{(2)}^{2}=67.22, \underline{p}<.0001
$$


The vast majority (96\%) of those requested to fasten their seat belts did so. However, as Table IV-39 reveals, the people most likely to refuse the request have been asked by individuais who are themselves infrequent users of seat belts. Finaliy, a similar pattern of results is found when the respondent herself/himself is requested by another person to buckle up. Ninety-seven percent of those asked to buckle up did so. All 30 of the frequent users and a 1132 of the sometimes users that were asked to fasten their seat belts obeyed the request, canpared to 29 out of $32(91 \%)$ of the infrequent users $(\underline{x}(2)=6.00, \underline{p}(.05)$.

The situational variables which best distinguish among frequent, sometimes, and infrequent seat belt users relate to physical aspects of the seat belt system (i.e., working condition) and social aspects of restraint systems (i.e., requesting others to buckle up). These data are consistent with the results obtained in the national telephone survey and illustrate the differences among user groups across a range of behaviors involving seat belts and restraint systems.

One final item concerning situational factors needs to be addressed. It will be remembered that the issue of alcohol (see footnote 1) was raised in a research question in the telephone survey. Table IV-40 reveals that driving after having a few drinks ranks sixth out of the 14 situations 7 isted concerning when seat belt use increases for sometimes users. Driving after having taken drugs or prescribed medication ranks seventh. These results are comparable to those reported in Table IV-13, which also reveal that sometimes users of seat belts (in the national sample) are most likely to increase their seat belt usage when the weather is poor. The situation in which a sometimes user of seat belts finds himself/herself has an impact on his/her decision to wear or not to wear seat belts.

Motivational Variables. Two of the seven research questions examining motivational factors generated to guide the analyses could be answered oniy with data obtained in the face-to-face survey. These questions are discussed in this section.

0 Are people who tend to be internally motivated in making decisions more likely to take personal safety precautions, including the use of seat belts, than people who often rely upon others to define their actions?

Individuals were categorized as internally moti vated or externally motivated based on their total summed score of nine questionnaire items (i.e., questions 41a-42c, see Appendix B). Scores could range from "9" (high internal motivation) through "18" (high external motivation). Eighty-two percent of the people were categorized as internally motivated (i.e., total summed score $<14$ ) and the remaining $18 \%$ were classified as externally motivated.

The data reveal no statistically significant difference between the seat belt usage rates of internally and externally motivated individuals. Eighty-seven percent of the frequent users, $85 \%$ of the sometimes users, and $75 \%$ of the infrequent seat belt users are categorized as internally motivated. This finding is somewhat surprising, as it might be expected that 
TABLE IV-39

Percent of Frequent, Sometimes, And Infrequent Seat Belt Users

Whose Request To Others To Buckle Up Have Been Obeyed/Ignored $(n=111)$

User Type

Frequent users

Sometimes users

Infrequent users Total
Request obeyed

40

37

20

\section{Request ignored}

1

0

$\frac{3}{4}$

\section{Total}

41

37

23

$$
\underline{x}^{2}(2)=6.85, \underline{p}<: 04
$$


Mean Response of Sometimes Seat Belt Users Indicating When Their Use of Seat Belts Decreases, Stays The Same, Or Increases

\section{Situation}

When the weather is poor like rain, snow or fog When asked by a passenger to put on a seat belt

When driving with children in the car

After having been or nearly in an accident

On a holiday

After having a few drinks

After taking drugs or prescribed medication

When in a car smaller than the one typically driven

During rush hours

During weekends

When on unfamilar streets

When driving alone

On a trip with more than one stop along the way

During the week day evenings
Mean

$$
\text { 4.06 }
$$

4.00

3.98

3.82

3.77

3.59

3.52

3.52

3.46

3.37

3.30

3.27

3.22

2.92

Note: Responses ranged from " 1 " (use of seat belts decreases very much) to " 5 " (use of seat belts increases very much) 
internally moti vated individuals would more likely be frequent seat belt users than infrequent users. The lack of a reliable difference may be attributed to the fact that such a large percentage $(82 \%)$ of the people are classified as internally motivated.

- Do people who perceive more potential accident hazards and adverse driving conditions tend to use seat belts as a precautionary measure more than those who pay less attention to possible dangerous situations?

Table IV-4I reveals that people perceive drinking and driving to be the most dangerous condition of the 13 conditions listed. Driving after having a few drinks is followed by driving after having taken drugs or prescribed medication and driving in poor weather. The condition perceived to be the least dangerous is driving alone. There is no reliable statistical difference among frequent, sometimes, and infrequent seat belt users concerning their overall perceptions of potential accident hazards and adverse driving conditions.

As was the case with the national sample, comfort and convenience ratings have an impact on seat belt use. Frequent users rate their seat belt systems significantly more comfortable than sometimes users, who in turn rate their seat belt systems as significantly more comfortable than infrequent users (see Table IV-42). In addition, Table IV-42 indicates a similar pattern for convenience ratings. Both frequent and sometimes users of seat belts rate their seat belt systems as more convenient than infrequent users. The most often cited (17\%) specific reason why people say seat belts are uncomfortable and inconvenient is that the seat belts "bother you when getting in and out of tight parking places."

Just as there were differences among the user groups in the national sample concerning their fears and concerns regarding driving safety, the face-to-face data reveal significant differences. Across al1 six concerns (see questions 10a-10f, Appendix B), frequent and sametimes users show less fear than infrequent seat belt users (see Table IV-43). The total "fear score" was obtained by summing across the six different concerns li.e., questions $10 \mathrm{a}-\mathrm{f}$ ). ' In addition, Table IV -43 reveals that frequent and sametimes users show less concern than infrequent users about being trapped in their car following an accident and that sometimes users show the least concern about the possibility of other drivers crashing into them. Both the national sample and the face-to-face survey reveal that infrequent and to some extent sometimes seat belt users show a good deal of concern about being trapped in their cars following an accident.

The data obtained regarding influence ratings of potential safety message sources from the national and face-to-face surveys are quite consistent. Table IV-44 presents the mean ratings of each potential source. Again, driver education instructors are rated as the most influential message source, followed by family or friends and the police. The least influential source is again the car dealer. Infrequent seat belt users rate all sources as being consistently less influential compared with ratings of frequent and sometimes users $(\underline{F}(2,901)=56.87, \underline{p}<.0001)$. 
Mean Ratings of Danger By All Respondents Across Different Conditions

\section{Condition}

After having a few drinks

After taking drugs or prescribed medication

When the weather is poor like rain, snow or fog

On a holiday

During rush hours

After having been in or nearly in an accident

When in a car smaller than the one typically driven

When on unfamiliar streets

During weekends

When driving with children in the car

thop along the way

During the week day evenings

When driving alone

\section{Mean}
1.52
1.68
1.75
1.85
2.03
2.26
2.49
2.60
2.64
2.78
3.24
3.33
3.52

Hote: Responses ranged from "1" (very dangerous) to "5" (very safe) 


\section{TABLE IV-42}

Mean Ratings of Comfort And Convenience of Restraint Systems By Frequent, Sometimes, And Infrequent Seat Belt Users

$$
E(2,190)=6.86, p<.002
$$

Iser Type

\section{Sometimes users}

3.58

2.75

Note: Scores ranged from " 1 " to " 5 ", with " 1 " being "very uncomfortable" or "very inconvenient" and "5" being "very comfortable" or "very convenient" 
Mean Ratings of Fears And Concerns As A Function of Frequent, Sometimes, And Infrequent Seat Belt Users

\section{User Type}

\section{Concern}

Being trapped in car following an accident.

$$
F_{(2,194)}=3.76, P<.03
$$

The possibility of other drivers crashing into you.

$$
\underline{F}_{(2,193)}=8.87, \mathrm{p}<.0003
$$

Total summed score

$$
\underline{F}(2,191)=3.72, \mathrm{P}<.03
$$

Note: Scores for each individual concern ranged from "1"(very little concern) to "5" (very much concern). The total summed score was obtained by summing across all six different individual concerns (questions 10a-10f in appendix B) and could range from " 6 " (very little concern) to "30" (very much concern). 


\section{TABLE IV-44}

Mean Ratings of Potential Influence Sources

\begin{tabular}{lc}
\multicolumn{1}{c}{ Source } & Mean \\
\hline Driver education instructor & 3.76 \\
Family or friends & 3.67 \\
Police & 3.65 \\
Automobile insurance agent & 3.51 \\
Professional race car driver & 3.51 \\
Priest, minister, or rabbi & 2.96 \\
Federal government official & 2.92 \\
State or local government official & 2.83 \\
Auto mechanic or serviceman & 2.69 \\
Nationally known sports figure or personality & 2.56 \\
Car dealer & 2.21
\end{tabular}

Note: Responses were scored from "1" (not very influential) to "5" (very influential) 
Consistent with the national sample, television, followed by radio and news paper, are perceived to be the most likely media sources to draw people's attention to safety messages. Frequent seat belt users rate magazines higher, that is, more effective at drawing people's attention to safety advertising, compared with sometimes and infrequent users $(F(2,193)=3.67, p<.03)$. As a whole, these findings provide confimation of the national sample results which indicate that driver education instructors and television are viewed as the most influential persons and media source, respectively, for giving automobile safety messages.

The user groups again differ in their behavior regarding personal health practices as well as in their attitudes toward heal th practices and seat belts. Individuals who take precautions regarding their personal health .le.g., do not smoke cigarettes, visit the dentist at least once a year, and engage in a constant exercise program) are more likely to be frequent and sometimes seat belt users compared to infrequent users (see Table IV-45).

In addition, most people (80\%) agree with the statement, "Wearing seat belts is like other good health practices, such as brushing your teeth and having regular medical checkups." This figure is identical to that reported for the national sample. And, consistent with the telephone survey data, infrequent seat belt users $(64 \%)$ are less likely to agree with the statement compared to frequent users $(97 \%)$ and sometimes users $(84 \%)$. The difference is presented in Table IV-46.

Finally, the user groups differ on one risk-taking variable, having unbuckled an already fastened seat belt during a trip. As can be seen in Table IV-47, frequent and sometimes users are more likely than infrequent users to have taken off their seat belt while a trip was in progress. This difference is probably due to the fact that infrequent users wear their seat belts 1 ess often than frequent and sometimes users and hence have 1 ess opportunity to unbuckle a seat belt during a trip.

The data obtained from the face-to-face survey serve to confin the results reported in the national telephone survey. The frequency breakdown of frequent, sometimes, and infrequent seat belt users is comparable in the two samples. Comparisons between self-reported and observed seat belt use indicates that the self-reported usage figures may be slightly exaggerated.

Although little was found involving significant contributions of demigraphic factors on seat belt usage, several situational variables again emerged as distinguishing among user groups. The physical and social aspects of the seat belt system, for instance, exert an influence on differentiating user groups. This is true regarding procedures taken when seat belts become tangled, beliefs about the effectiveness of loose fitting seat belts, and reactions of others to requests to fasten seat belts. These same situational factors also emerge in the telephone survey as factors which distinguish among user groups.

A variety of motivational factors that affect seat belt usage, identified in the national telephone survey, appear again in the face-to-face results . Ratings of comfort and convenience consistently have an influence on seat belt usage. Greater comfort and convenience are associated with increased use of 
TABLE IV-45

Percent of Frequent, Sometimes, And Infrequent Seat Belt Users As A Function of Whether They Take Precautions Regarding Their Personal Health

$(n=183)$

\begin{tabular}{|c|c|c|c|}
\hline User Type & Precautions taken & Precautions not taken & Total \\
\hline Frequent users & 23 & 6 & 29 \\
\hline Sometimes users & 25 & 9 & 34 \\
\hline Infrequent users & 21 & 16 & 37 \\
\hline Total & 69 & 31 & 100 \\
\hline
\end{tabular}


TABLE IV-46

Percent of Frequent, Sometimes, And Infrequent Seat Belt Users Agreeing/Disagreeing With The Statement, "Wearing

Seat Belts Is Like Other Good Health Practices, Such As

Brushing Your Teeth And Having Regular Medical Checkups"

$(n=194)$

User Type

Frequent users

Sometimes users

Infrequent users Total

\section{Agree with statement}

29

27

24

\section{Disagree with statement}

1

5

13
Total

30

32

38 


\section{TABLE IV -47}

Percent of Frequent, Sometimes, And Infrequent Seat Belt Users Who Have/Have Not Unbuckled Their Seat Belt During A Trip $(n=195)$

User Type

Frequent users

Sometimes users

Infrequent users Total

\section{Unbuckled seat belt during trip}

\begin{tabular}{lcc} 
Yes & No & Total \\
\cline { 2 - 3 } 14 & 15 & 30 \\
13 & 19 & 33 \\
$\frac{8}{36}$ & $\frac{29}{64}$ & $\frac{37}{100}$
\end{tabular}

$\stackrel{\circ}{\circ}$

$$
\frac{x^{2}}{(2)}=10.68, p<.005
$$


seat belts. Infrequent users in both the national and face-to-face surveys report that they would be less influenced by various sources giving advice on seat belts compared with sometimes and frequent users of seat belts.

Finally, the user groups consistently differ in their behaviors involving and attitudes toward personal heal th maintenance. People who fasten their seat belts infrequently tend to engage in personal health maintenance behavior less often and are not as likely to equate seat belt usage with other health practices.

The number of consistent findings across the telephone and face-to-face surveys allow for greater confidence in the data. The observation data, to follow, add further information regarding seat belt usage.

Observational Data

Data were obtained on twel ve variables (see Appendix C) for 197 automobiles during the observational segment of the study. For each of four observations made per automobile/license plate number, it was noted whether or not the driver of the car was wearing a seat belt. In the analyses that follow, calculations are based on the number of actual observations made, rather than the individual automobiles/license plate number. That is, instead of using 197 different $7 i$ cense plate numbers (matched to their corresponding license plate numbers on the face-to-face survey), in the calculations, the analyses are based on all 788 separate observations (197 automobiles $\times 4$ citings each $=788$ separate observations). Because of this inflated number, the probability level of pr.01 was chosen as the cutoff for defining statistically significant differences.

Before examining the observational usage data, it should be pointed out that one self-report measure of general seat belt use was obtained as a function of the type of setting in which the automobile was observed. Table IV-48 reveals that people report wearing seat belts more often in residential settings compared to work and/or day care settings. The frequency distribution of self-reported seat belt use is consistent with the observed 'seat belt use distribution found in residential, work, and day care settings. As Table IV-49 indicates, fastened seat belts were most often cited in residential settings.

Although a person's race did not emerge from the face-to-face survey as a variable that distinguishes among the user groups, there is a significant observed difference in seat belt use between whites and non-whites (See Table IV-50). The data reveal that white drivers are significantly more 1ikely than non-white drivers to be observed wearing seat belts.

The age of the observed car was recorded and it was found that seat belt use varied as a function of the automobile's age. Table IV-51 shows greater observed seat belt use by drivers of recently made cars campared to newer and/or older models.

Finally, there is a significant observed difference in seat belt use as a function of the presence/absence of children passengers. Surprisingly, fewer drivers are observed wearing seat belts when children are riding in the car 
TABLE IV -48

Percent of Individuals Reporting Seat Belt Usage As A Function of Work, Residential, Or. Day Care Setting

$$
(n=747)
$$

\begin{tabular}{|c|c|c|c|c|c|}
\hline \multirow[b]{2}{*}{ Site } & \multirow[b]{2}{*}{ Always } & \multicolumn{2}{|c|}{ Reported Seat Belt Use } & \multirow[b]{2}{*}{ Never } & \multirow[b]{2}{*}{ Total } \\
\hline & & Most of the time & Sometimes & & \\
\hline Work & 2 & 2 & 8 & 14 & 25 \\
\hline Residential & 14 & 6 & 11 & 30 & 61 \\
\hline Day Care & 1 & 1 & 3 & 9 & 14 \\
\hline Total & 17 & 8 & 21 & 53 & 100 \\
\hline
\end{tabular}


TABLE IV -49

Percent of Observed Seat Belt Usage As A Function of Hork, Residential, Or Day Care Setting

$(n=751)$

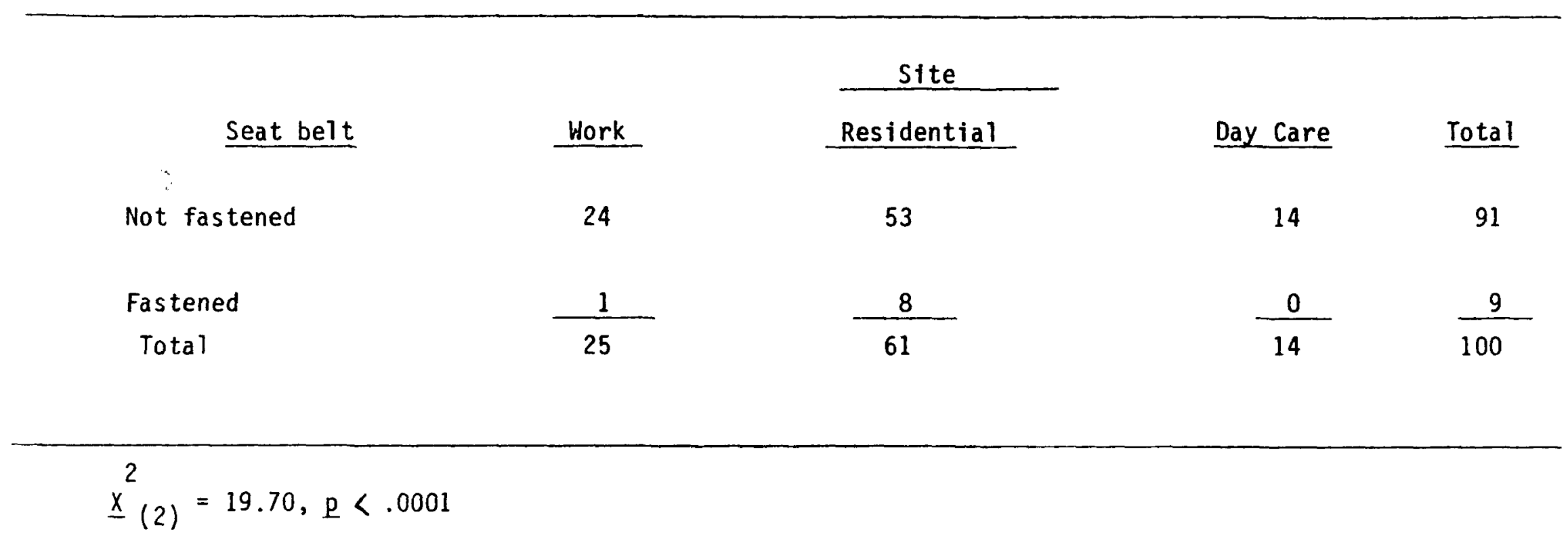


TABLE IV-50

Percent of Observed Seat Belt Usage As A Function

of Race

$(n=751)$

\begin{tabular}{|c|c|c|c|}
\hline \multirow[b]{2}{*}{ Seat belt } & \multicolumn{2}{|c|}{ Race } & \multirow[b]{2}{*}{ Total } \\
\hline & White & Nonwhite & \\
\hline Not fastened & 67 & 24 & 91 \\
\hline $\begin{array}{c}\text { Fastened } \\
\text { Total }\end{array}$ & $\frac{9}{76}$ & $\frac{0}{24}$ & $\frac{9}{100}$ \\
\hline
\end{tabular}


TABLE IV-5I

Percent of Observed Seat Belt Usage As A Function

of The Car's Age

$(n=750)$

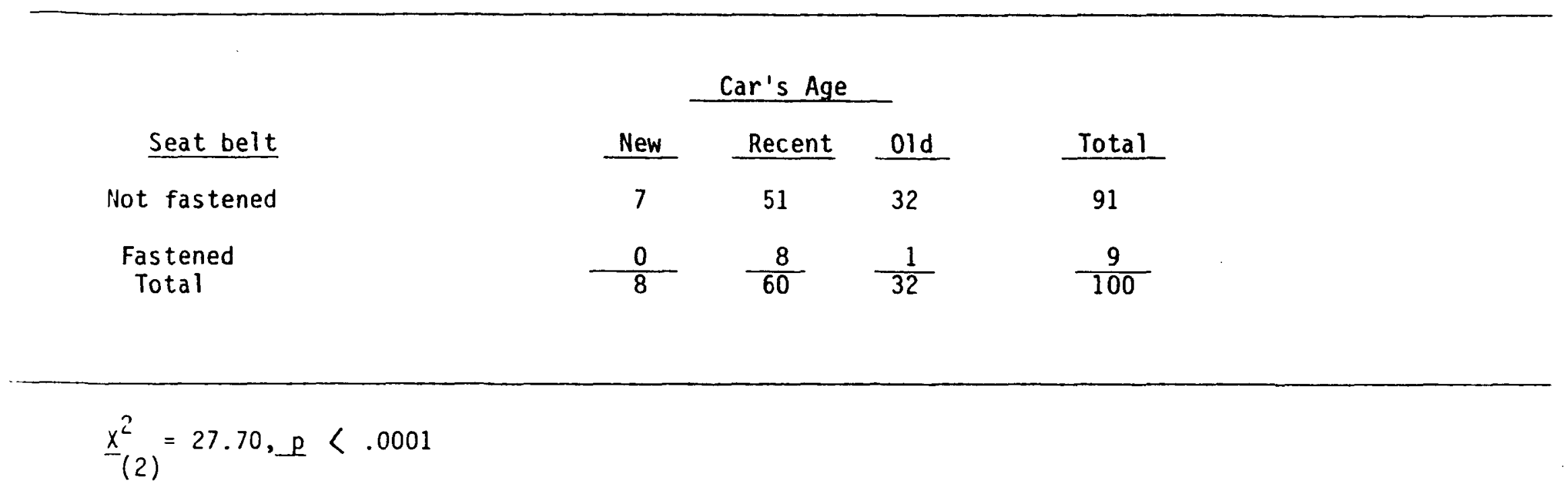


versus when there are no children present (See Table IV-52). Given the findings obtained in the face-to-face and telephone surveys, one might expect the opposite results regarding seat belt use and the presence/absence of children. Although respondents in the face-to-face survey do not perceive the situation of having children in the car as particularly dangerous (see Table IV-41), they report that seat belt use is very 71 kely to increase when children are present (See Table IV-40). In addition, $43 \%$ of those who request others to buckle up mention that they always make kids wear seat beits. In the telephone survey, $21 \%$ of the drivers who have asked passengers to fasten seat belts remark that they always make kids buckle up. And, Table IV-13 reveals that the presence of children in the car is one of the top three situations which produces an increase in seat belt use. The discrepancy between observed seat belt use and self-report use may be accounted for by the degree of social sensitivity of the issue. It is socially desirable to say that you force children to wear seat belts and that seat belt usage increases when chil dren are in the car. In reality, however, it may become more inconvenient to buckle up when children are present and the use of seat belts declines.

The results obtained fran the observational portion of the study shed further light on the issue of seat belt use. The data are useful in demonstrating that usage rates vary as a function of the type of setting being driven to or from and that actual observed instances of fastened seat belts are lower than instances of self-report seat belt use. 
TABLE IV-52

Percent of Observed Seat Belt Usage As A Function of The Presence/ Absence of Child Passengers

$(n=751)$

\section{Seat Belt}

Not fastened

Fastened

Total

\begin{tabular}{c} 
Present \\
\hline 14 \\
$\frac{0}{15}$
\end{tabular}

Child Passenger

Absent

76

9
Total

91

9 


\section{SUMMARY AND CONCLUSIONS}

The principal objective of this project was to study the demographic, situational, and motivational factors associated with seat belt usage. Following an extensive literature review and the development of a conceptual framework, specific research questions were formulated for emp irical investigation. To answer those questions, two surveys were designed for field administration.

The first survey was a telephone survey of 1,020 individuals randomiy selected and interviewed throughout the United States, plus oversamples of 109 individuals in a relatively high seat belt use area (Seattle) and 99 individuals in a relatively low seat belt use area (Dallas/Fort Worth). The second survey focused on 197 individuals interviewed face-to-face following observations of actual seat belt usage in a regional Maryland area. This chapter presents the summary findings of these surveys and draws certain overall conclusions regarding the results.

\section{Seat Belt Usage}

The major findings relative to basic seat belt usage are highlighted below.

- Seat belts are most often used on long trips and in poor weather rather than on short trips.

- Individuals use their seat belts slightly more often when they are drivers as opposed to when they are passengers.

- Approximately $21 \%$ of individuals have increased their seat belt usage.

- Across long trips, short trips, and trips in poor weather, $29 \%$ of people can be classified as frequent users, $30 \%$ as sometimes users, and $41 \%$ as infrequent users.

Although seat belt usage tends to be relatively high under certain driving conditions, the overall usage rate is inordinately low. This finding is consistent with those of other studies of restraint usage. The predominant majority are infrequent or at best sometimes users.

The basic findings on seat belt usage suggest some strategies. for certain promotional campaigns. Encouraging is the fact that a noticeable number of individuals indeed have increased their seat belt usage in the past. It would appear that a greater increase in usage would result if people could be informed that it is just as important to wear seat belts during short trips around town as it is on long trips or when the weather is bad. Also, people should be informed that the chance of injury or death is just as great when not wearing seat belts as a passenger as opposed to a driver. While seemingly obvious, these facts nevertheless should be pointed out in messages designed to increase the use of restraint systems. 
Of the several demographic variables studied, only two were found to have a significant association with seat belt use.

0 Frequent users tend to be older (especially 65+). Younger individuals (especially 15-24) tend to be infrequent users.

o Frequent seat belt users tend to be more educated.

Age and education were the only demographic factors found predictive of restraint usage. This finding has some implications for the design of promotional strategies. It could be pointed out to the younger age groups, for instance, that wearing seat belts is a mature thing to do under the theme that growing older is growing wiser. This approach would appeal to those who wish to emulate respected elders. Also, middle age and older individuals could be appealed to by suggesting that seat belt use is a sign of maturity and precaution as one grows older. In any case, promotional campaigns should be cognizant of the fact that different age groups have a differential tendency to heed and act upon admonitions to increase seat belt usage.

\section{Situational Factors}

The following are the major findings relative to situational factors related to seat belt usage.

- The greatest increase in seat belt usage by sometimes users occurs when the weather is poor.

- There is a slight decrease in seat belt usage by sometimes users when they drive alone.

- Frequent users tend to drive more on divided highways than on rural roads or city streets.

- Individuals who drive imported cars are more likely to be frequent users than individuals who drive domestic cars.

- Individuals who have a separated lap and shoulder belt are more often infrequent seat belt users than those who have a combined lap and shoulder belt.

- Half of the people have asked others to buckle up, most of whom have done so. Infrequent users are the least likely to ask others to buckle up.

Promotional campaigns to increase seat belt usage might benefit from some of the above findings. First of all, promoting the use of seat belts under adverse weather conditions and other hazardous driving conditions could sensitize people to the importance of wearing belts. Hopefully, this behavior would then carry over to other situations not quite as adverse and the habit of wearing belts would be encouraged. Similarly, encouraging people to use helt: when driving on divided highways might carry over to other $k$ inds of 
driving. In this regard, it would be important to point out the potential consequences of not wearing belts on city streets as well as on the highway. As far as driving alone is concerned, increased usage might come about if it were emphasized that the consequences of death and injury to the driver are as costly to beloved ones and friends regardless of whether or not they are riding with passengers.

The fact that most individuals buckle up when asked to do so by at least half the respondents studied offers promise for designing influential

strategies. Individuals should be encouraged to ask others to fasten the ir seat belts under the expectation that they will do so without much hesitation and that it will not be an imposition or embarrassment. Although infrequent users may be less likely to ask others to buckle up, they themselves buckle up if asked to do so. The experience of wearing belts might also influence them to buckle up when not asked in various situations, particularly when others are in the car.

\section{Motivational Factors}

The principal findings regarding motivational factors associated with seat belt usage are outlined below.

- Frequent users show less concern about being trapped in the ir car during an accident and less concern about driving with others in the car.

- Frequent users rate their seat belt systems as more comfortable and convenient than sometimes or infrequent users.

- The most predominant opinion on how to get others to use the ir seat belts is to make some general comment regarding safety, followed by show accident pictures and tell statistics.

- The most influential sources of persuasion to wear seat belts are driver education instructors, the police, and family members or friends.

- Television is by far the most often cited media source that people would pay attention to regarding autombile safety.

o The driving condition ranked most dangerous is driving after having taken drugs or prescribed medication, followed by driving after having a few drinks and driving in poor weather.

- Individuals who take precautions concerning their personal health (e.g., don't smoke, visit the dentist regularly, engage in a constant exercise pattern) are more likely to be frequent and somet imes users.

- Most people agree with the statement "Wearing seat belts is like other good health practices, such as brushing your teeth and having regular medical checkups." 
Seat belt promotion would appear to benefit from several of the findings regarding motivational factors. For instance, information in promotional messages is needed to dispel the myth that seat belts often trap passengers in a car following an accident. This information needs to be aimed at infrequent and sometimes users, those most concerned about being trapped, and should explain that rarely, if ever, are seat belts the cause of being trapped in an automobile. General safety messages also would help emphasize what seat belts would do as opposed to wouldn't do in the case of an accident. The additional use of pictures to show what can happen if seat belts aren't used and accompanying statistics would strengthen the influence of these messages.

The study shows that the comfort and convenience of seat beits are strongly associated with their use. Thus, it would seem important to emphasize the best comfort and convenience features of restraint systems in an at tempt to encourage increased use. Discomfort and inconventence could be downplayed as applicable only under a few temporary driving conditions (e.g., backing up the car) and insignificant compared to the safety advantages of wearing beits.

Other implications for promotional campaigns relate to the sources of safety messages and the media through which they should be exposed. The results show that the most influential sources of those studied are driver education instructors, police, and family or friends, and that the most effective medium is television. Thus, television spots featuring a general safety message by the above type of individuals would appear to be fairly influential in an overall campaign to increase seat be it usage.

Finally, the study shows that wearing seat belts is considered a good habit not unlike other good health practices, such as exercising, having regular medical checkups, and not smoking. Accordingly, seat belt usage might be increased by appealing to people's desire to maintain good health habits. Regular use can be regarded as a healthy precaution against possible injury or death much as other good health practices.

\section{Imp lications for Future Research}

The study also provides certain methodological implications which can be used to direct future research efforts. One implication is that a telephone survey may be just as effective as a face-to-face survey in eliciting reasons why people use or do not use seat belts and what might motivate them to do so. The open-ended questions in the face-to-face survey failed to delineate precisely the answers which were asked. The major ity of respondents either could not or did not articulate the ir motivations in clear terms. It appears that individuals do not really specify in much detail the ir reasons for seat belt usage. Hence, many responses to open-ended questions were obtained which were quite general in nature and not as much insight was gained from these questions as expected. Therefore, the use of a telephone survey with as many specific response alternatives as possible appears as effective as a face-to-face survey including response probes and open-ended questions regarding seat belt usage.

It aiso might be that the response alternatives to some items in the present surveys could be improved by providing a more adequate array of 
answers. Some of the predefined answers to some questions appeared too stringent and the open-ended response of "other" became the predominant choice. A better array of potential answers might be provided by a closer inspection of some of the open-ended responses.

A more clinical approach to discovering the underlying reasons for seat belt usage or non-usage also might be beneficial. Instead of relying on the answers to specific questions, exploring the psychodynamics of individuals assembled in small discussion groups would appear a means to uncover the reasons underlying their usage behavior. Trained psychologists and transportation specialists could probe more deeply into the reasons for seat belt usage. The groups would not be focus groups whose general opinions would be solicited, but groups compr ised of individuals whose behavior would be probed in depth.

Furthermore, additional research could be conducted using the database from the present study. It may be recalled that stringent probability levels were considered cutoff points. These probability levels could be relaxed somewhat in examining the results. In particular, certain results from the face-to-face survey could be assessed in preparation for a more clinical study of seat belt usage. The results could be used to formulate probes into the reasons underlying seat belt usage behavior. Furthermore, by relaxing the probability level for significant responses, more meaning and direction might result from a variety of items in the survey instruments. Several analyses revealed significant results at lower probability levels and might be considered instructive regarding seat belt use and individual motivations to use them in certain situations. A wealth of information remains undiscovered in the database assembled from the telephone, face-to-face, and observational surveys.

An additional concern relative to interpreting the present results concerns certain items which were rank-ordered by respondents. Just because items were ranked relatively lower than others does not necessarily mean they are unimportant. For instance, the fact that car dealers were regarded less influential than driver education instructors does not mean that car dealers are not an appropriate target group for persuading the public to use seat belts. Similar cautions should be exercised in interpreting other ranked items.

The preceding account of the basic study findings and implications for future research summarize the results of both the telephone and face-to-face surveys. Hopefully, these findings and others detailed in the report chapters will assist in future efforts to promote the use of seat belts and increase traffic safety. 


\section{REFERENCES}

Bales, R. and Couch, A. The value profile: A factor analytic study of value statements. Sociological Inquiry, $1969,39,3-17$.

Barker, R. G. Ecology and motivation, Nebraska symposium on motivation 1960. The University of Nebraska Press, 1960.

Beitel, G. A., Sharp, M. C., and Glauz, W. D. Seatbelt use by nightime drivers. Journal of Safety Research, 1974, 6, 72-77.

Berkowitz, $L$. and Lutterman, $K$. The traditionally soctally responsible personality. Public Opinion Quarterly, 1968, 32, 169-185.

Bigelow, B. Review of programs designed to encourage use of safety belts. by NHTSA, for the special cominttee to Study Method for Increasing, Use of Safety Belts, Transportation Research Board, 1979.

Campbe11, B. J. Seatbelt Use among drivers in accidents and drivers in the population at risk. Chapel Hill, North Carolina: The University of North Carolina Safety Research Center, January, 1969.

Campbe11, B. J., O'Neil1, B. and Tingley, B. Comparative injurles to bel ted and unbelted drivers of sub-compact, compact, intermediate, and standard cars. Paper presented at the intrd International Congress of Automodte Safety, San Francisco, 1974.

$\mathrm{Cl}$ aybrook, J. Presentation at the first National Conference in Child Passenger Protection, NHTSA, December 10-12, 1979.

Counc 11, F. M. Seatbelts: A follow-up study of their use under nonmal driving condittons. Chapel HiT, North Carolina: The University of North CarolTha Highway Safety Research Center, October, 1969.

Dobson, R. H. Seatbelt users: An analysis of who they are and why. Paper presented at the meeting of the Society of Automobrle Engineers, Detroit, 1979.

Fhaner, G., and Hane, M. Seat belts: Factors influencing their use. A iiterature survey. Accident Anaiys is \& Prevention, 1973 $5,27-43$. (a)

Fhaner, G., \& Hane, M. Seat belts: The importance of situational factors. Accident Analysis \& Prevention, 1973, 5, 767-285. (b)

Fhaner, G., \& Hane, M. Seat belts: Relations between beliefs, attitude, and use. Journal of Applied Psychol ogy, 1974, 59, 472-482.

Fhaner, G., \& Hane, M. Seat belts: Contextual factors and bias of reported use. Journal of Safety Research, $1974,6,166-170$ (b). 
Fhaner, G. and Hane, M. Seatbelts: Changing usage by changing beliefs. Journal of Applied Psychology, 1975, 60, 589-598.

Foldvary, L. A. and Lane, J. C. The effectiveness of compulsory wearing of seatbelts in casualty reduction. Accident Analys is and Prevention, 1974, 6, 59-81.

Hanson, R. M. and Rubin, I. J. Letter communication: Carl E. Nash Department of Transportation National Highway Traffic Safety Administration, March 13, 1978.

Helsing, K. J. and Cornstock, G. W. What kinds of people do not use seatbelts? American Journal of Public Health, 1977,67, 1043-1050.

Insurance Institute for Highway Satey (IIHS). Bibliography of avai?able articles, 1980.

Knapper, C. K., Cropley, A. J. and Moore, B. J. Attitudinal factors in the non-use of seatbelts. Accident Analys is and Prevention, 1976, 8, 241-246.

Lane, R. E. Political personality and electoral choice. American Political Science Review, 1955, 69, 173-190.

Lewin, K. Principles of topological psychology. New York: McGraw Hil1, 1936.

Lincorp Research, Inc. Memorandum of IIHS study "Auto industry belt use campaign fails". Southfield, Michigan: Lincorp Research, The., September, 1977.

Market Opinion Research (MOR). An analysis of the factors affecting seatbelt use. Detroit, Michigan: Market Opinion Research, December, 1977.

Marzoni, Jr., P. Motivating factors in the use of restraint systems. (DOT-HS-800585T Philadelphia, PA: National Analysts, Inc., September, 1971.

Miller, M. M. and Stark, H. J. H. Ejection in car accidents. (PB-182.949) Crowthorne, England: Road Research Lab, 1968.

Morris, J. B. Seatbelt performance in 30mph barrier impacts. (PB-269962/7ST) Washington, D.C.: National Highway Traffic Safety Adminis tration Official Véhicie Systems Research, April 1977.

Motorists Information, Inc. (MII). Michigan safety belt project report. Detroit, Michigan: Motorist information, Inc., Apri 1978.

National Highway and Transportation Safety Administration (NHTSA). Child and infant restraints. June, 1979.

National Highway and Transportation Safety Administration (NHTSA). Highway safety literature. $1979 \mathrm{~b}$. 
National Technical Information Service (NTIS). Automobile safety seat beits: A bibliography with abstracts. Published Searen, 1980.

Opinion Research Corporation (OCR). Safety belt usage in three Michigan cities before and after studies to determine the effectiveness of MVWA safety bett miss medra campargn. Princeton, New Jersey: Optnton Research Corporation, Vecember, 1977.

Peter D. Hart Associates, Inc. Public attitudes toward restraint systems: summary report. Peter D. Hart Assoctates, Inc.: Washington, U.C., 1978.

Philpot, Perry, Hughes, Wyrick, Cullen, Lo, Trent, and Geiss. 1978 Annual report Tennessee child passenger safety program. Final Report to National highway Traffic Safety Adintnistration. Apr11, 1979.

Robertson, L. S. The seatbelt use law in Ontario: Effects on actual use, Canadian Journal of Public Health, 1978, 69, 154-157.

Robertson, L. S. Auto industry belt use campalgn falls. Washington, D.C.: Insurance inst teute for Hrghiwy sarety, August, 1977.

Sabey, B. E., Grant, B. E. and Hobbs, C. A. Alleviation of injuries by use of seat belts. (PB-276837/2ST) Crowthorne, England: Transport and Road Research Lab, 1977.

Scherz, R. G. Restraint systems for the prevention of injury to children in automobile accidents. American Journal of Public Health, 1976, 66(5), 451-6.

Smart, N. S., Hartunian, N. S. and Thompson, M.S. The incidence and economic costs of cancer, motor vehicle injuries, coronary heart disease, and stroke: a comparative analysis. American Journal of Public Health December, 1980.

Stoke, C. B. Seatbelt and shoulder strap use among urban travelers: A comparison of survey results from 1974, 1975 and 1976. (VHTRC T/-R35) CharTottesville, Virginta: Virginta Highway and Transportation Research Counc 11, January, 1937.

Sweeter, D. A. Attitudinal and social factors assocfated with use of seatbelts. Journal of Heal th and Soctal Behavior, 1967, 8, 116-124.

Tenekron, incorporated. 1978 survey of public perceptions on highway safety. (DOT HS-6-01424) Washington, O.C.: Tenekron, Incorporated, November, 1978.

Valecha, G. K. and 0strom, T. M. An abbrevlated measure of internal-external locus of control. Journal of Psychological Reports, 1974.

Waller, P. F., and Barry, P. Z. Seatbelts: A Comparison of observed and Reported Use. Chapei Hill, North Carolina: The Universtiy of North Carolina Hrghway Safety Research Center, May, 1969. 
Warwick, D. P., and Lininger, C. A. The sample survey: Theory and practice. New York: McGraw Hi1 1975.

Whitley, S. The U.S. and the U.S.S.R.: A Report of the Public's Perspective on United States-Russian Relations. in Lage 1961 in D. Bobrow (ed.) Components of Defense Policy. Chicago: Rand McNally, 1965, 164-174.

Williams, A. F. and Robertson, L. S. Observed Daytime Seatbelt Use in Vancouver Before and After the British Columbia Belt Use Law. Canadian Journat of Pubtic Heat th, 1979, 70, 320-332. 
ID/PHONE

$[1: 1-10\}$

Hello. I am

from Lawrence Johnson \&

Associates, Inc. a research $19 \mathrm{~m}$ based $1 \mathrm{n}$ Washington, $0 . C$. Our $f 1 \mathrm{rm}$ is conducting a study for the U.S. Department of Transportation. We are surveying the driving habits of American drivers and through a random selection process you were picked to partfcipate.

It is very important that we obtain your views as they are representative of many others across the country. Your voluntary particlpation will be greatly appreciated. It should take only about 20 to 25 minutes to complete the survey. All information you provide w11l be kept confldential and your name or other identifying information will not be assoclated with the responses you give. Your assistance will greatly help state and local transportation planners do their job. Feel free to ask me to stop and explain any questions which you don't understand, and again remember that all your answers will be confidential.

1) Are you currently a licensed driver?

Yes......1

NO......2 (RETURH TO SCREENER)

1)a. In what year did you first recefve your license? 19

$(1: 13-14)$

2) How many cars, vans or trucks are in your household?

$\begin{array}{lll}\text { None....... (GO TO 2a) } & 1 & 35 \% \\ 1 \text { ( or more...* (GO TO 2b) } & 3 & 40 \% \\ & 3 & 17 \% \\ \end{array}$

2)a. Is there any car that you drive at least once a month?

$[1: 16]$

Yes.......1

No.......2 Thank you very much, but we are only interviewing persons who drive a car at least once a month. 
2)b. Is the car you drive most often personally owned or owned by a company for business purposes?

$[1: 17]$

$$
\begin{aligned}
95 \% & \text { Personally owned....... } \\
5 \% & \text { Business owned........ }
\end{aligned}
$$

2)c. What make, year, ano model is it? CHRYSLER $11 \%$

$[1: 18] \quad 1 / 1$, EUROPEAN $6 \%$

What percentage of your driving is for: (READ RESPONSES)

3)a. About how many miles do you estimate you travel during an average work day in: (READ RESPONSES IF NOT 0\% in Question 3)

$$
\begin{aligned}
& \text { Commuting to and from work } \\
& \text { Other work-related travel } \\
& \text { Personal travel }
\end{aligned}
$$

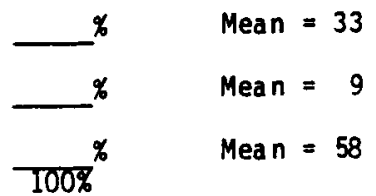

D

3)b.

Cormuting to and from work

Other work-related travel

Personal travel

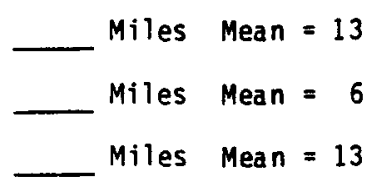

About what percentage of your total weekly travel time is on: (READ RESPONSES)

Divided highways
Two-lane rural highways
City streets

$\begin{aligned} \text { \% } & \text { Mean }=28 \\ \% & \text { Mean }=31 \\ \% & \text { Mean }=41\end{aligned}$

D

4) Did you receive your initial driver training in school or from a commercial driver education instructor?

$[1: 47]$

$[1: 48-49]$ 
5) How often do you wear seat belts when driving on roads which 11:50\} are wet, or snow and ice covered? (READ RESPONSES)

\begin{tabular}{|c|c|}
\hline $24 \%$ & Always........... \\
\hline $13 \%$ & Most of the time...2 \\
\hline $23 \%$ & Somet imes........3 \\
\hline $40 \%$ & Never...........4 \\
\hline
\end{tabular}

5) a. How often do you wear seat belts when driving on long trips? (READ RESPONSES)

$[1: 51]$

\begin{tabular}{|c|c|}
\hline $27 \%$ & Always............ \\
\hline $15 \%$ & Most of the time..2 \\
\hline $19 \%$ & Somet imes........3 \\
\hline $37 \%$ & Never...... \\
\hline
\end{tabular}

5)b. How often do you wear seat belts when driving on short trips around town? (READ RESPONSES)

$[1: 52]$

\begin{tabular}{|c|c|}
\hline $16 \%$ & Always...........1 \\
\hline $7 \%$ & Most of the time..2 \\
\hline $17 \%$ & Somet ines........3 \\
\hline $61 \%$ & Never.......... \\
\hline
\end{tabular}

6) Does the front seat of your (YEAR) of safety belt available for use?

$[1: 53]$

$97 \%$

Yes...............1

$3 \% \quad$ No..............2 (GO TO 9 )

6)a. Is it just a seat belt or does it have a shoulder strap also?

$16 \%$ Seat belt only....1

$82 \% \quad$ Seat belt and shoulder strap....2

6)b. Can you put on just one and not the other?

$[1: 55]$

Yes, separated

seat belt and

$35 \%$ shoulder strap....1

$61 \%$

No, combined seat belt and shoulder strap....2 
6)c. Has anyone told you or demonstrated how to put on the beit?

$\begin{array}{lll}{[1: 56 ;} & 33 \% & \text { Yes,............. Who? } \frac{16 \% \text { Car Salesperson }}{16 \% \text { Relative }} \\ {[1: 57]} & 67 \% & \text { No............ }\end{array}$

6)d. Do you think this safety belt system is in good working condition?

95\% Yes............

$3 \%$

.2 (SPECIFY REASON:

Don't know.....8 (SPECIFY WHY:

6)e. Do you have any trouble putting on or adjusting the belt?

$[1: 60]$

$[1: 61]$

$6 \%$

Yes............ Why?

$93 \%$

No..............2

6)f. Please tell me whether you agree or disagree with the following sentence. "I don't think seat belts work properly when they fee 1 loose around me after I fasten them."

$[1: 62]$

$43 \%$
$52 \% \quad$ Disagree................ (G0 TO 7 )

6)g. Have you always felt this way?

$92 \%$
$6 \%$
No............... Why?

7) On a scale of 1 to 3, with 1 being "uncomfortable" and 3 being "comfortable". how would you rate the seat belt system in your car?

$[1: 65]$ Uncomf ortable

Comfortable

$$
\begin{array}{lll}
1 & 2 & 3 \\
15 \% & 33 \% & 47 \%
\end{array}
$$

8) On a scale of 1 to 3 , with 1 being "inconvenient" and 3 being "convenient", how convenient is it for you to put on the seat belt in the car?

$$
\text { Inconvenient Convenient }
$$

$\begin{array}{ccc}1 & 2 & 3 \\ 21 \% & 26 \% & 50 \%\end{array}$


9) Many people say that seat belts can be inconvenient or uncomf ortable to use. Which of the following do you feel is the main reason they say this? (READ RESPONSES)

$[1: 67]$

\begin{tabular}{|c|c|}
\hline $8 \%$ & $\begin{array}{l}\text { They are hard to } \\
\text { adjust................ }\end{array}$ \\
\hline $12 \%$ & $\begin{array}{l}\text { They bother you when } \\
\text { getting in and out of } \\
\text { tight parking places....2 }\end{array}$ \\
\hline $23 \%$ & $\begin{array}{l}\text { They bother you when } \\
\text { backing up and going } \\
\text { in reverse.............. }\end{array}$ \\
\hline $14 \%$ & They are too tight.....4 \\
\hline $39 \%$ & Other............ \\
\hline
\end{tabular}

10) In the last five years, how many accidents have you or your family and friends been in either as a driver or a passenger where someone was injured and required some medical attention?

$[1: 68-69]$

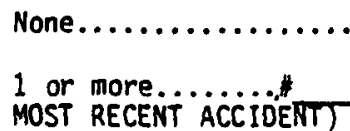

(GO TO 11)

(READ 10a THROUGH 10F FOR MOST RECENT ACCIDENT)

10)a. Were you in the (most recent) accident?

$$
48 \%
$$

Yes.............

$52 \%$

No. .2 (GO TO 10-d)

10)b. Were you the driver in the accident?

$\begin{array}{rr}65 \% & \text { Yes............ } \\ 35 \% & \text { No............ }\end{array}$

10)c. Was anyone seriously hurt in the acfident?

\begin{tabular}{|c|c|c|c|}
\hline$[1: 72]$ & $41 \%$ & Yes.............1 Who? & $29 \%$ Other Person \\
\hline$[1: 73]$ & $59 \%$ & No............2 & $\begin{array}{l}18 \% \text { More Than One Person } \\
12 \% \text { Friend }\end{array}$ \\
\hline
\end{tabular}

10)d. Did you wear your seat belt more or less often right after the accident?

\begin{tabular}{|c|c|c|}
\hline \multirow{5}{*}[1:74]{} & $19 \%$ & More often.......1 \\
\hline & $6 \%$ & Less often.......2 \\
\hline & $42 \%$ & As often........3 (GO TO (10-f) \\
\hline & $5 \%$ & $\begin{array}{l}\text { Always wore it } \\
\text { before.........4 }\end{array}$ \\
\hline & $27 \%$ & $\begin{array}{l}\text { Never wore it } \\
\text { before..........5 }\end{array}$ \\
\hline
\end{tabular}

[End Card One]

$[2: 1-10] \quad 10$

$[2: 11] \quad 2$ 
10)e. What was it about the accident that made you wear your seat belt (more) (less) of ten than before?

$[2: 12-13]$ $30 \%$ Person Hurt/Killed Due to not Wearing

26\% Other Reason

13\% Belt Prevents Being Thrown

10)f. Do you wear your seat belt as often now as you did immediately following this accident?

$\begin{aligned} 6 \% & \text { Always have worn it } \ldots \ldots \ldots 1 \\ 25 \% & \text { Never have worn it } \ldots \ldots \ldots 2 \\ 51 \% & \text { As of ten } \ldots \ldots \ldots \ldots \ldots \ldots . \\ 5 \% & \text { More often } \ldots \ldots \ldots \ldots \ldots .4 \quad \text { Why? } \\ 13 \% & \text { Less often............. Why? Lazy, too Much Trouble }\end{aligned}$

11) People have many different concerns with regard to their safety while driving. For the following types of concerns, please rate your level of concern between 1 and 3 , if 1 is "little concern" and 3 is "much concern":

$\begin{array}{ll}\text { Litt le } & \text { Much } \\ \text { Concern } & \text { Concern }\end{array}$

a. The chance of beins injured in

Mean Rank an automobile accicent

b. Your car's handling ability

$\begin{array}{l:llll}1 & 2 & 3 & =2.53 & \frac{\text { Mean }}{2} \\ 1 & 2 & 3 & =2.14 & 6 \\ 1 & 2 & 3 & =2.40 & 3 \\ 1 & 2 & 3 & =2.36 & 4 \\ 1 & 2 & 3 & =2.71 & 1 \\ 1 & 2 & 3 & =2.24 & 5\end{array}$

c. Being trapped in your car following an accident

d. Your driving ability in poor weather like rain, snow, or fog 
12) In general, when you are a passenger in someone's else's car, how much of the time do you use seat belts? (READ RESPONSES)

$[2: 22]$

\begin{tabular}{|c|c|}
\hline $12 \%$ & Always............. \\
\hline $15 \%$ & Most of the time....2 \\
\hline $31 \%$ & Sometimes..........3 \\
\hline $41 \%$ & Never. \\
\hline
\end{tabular}

12)a. How much of the time do you use them when you are driving? (REAO RESPONSES)

\begin{tabular}{|c|c|}
\hline $19 \%$ & Always.............. (Go ro 14) \\
\hline $14 \%$ & Most of the time...2 \\
\hline $28 \%$ & Somet imes..........3 \\
\hline $39 \%$ & Never...........4 \\
\hline
\end{tabular}

13) On a scale from 1 to 3 , with 1 being "decreases, " 2 being "stays about the same as usual," and 3 being "increases," please tell me if your use of seat belts changes when you are driving in the following situations.

\begin{tabular}{|c|c|c|c|c|c|c|c|}
\hline & & & Decreases & $\begin{array}{l}\text { Stays the } \\
\text { Same }\end{array}$ & Increas & $\begin{array}{l}\text { Ises } \\
\text { Mean }\end{array}$ & Rank \\
\hline$[2: 24]$ & a. & During weekends & 1 & 2 & 3 & $=2.17$ & 8 \\
\hline$[2: 25]$ & b. & On a holiday & 1 & 2 & 3 & $=2.49$ & 4 \\
\hline$[2: 26]$ & c. & During rush hours & 1 & 2 & 3 & $=2.33$ & 7 \\
\hline$[2: 27]$ & d. & $\begin{array}{l}\text { On a trip where you } \\
\text { make more than } \\
\text { one stop a long the way }\end{array}$ & 1 & 2 & 3 & $=2.05$ & 9 \\
\hline$[2: 28]$ & e. & $\begin{array}{l}\text { When in a car } \\
\text { smaller than the } \\
\text { one you typically } \\
\text { drive }\end{array}$ & 1 & 2 & 3 & $=2.36$ & 6 \\
\hline$[2: 29]$ & f. & When driving alone & 1 & 2 & 3 & $=1.93$ & 10 \\
\hline$[2: 30]$ & g. & $\begin{array}{l}\text { When you are driving } \\
\text { with children in the } \\
\text { car }\end{array}$ & 1 & $?$ & 3 & 251 & $?$ \\
\hline$[2: 31]$ & n. & $\begin{array}{l}\text { When the weather } \\
\text { is poor like rain, } \\
\text { snow, or fog }\end{array}$ & 1 & 2 & 3 & $=2.68$ & 1 \\
\hline$[2: 32]$ & i. & $\begin{array}{l}\text { After taking drugs or } \\
\text { prescribed medication }\end{array}$ & 1 & 2 & 3 & $=2.39$ & 5 \\
\hline$[2: 33]$ & j. & $\begin{array}{l}\text { After you have been } \\
\text { in or nearly in an } \\
\text { accident }\end{array}$ & 1 & 2 & 3 & $=2.64$ & 2 \\
\hline
\end{tabular}


14) Is your use of seat belts today the same as it's always been?
$[2: 34] \quad 66 \%$
Yes................. (GO TO 15)
$11 \%$ No, less..........2
$21 \%$ No, more...........3 (GO TO 14c)

14)a. Can you think back to a perfod when you used seat belts most of the time?
[2:35] $87 \%$ Yes.............. What got you started? 53\% Other Reason
$[2: 36] \quad 13$
No................ Why didn't you?
(GO TO 13)

14 )b. Has your use of seat belts changed since that $t$ ime? (PROBE FOR MORE OR LESS OFTEN)

$[2: 37] \quad 8 \% \quad$ Yes, more often..........

$91 \%$ Yes, use less often......2

14c) Could you explain the reason for this? (PROBE FOR WHY AND WHEN, ESPECIALLY IF RELATED TO COMFORT/CONVENIENCE)

$[2: 38-39]$

$40 \%$ Got Lazy

$36 \%$ Other Reason

15) Before you started to drive, did your parents or guardian or any adult you rode with consistently tell' you to wear seat belts when in the ir car?

$[2: 40]$

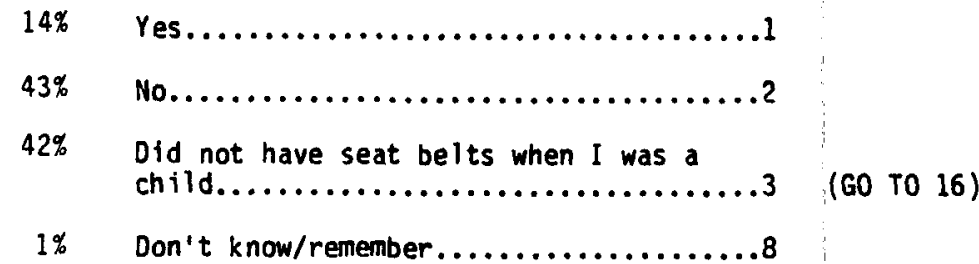

15)a. Did they wear seat belts themselves most of the time?

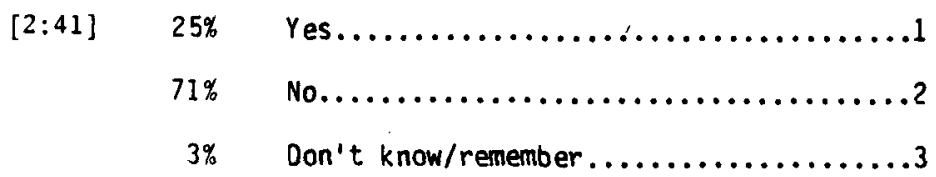


16) In general, does your employer or business require that you wear seat belts when driving a company car or on business travel in your own car?

$[2: 42]$

$\begin{aligned} 11 \% & \text { Yes............. } \\ 48 \% & \text { No............. } \\ 3 \% & \text { Don't know......8 } \\ 39 \% & \text { Not applicable....9 }\end{aligned}$

17) There are occasions when it is difficult to put on a seat belt, like when it gets tangled or stuck behind the seat. When those occasions happen in your car, do you: (READ RESPONSES)

\begin{tabular}{|c|c|}
\hline $24 \%$ & $\begin{array}{l}\text { Work at it until } \\
\text { you resolve the } \\
\text { problem........... }\end{array}$ \\
\hline $6 \%$ & $\begin{array}{l}\text { Try hard but stop } \\
\text { if it takes too } \\
\text { much effort.......2 }\end{array}$ \\
\hline $9 \%$ & $\begin{array}{l}\text { Leave it alone } \\
\text { if it does not } \\
\text { respond } \\
\text { immed lately.......3 }\end{array}$ \\
\hline $28 \%$ & $\begin{array}{l}\text { Doesn't happen } \\
\text { in my car....... } \\
\text { Never use the }\end{array}$ \\
\hline & seat beits..... \\
\hline
\end{tabular}

18) When you have driven other people in your car, have you ever asked them to buckle up their seat beits?

50\% $49 \%$ Yes....................... (GO TO 18-4)

18)a. Were you wearing seat belts when you asked them to do so?

$84 \% \quad$ Yes.............

18)b. Could you describe the situations in wich you asked them to put on the ir seat

belts? 39\% Always Ask

21\% ATways Make Kids Wear Then

$[2: 46-47]$ $16 \%$ Bad Weather 
18)c. Did they do so?

\begin{tabular}{|c|c|c|}
\hline$[2: 48]$ & $94 \%$ & Yes.............. \\
\hline & $5 \%$ & No........... (GO TO 18-e) \\
\hline
\end{tabular}

18)d, Do you think they did so mostly: (READ RESPONSES)

$$
\begin{aligned}
& 44 \% \quad \text { Out of courtesy?...1 } \\
& 28 \% \text { Because it was } \\
& \text { the right thing } \\
& \text { to do? ............. } \\
& \text { 7\% Make Children Wear Them. } 3 \\
& \text { 19\% 0ther............ (SPECIFY: }
\end{aligned}
$$

18) e. Do you feel that on occasions when you have other people in the car that if you buckled up that the other people would buckle up too without you having to ask them?

$64 \% \quad$ Yes............

19) Have you ever been in a car without your seat belt fastened and beeh asked to put it on?
$40 \%$
Yes..............
$60 \%$
No..............2 (GO TO 20)

19) a. Was the person who asked you a driver or a passenger?

$\begin{aligned} 86 \% & \text { Driver.......... } \\ 9 \% & \text { Passenger........ } \\ 5 \% & \text { Both............ }\end{aligned}$

19)b. What was your relationship with the person(s) who asked? (READ RESPONSES - CIRCLE ALL THAT APPLY)

\begin{tabular}{lll} 
& \multicolumn{2}{l}{ Yes } \\
\cline { 2 - 3 } Spouse & 1 & $17 \%$ \\
Parent & 1 & $15 \%$ \\
Friend & 1 & $64 \%$ \\
Relative & 1 & $36 \%$ \\
Workmate & 1 & $17 \%$ \\
Other & 1 & $7 \%$
\end{tabular}

\begin{tabular}{cc:c} 
No & & Rank \\
\hline 2 & $82 \%$ & 3 \\
2 & $85 \%$ & 5 \\
2 & $36 \%$ & 1 \\
2 & $64 \%$ & 2 \\
2 & $\begin{array}{l}83 \% \\
92 \%\end{array}$ & 4 \\
2 (SPECIFY & 6
\end{tabular}


19)c. Did you put on your seat belt when asked?

[2:59] 94\% Yes................

$5 \%$

No...................

20) There are some individuals whose advice would have an influence in getting people to wear their seat belts. On a scale of 1 to 3. with l being "not influential" and 3 being "influential," please rate the influence each of the following types of individuals have had or would have regarding your own use of seat belts?

$[2: 60\}$ a. The police

b. A federal government official

c. A state or local government official

d. An automobile insurance agent

e. A priest, minister, or rabbi

f. A car dealer

g. An auto mechanic or serviceman

n. Family or friends

i. A driver education instructor j. A professional race car
driver

k. A nationally known sports figure or personality

$$
\begin{gathered}
\text { Not } \\
\text { Influentfal }
\end{gathered}
$$

1

$$
1
$$

1

1

2

$\begin{array}{ll}R & R \\ \text { Influential } & \text { M } \\ \text { Mean } & N \\ \frac{K}{2.34} & \frac{K}{2}\end{array}$

2

$3=\frac{\operatorname{mean}}{2.34} \frac{K}{2}$

2

$3 \cdot 2.126$

1

1

1

1

1

1

2

1

5

[End Card Two]

$[3: 1-10] 10$

[3:11] 3 
21) How many children four years of age or under are there in your household?

$[3: 12]$

$\begin{array}{ll:r}\text { Children...................... (G0 T0 22) } & 0 & 81 \% \\ \text { None........ } & 14 \% \\ & 2 & 5 \%\end{array}$

21) a. Do you have child car seats? $70 \%$

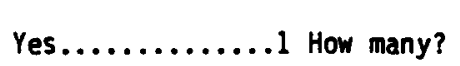

$30 \%$

No................ (GO TO 22)

21)b. How often do you use a safety seat when a child is in the car?

$$
\begin{aligned}
& \text { 80\% Always........... (G0 TO 21-e) } \\
& 17 \% \text { Sometimes........2 } \\
& \text { 4\% Never............3 (G0 TO 21-e) } \\
& \text { Mean }=1.23
\end{aligned}
$$

21)c. Under what circumstances do you not use a safety seat? (PROBE) 56\% Short Trips Locally

$[3: 16-17]$

21)d. Why?

$[3: 18-19]$

\begin{tabular}{|c|c|}
\hline $69 \%$ & Purchased.........1 \\
\hline $8 \%$ & A gift...........2 (GO TO $21-g)$ \\
\hline & Loaned/rented.....3 (60 T0 21- \\
\hline
\end{tabular}

21)e. How was (were) the restraint(s) obtained? (Was it/were they): (READ RESPONSES)

$[3: 20]$

21)f. What determined which one(s) you purchased? $80 \%$ Other Reason

$[3: 21-22]$ 
21)g. Were you given written instructions or a demonstration on how to use the safety seats?

$[3: 23]$

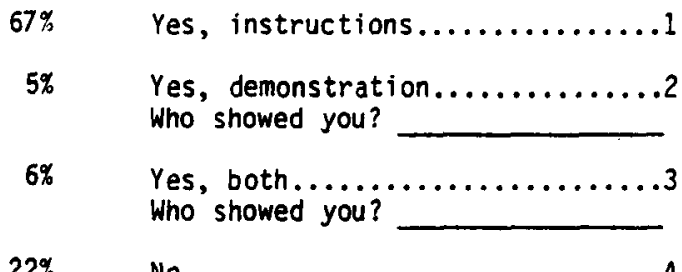

22) To which one of the following sources would you be most likely to pay attention regarding automobile safety messages?

\begin{tabular}{|c|c|c|}
\hline & $\mathrm{N}$ & Rank \\
\hline Radio.................. & 185 & 2 \\
\hline Newspaper $\ldots \ldots \ldots \ldots \ldots 2$ & 124 & 3 \\
\hline Television............ & 536 & 1 \\
\hline Pamph let............ & 43 & 6 \\
\hline Magazine............. & 62 & 4 \\
\hline Poster..............6 & 54 & 5 \\
\hline
\end{tabular}

23) Where do you most of ten go to have your car serviced or repaired? (READ RESPONSES)

$[3: 30]$

$\begin{aligned} 29 \% & \text { Dealer........... } \\ 7 \% & \begin{array}{l}\text { Department store } \\ \text { auto center } \\ \text { or other comercial } \\ \text { service center....2 }\end{array} \\ 17 \% & \text { Gas station......3 } \\ 34 \% & \begin{array}{l}\text { Independent } \\ \text { service garage....4 }\end{array} \\ 11 \% & \text { Self/Friend/Relative }\end{aligned}$

24) It is common knowledge that certain people have done things to their seat belt systems so they would not have to use them. Have you ever disconnected a safety belt system in any way so it would be easier not to use?

$\begin{array}{lll}{[3: 31]} & 12 \% & \text { Yes............. Why? } 71 \% \text { Buzzer Annoying } \\ {[3: 32]} & 88 \% & \text { No............ }\end{array}$


25) Regardless of your personal opinion regarding seat belts, if you were given the job of getting people to use them more often, how would you convince them?

$[3: 33-34]$ 36\% General Comment Re. So fety

$20 \%$ Show Accident Plctures

15\% Tell Statistics

(GO TO 26 IF ANSWER IS "couldn't do anything")

25)a. Why do you think this would

work? 33\% Other Reason

$31 \%$ oon't know

$[3: 35-36] \longrightarrow$ 13\% Restated 25

26) Finally, I'd like to ask you a few general questions which we will use to find out the types of people we are surveying in this study and a little bit about the ir backgrounds. Please tell me the range in wich your age falls. (READ RESPONSES)

$[3: 37]$

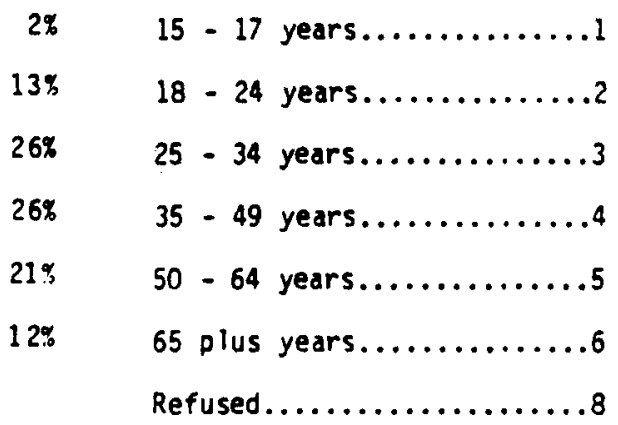

27) Considering all household members, please estimate in which range the total household income falls. Is it: (READ RESPONSES)

$[3: 38] \quad 3 \% \quad$ Less than $5,000 \ldots 1$

22\% Between 5,000

$22 \%$ and $14,999 \ldots \ldots .2$

Between 15,000

$28 \%$ and $24,999 \ldots \ldots \ldots 3$

Between 25,000

21\% and $34,999 \ldots \ldots .4$

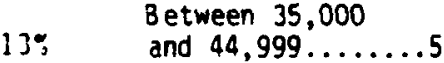

$7 \% \quad 50,000$ and over...6

5\% Refused.........8 
28) What was the last grade of school you completed? (REAO RESPONSES)

[3:39] $\quad \begin{aligned} 5 \% & \text { Grade 1-8....... } \\ 12 \% & \begin{array}{l}\text { Some hijh school..2 } \\ \text { Graduated from } \\ \text { high school.....3 } \\ \text { Vocational or } \\ \text { technical school..4 }\end{array} \\ 7 \% & \begin{array}{l}\text { Some college.....5 } \\ 21 \%\end{array} \\ 15 \% & \begin{array}{l}\text { Graduated } \\ \text { college.........6 } \\ \text { Post graduate } \\ \text { work............. }\end{array}\end{aligned}$

29) About how tall are you?

$[3: 40]$

$\{3: 41-42]$

Feet

Inches

Mean $=67.22$ inches

30) If you smoke, about how many cigarettes do you smoke a day?

$\begin{array}{ll}45 \% & \begin{array}{l}\text { Don't smoke } \\ \text { cigarettes......... }\end{array} \\ 7 \% & \begin{array}{l}\text { Less than } \\ 1 / 2 \text { pack......... (GO TO } 31)\end{array} \\ & \begin{array}{l}1 / 2 \text { to less than } \\ 7 \%\end{array} \\ 18 \% & 1 \text { pack........... (GO TO } 31) \\ 18 \text { pack or more....3 (GO TO } 31)\end{array}$

30)a. Did you ever smoke cigarettes?

$[3: 44]$

$41 \% \quad$ Yes..............

$58 \%$ No.............2 (60 TO 31)

30)b. What made you $53 \%$ not healthy stop? $42 \%$ other

$[3: 45-46]$ 
31) How often do you visit the dentist to have your teeth cherked?

$[3: 47]$

$\begin{array}{ll}42 \% & \text { Every } 6 \text { months....1 } \\ 28 \% & \begin{array}{l}\text { Every year....... } \\ \text { Every } 2 \text { years } \\ \text { or more......... }\end{array} \\ 9 \% & \begin{array}{l}\text { On ly when something } \\ \text { bothers me....... }\end{array} \\ 10 \% & \text { Dentures }\end{array}$

32) Do you jog, cycle, swim, or engage in any constant exercise pattern?

$57 \% \quad$ Yes..............

$43 \% \quad$ No.............. (60 TO 33 )

32) a. How often during the week do you do so? \# Times Mean $=4.0$ [3:49]

33) Do you agree or disagree that wearing seat belts is like other good health practices, such as brushing your teeth and having regular medical checkups?

$\begin{array}{ll}80 \% & \text { Agree........... } \\ 18 \% & \text { Disagree........ }\end{array}$

34) About how often do you gamble during the year? \#TIMES_Mean = 3.9 (EXAMPLE, IF NEEDED: Lotteries, horse races, office pooTs, casinos, bingo, etc.)

$[3: 51-52]$

35) Finally, how would you describe the area in which you live? It is:

$[3: 53]$

$\begin{array}{ll}28 \% & \text { Urban (city) } \ldots \ldots 1 \\ 38 \% & \begin{array}{l}\text { Suburban } \\ \text { (suburbs) } \ldots \ldots \ldots .\end{array} \\ 33 \% & \text { Rural (country) } \ldots .3\end{array}$

TERMINATE INTERVIEW

\begin{tabular}{|c|c|c|c|c|}
\hline 36) & (NOTE SEX) & & FINISH TIME & AM \\
\hline$\{3: 54\}$ & Male..................... & $51 \%$ & INTERVIEW LENGTH & Mins \\
\hline$[3: 55-56]$ & Female................. & $49 \%$ & & \\
\hline
\end{tabular}

INTERV IEWER SIGNATURE

[End Card Three]

0001000.513 
OMB No. 2127-0500

Expires 3/31/83

A STUDY OF DEMOGRAPHIC, SITUATIONAL

AND MOTIVATIONAL FACTORS AFFECTING RESTRAINT USAGE IN AUTOMOB ILES.

Interview Questionnaire

\section{Conducted For}

The U.S. Department of Transportation National Highway Traffic Safety Administration Office of Oriver and Pedestrian Safety Research

Contract \# OTNH 22-80-C-17278 
$[1: 7] 1$ Make of Vehicle Year

[1:8]

[1:9-10] Size Style (MODEL)

[1:11] Interviewer Time Began $A M$

Hello. I am from Lawrence Johnson Associates, Inc., a research firm based in Washington D.C. Our firm is conducting a survey for the U.S. Department of Transportation. The purpose of this survey is to learn more about driving and driving habits. As a part of this survey, an appointment was made to talk to (NAME OF RESPONDENT). Are yOu (NAME OF RESPONDENT)?

$$
\begin{aligned}
& \text { Yes............. (CONTINUE WITH INTRODUCTION) } \\
& \text { No.............. is he/she here now and could } \\
& \text { he/she talk with me? } \\
& \text { Yes............. (REPEAT INTRODUCTION) } \\
& \text { No.............2 When could I come back } \\
& \text { and talk to him/her? }
\end{aligned}
$$

As we mentioned to you over the phone, we would like to ask you about your ideas and opinions concerning certain driving habits. Your voluntary participation is greatly appreciated. All information you provide will be kept confidential, and your name or any other identifying information will not be associated with the responses you give. Your assistance will greatly help state and local transportation planners to do their jos. Also, feel free to ask me to stop and explain any questions which you don't understand, and again remember that all your answers will be confidential.

1) Would you te 11 me the model of your (YEAR AND MAKE LISTED ABOVE)

$[1: 12-13] \quad$ Mode $]$

2) What percentage of your driving is for: (READ RESPONSES)

$[1: 14-16]$

$[1: 17-19]$ Commuting to and from work

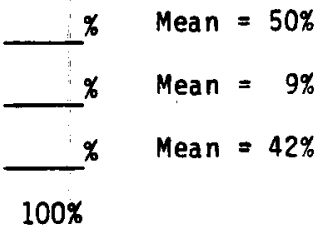

2)a. About how many miles do you estimate you travel during an average work day in: (READ RESPONSES IF NOT O\% in 2) 
2)b. About what percentage of your total weekly travel time is on: (READ RESPONSES)

$\begin{array}{llll}{[1: 29-31]} & \text { Divided highways } & \% & \text { Mean }=36 \% \\ {[1: 32-34]} & \text { Two-lane rural highways } & \% & \text { Mean }=17 \% \\ {[1: 35-37]} & \text { City streets } & \% & \text { Mean }=47 \%\end{array}$

3) Did you receive your initial driver training in school or from a commercial driver education instructor?

$\begin{array}{lll}{[1: 38]} & 28 \% & \text { Yes, school......1 How long ago? } \\ {[1: 39-40]} & 23 \% & \text { Yes, comercial...2 How long ago? } \\ & 48 \% & \text { No.............. }\end{array}$

4) How often do you wear seat belts when driving on roads which are wet, or snow and ice covered? (READ RESPONSES)

$[1: 41]$

$\begin{array}{ll}25 \% & \text { Always.......... } \\ 12 \% & \text { Most of the time..2 } \\ 25 \% & \text { Somet imes....... } \\ 38 \% & \text { Never......... } \\ & \text { Mean }=2.79\end{array}$

4)a. How often do you wear seat belts when driving on long trips? (READ RESPONSES)

$[1: 42]$

$\begin{array}{ll}31 \% & \text { Always.......... } \\ 14 \% & \text { Most of the time..2 } \\ 19 \% & \text { Somet imes........ } \\ 36 \% & \text { Never.......... }\end{array}$

4)b. How often do you wear seat belts when driving on short trips around town? (READ RESPONSES)

$[1: 43]$

$\begin{aligned} 14 \% & \text { Always.......... } \\ 8 \% & \text { Most of the time..2 } \\ 21 \% & \text { Sometimes....... } \\ 57 \% & \quad \text { Never ......... } \\ & \text { Mean }=3.17\end{aligned}$

4)c. How often do you use seat belts on your way (to/from) (APPROPRIATE BEHAVIOR SETTING: WORK, DAY CARE, OR HOME)?

$[1: 44]$

$\begin{aligned} 17 \% & \text { Always.......... } \\ 8 \% & \text { Most of the time..2 } \\ 21 \% & \text { Somet imes....... } \\ 54 \% & \text { Never......... } \\ & \text { Mean }=3.09\end{aligned}$


5)

5)a. Is it just a seat belt or does it have a shoulder strap also?

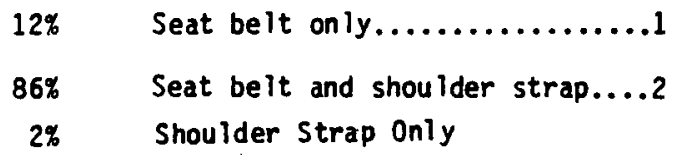

5)b. Can you put on just one and not the other?

$$
\begin{aligned}
& 32 \% \quad \text { Yes, separated seat belt and shoulder strap...... } \\
& 67 \% \quad \text { No, combined seat belt and shoulder strap......... }
\end{aligned}
$$

5)c. Has anyone told you or demonstrated how to put on the belt?

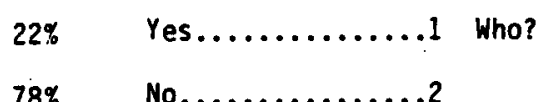

\begin{tabular}{|c|c|c|c|}
\hline$[1: 50]$ & $93 \%$ & Yes.............1 & \\
\hline$[1: 51]$ & $5 \%$ & No.............2 & (SPECIFY REASON): \\
\hline & $2 \%$ & Don't know.......8 & (SPECIFY WHY): \\
\hline
\end{tabular}

5)d. Do you think this safety belt system is in good working condition?

5)e. Do you have any trouble putting on or adjusting the belt?

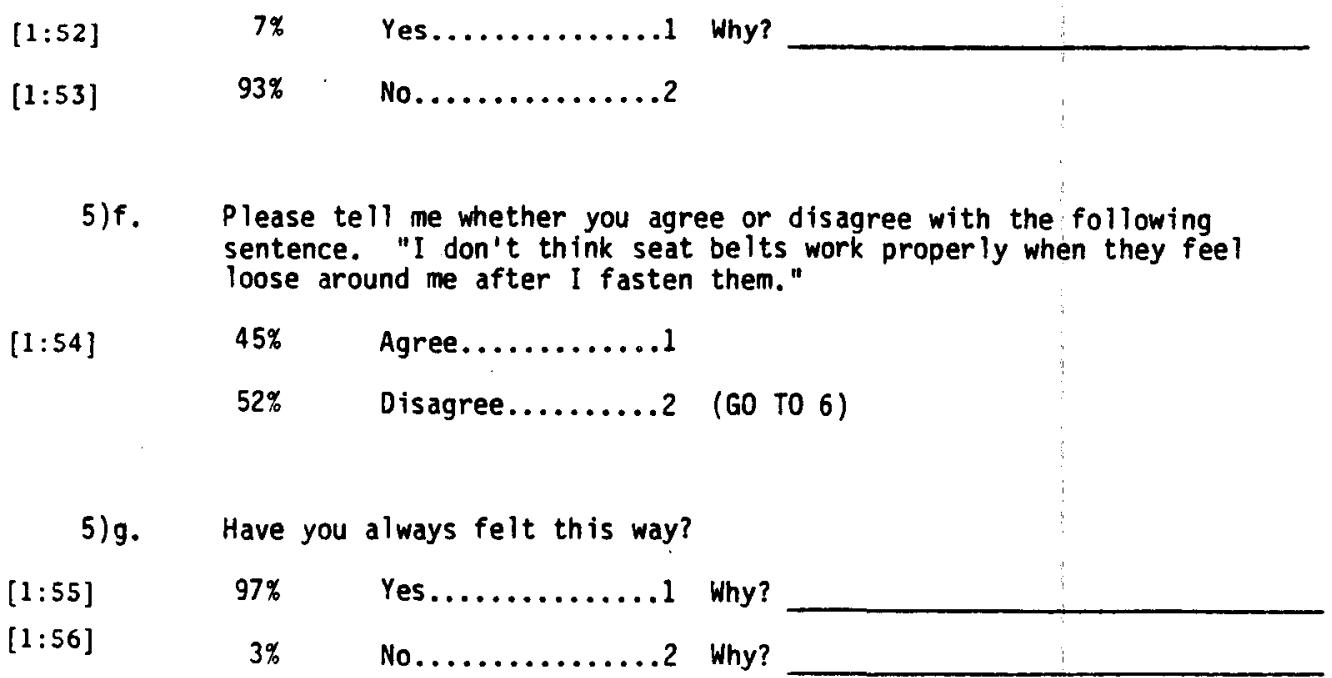


6) On a scale of 1 to 5 , with 1 being "very uncomfortable" and 5 being "very confortable", how would you rate the seat belt system in your car? (SHOW CARD A) Very

$\{1: 57\}$ Uncomf or table

Very Comf ortable

1

2

3

4

5

7) On a scale of 1 to 5, with I being "very inconvenient" and 5 being "very convenfent", how convenient is it for you to put on the seat belt in the car? (SHOW CARO B)

Very Inconventent

$\begin{array}{rc}1 & 3 \\ & \text { Mean }=3.73\end{array}$

Many people say that seat belts can be inconvenient or uncomfortable to use. Which of the following do you feel is the main reason they say this? (READ RESPONSES)

9) In the last five years, how many accidents have you or your famtly and friends been in either as a driver or a passenger where someone was injured and required some medical attention?

[1:60-61] (PROBE IF RESPONOENT IS UNSURE. IF $0,{ }^{\circ}$ GO TO 10; IF 1 OR MORE, ASK 9-d THROUGH 9-f FOR MOST RECENT ACCIDENT)

9)a. Were you in the (most recent) accident?

$[1: 62]$

$41 \%$

Yes..............

$59 \%$

No................ (GO TO $9-\mathrm{C})$

9)b. Were you the driver in the accident?

$76 \%$

Yes...............

$24 \%$

No.............2

9)c. Was anyone seriously hurt in the accident?

$43 \%$

$57 \%$

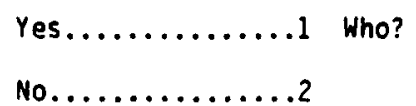

Very Convenient

4. 5 
9)d. Did you wear your seat belt more or less often right after the accident?

$[1: 66]$

$$
\begin{aligned}
& \text { 25\% Yes, more often } \ldots \ldots \ldots \ldots \ldots 1 \\
& \text { 5\% Yes, less often............. } \\
& 44 \% \text { No, as often (SAME).......... (GO TO 9-f) } \\
& \text { 7\% No, always wore it before.....4 (GO TO 9-f) } \\
& 20 \% \text { No, never wore it before......5 (GO TO 9-f) }
\end{aligned}
$$

9)e. What was it about the accident that made you wear your seat belt (more/less) often than before? (RECORD VERBATIM)

56\% Person Hurt/Killed Due To Not Wearing Belt

$[1: 67-68]$

9)f. Do you wear your seat belt as often now as you did immediately following this accident?

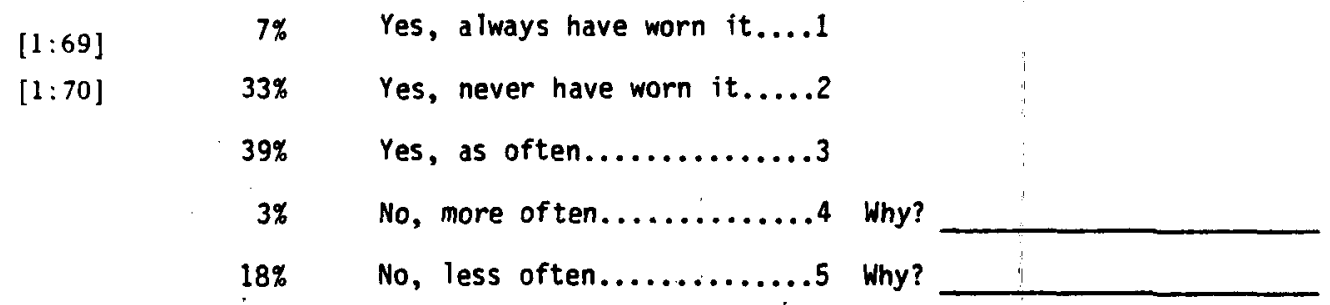

10) People have many different concerns with regard to their safety while driving. For the following types of concerns, please rate your level of concern between 1 and 5 , if 1 is "very little concern" and 5 is "very much concern": (SHOW CARD C)

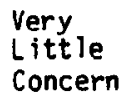

$[1: 71]$

$[1: 72]$

$[1: 73]$

$[1: 74]$

$[1: 75]$

$[1: 76]$ a. The chance of being injured in an automobile accident

b. Your car's handling ability

c. Being trapped in your car following an accident

d. Your driving ability in poor weather like rain, snow, or fog

e. The possibility of other drivers crashing into you

f. Driving with other people in the car
Very

Concern

Mean Rank

$\begin{array}{lll:llll}1 & 2 & 3 & 4 & 5 & 4.24 & 2 \\ 1 & 2 & 3 & 4 & 5 & 3.42 & 6 \\ 1 & 2 & 3 & 4 & 5 & 3.74 & 4\end{array}$

$\begin{array}{lll:llll}1 & 2 & 3 & 4 & 5 & 3.93 & 3\end{array}$

$1 \quad 2 \cdot 3 \quad 4 \quad 5 \quad 4.53 \quad 1$

$\begin{array}{lll:llll}1 & 2 & 3 & 4 & 5 & 3.62 & 5\end{array}$ 
11) In general, when you are a passenger in someone's else's car, how much of the time do you use seat beits? (READ RESPONSES)

$[1: 77]$

$\begin{aligned} 8 \% & \text { Always.......... } \\ 18 \% & \text { Most of the time..2 } \\ 36 \% & \text { Sometimes........ } \\ 38 \% & \text { Never......... } \\ & \text { Mean }=3.02\end{aligned}$

11)a. How much of the time do you use them when you are driving? (READ RESPONSES)

$[1: 78]$

\begin{tabular}{|c|c|}
\hline $16 \%$ & Always............ (GO TO 13) \\
\hline $16 \%$ & Most of the time...2 \\
\hline & Somet ines........3 \\
\hline $38 \%$ & Never...........4 \\
\hline
\end{tabular}

$[2: 1-6]$ Repeat Vehicle 10

$[2: 7] \quad \underline{2}$ 
12) On a scale from 1 to 5 , with 1 being "decreases very much," 3 being "stays about the same as usual," and 5 being "increases very much, please tell me if your use of seat belts changes when you are driving in the following situations. (SHOW CARO D)

[2:8] a. During the weekday $\begin{array}{lc:c}\text { Decreases } & \begin{array}{c}\text { Stays the } \\ \text { Very Much }\end{array} & \begin{array}{l}\text { Increases } \\ \text { Very Much Mean Rank }\end{array}\end{array}$ evenings

$[2: 10] \quad c$. On a holiday

d. During rush hours

e. On a trip where you make more than one stop along the way $1 \quad 2$

f. When in a car smaller than the one you typically drive

When asked by a passenger to put on your seat belt

h. When driving alone

i. When you are driving with children in the car

j. When the weather is poor like rain, snow, or fog

k. After having a few drinks

1. After taking drugs or prescribed medication

m. After you have been in or nearly in an accident

n. When on unfamiliar streets

123

123

\begin{tabular}{|c|c|c|}
\hline 4 & 5 & 2.92 \\
\hline 4 & 5 & 3.37 \\
\hline 4 & 5 & 3.77 \\
\hline 4 & 5 & 3.46 \\
\hline 4 & 5 & 3.22 \\
\hline 4 & 5 & 3.52 \\
\hline 4 & 5 & 4.00 \\
\hline 4 & 5 & 3.27 \\
\hline 4 & 5 & 3.98 \\
\hline 4 & 5 & 4.06 \\
\hline 4 & 5 & 3.59 \\
\hline 4 & 5 & 3.52 \\
\hline 4 & 5 & 3.82 \\
\hline 4 & 5 & 3.30 \\
\hline
\end{tabular}

(FOR EACH "4" OR "5" ANSWER IN 12, ASK:) Why does your use of seat belts increase (READ SITUATION)? (RECORD RESPONSE LETTERS ON LINE(S) BELOW AND WRITE IN THE REASON(S))

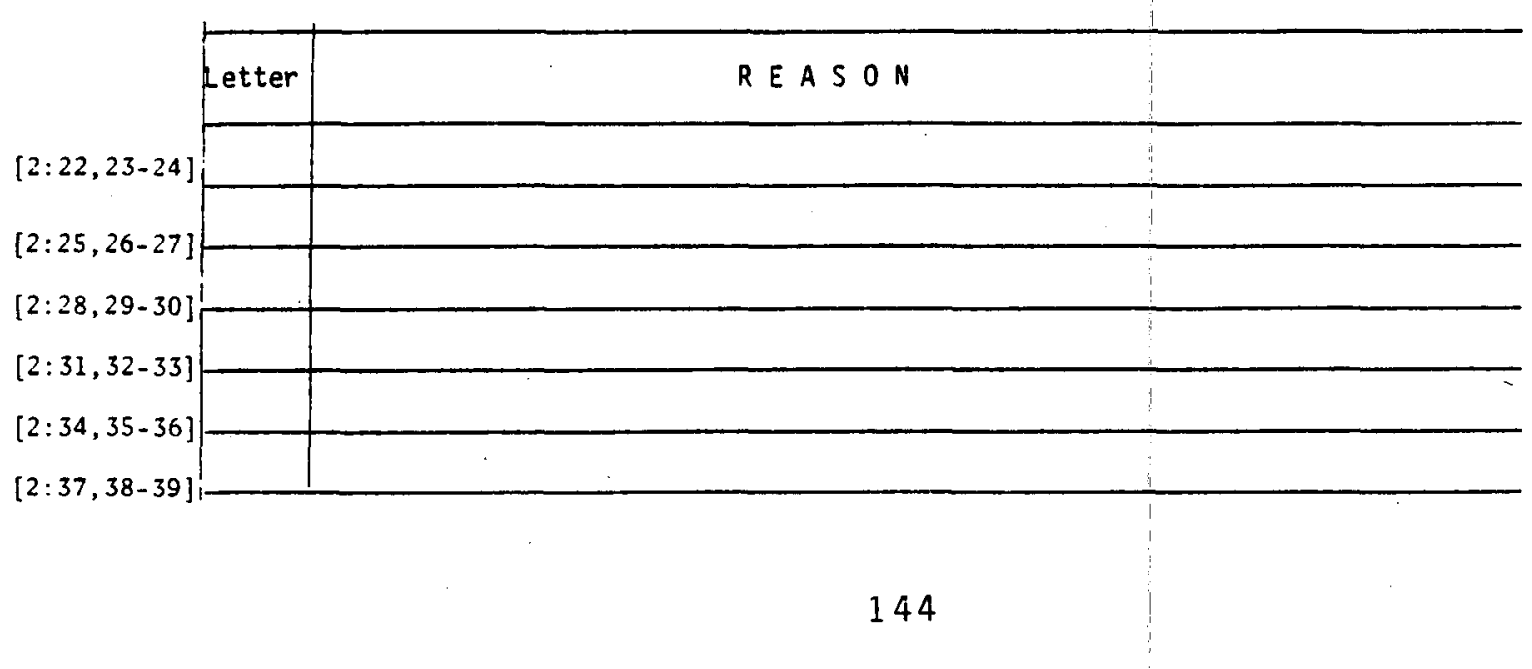


13) Is your use of seat belts today the same as it's always been?

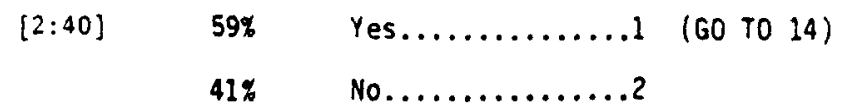

13)a. Can you think back to a period when you used seat belts most of the time?

[2:41] $76 \%$ Yes............ What got you started?

[2:42] $24 \% \quad$ No.............. Why didn't you?

(GO TO 14)

13)b. Has your use of seat belts changed since that time?

(PROBE FOR MORE OR LESS OFTEN)

[2:43] 25\% Yes, more often..........

$65 \%$ Yes, use less of ten........2

Could you explain the reason for this? (PROBE FOR WHY ANO WHEN, ESPECIALLY IF RELATED TO COMFORT/CONVENIENCE)

$[2: 44-45]$

14) Before you started to orive, did your parents or guardian or any adult you rode with consistently tell you to wear seat belts when in their car?

$[2: 46]$

$15 \%$

Yes...........................

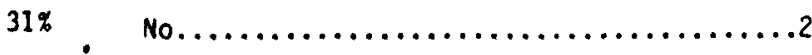

$54 \%$ Oid not have seat belts when I was

chfld............................ (Go TO 15)

1\% Don't know/remember................

14)a. Oid they wear seat belts themselves most of the time?

$[2: 47]$

\begin{tabular}{|c|c|}
\hline $29 \%$ & 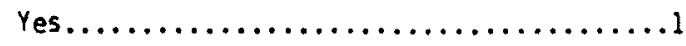 \\
\hline $67 \%$ & No........................... \\
\hline & now/remember. \\
\hline
\end{tabular}

15) In general, does your emplayer or business require that you wear seat belts when driving a company car or on business travel in your own car?

$[2 ; 48]$

$\begin{aligned} 8 \% & \text { Yes........... } \\ 49 \% & \text { No.......... } \\ 3 \% & \text { Don't know..... } \\ 41 \% & \text { Not applicable...9 }\end{aligned}$


16) There are occasions when it is difficult to put on a seat belt, like when it gets tangled or stuck behind the seat. When those occasions happen in your car, do you: (READ RESPONSES)

[2:49] $30 \% \quad$ Work at it until you resolve the problem..........

9\% Try hard but stop if it takes too much effort.....2

Leave it alone if it does not

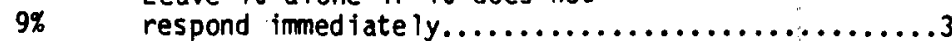

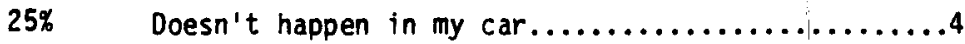

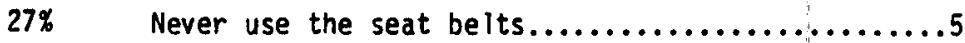

17) When you have driven other people in your car, have you ever asked them to buck le up their seat belts?

[2:50] $\quad 55 \% \quad$ Yes..............

45\% No.............. (GO TO 17-d)

17)a. Were you wearing seat belts when you asked them to do so?

$\begin{array}{ll}76 \% & \text { Yes............. } \\ 24 \% & \text { No............ }\end{array}$

17)b. Could you describe the situations in which you asked them to put on their seat belts? (PROBE IF "DON'T REMEMBER")

$[2: 52-53]$ 43\% Always Make Kids Wear Them

17)c. Did they do so?

$96 \%$
$4 \%$
$\quad$ No.................... (GO TO 17-e)

17)d. Do you think they did so mostly: (READ RESPONSES)

$\begin{array}{ll}37 \% & \text { Out of courtesy? } \ldots \ldots \ldots \ldots \ldots \ldots \ldots \ldots \ldots \ldots \ldots \ldots \ldots \ldots \ldots \\ 29 \% & \text { Because it was the right thing to do? } \ldots \ldots \ldots \ldots \ldots \ldots\end{array}$

17)e. Do you feel that on occasions when you have other people in the car - that if you buckled up that the other people would buck le up too without you having to ask them?

$[2: 56]$

\begin{tabular}{|c|c|}
\hline $63 \%$ & Yes............. \\
\hline 35 & No........... \\
\hline
\end{tabular}


18) Have you ever been in a car without your seat belt fastened and been asked to put it on?

$[2: 57]$

$49 \% \quad$ Yes..............

$51 \%$ No.............. (GO TO 19)

18)a. Was the person who asked you a driver or a passenger?

$[2: 58] \quad 86 \% \quad$ Driver...........

11\% Passenger.........2

3\% Both................

18)b. What was your relationship with the person(s) who asked? (READ RESPONSES - CHECK ALL THAT APPLY)

$[2: 59] \quad 11 \%$ Spouse $[2: 61] \underline{55 \%}$ Friend $[2: 63] \quad 20 \%$ Workmate

$[2: 60] \underline{12 \%}$ Parent $[2: 62] \quad 18 \%$ Relative $[2: 64] \quad 4 \%$ Other (SPECIFY BELOW)

18)c. Did you put on your seat belt when asked?

[2:65] $97 \%$ Yes.............


19) Please tell us how safe you think it is to drive under the following conditions on a scale of 1 to 5 , with 1 being "very dangerous" and 5 being "very safe." (SHOW CARD E)

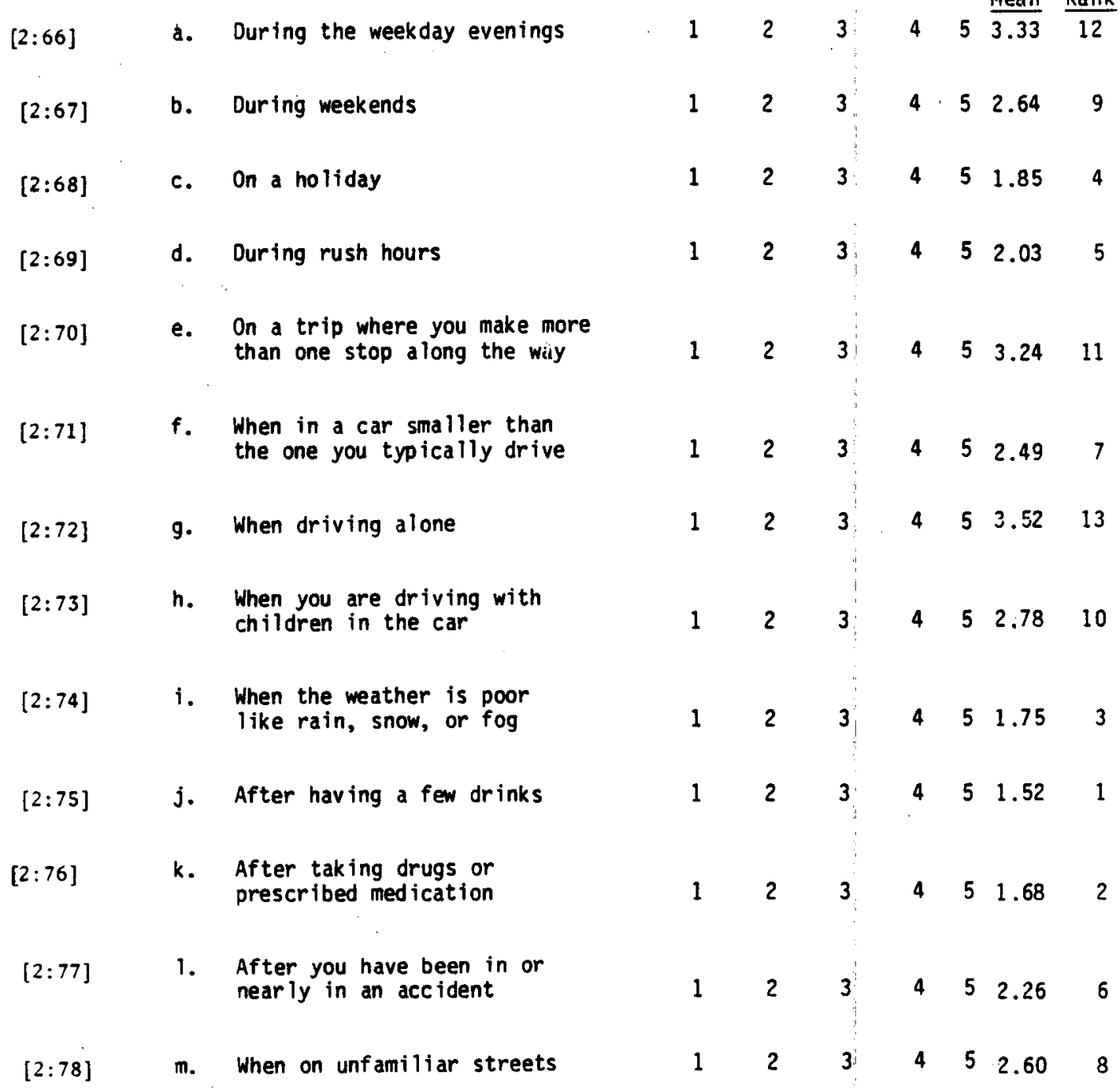

[End Card Two]

[3:1-6] Repeat Vehicle 1D

$[3: 7]$

3 

getting people to wear their seat belts. On a scale of 1 to 5 , with 1 being "not very influential" and 5 being "very influential," please rate the influence each of the following types of individuals have had or would have regarding your own use of seat belts? (SHOW CARD F)

a. The police

$$
\text { Not Very }
$$

Very

$$
\text { Influential Influential }
$$

b. A federal government official

c. A state or local government official

d. An autornobile insurance agent

$\begin{array}{ccccccc}1 & 2 & 3 & 4 & 5 & \frac{\text { Mean }}{3.65} & \frac{\text { Rank }}{3} \\ 1 & 2 & 3 & 4 & 5 & 2.92 & 7 \\ 1 & 2 & 3 & 4 & 5 & 2.83 & 8 \\ 1 & 2 & 3 & 4 & 5 & 3.51 & 4 \\ 1 & 2 & 3 & 4 & 5 & 2.96 & 6 \\ 1 & 2 & 3 & 4 & 5 & 2.21 & 11 \\ 1 & 2 & 3 & 4 & 5 & 2.69 & 9 \\ 1 & 2 & 3 & 4 & 5 & 3.67 & 2 \\ 1 & 2 & 3 & 4 & 5 & 3.76 & 1 \\ 1 & 2 & 3 & 4 & 5 & 3.51 & 5 \\ 1 & 2 & 3 & 4 & 5 & 2.56 & 10\end{array}$

21) Do you usually listen to stations on your car radio that primarily play music or are they talk/all news stations?

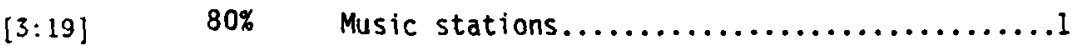

6\% Talk/all news stations.................. (GO TO 22)

$9 \%$ Other (SPECIFY):___..3 (GO TO 22)

$5 \%$ Don't listen to radio very much............ (G0 T0 22)

\begin{tabular}{|c|c|}
\hline $25 \%$ & Rock................................ \\
\hline $30 \%$ & 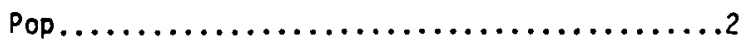 \\
\hline $12 \%$ & 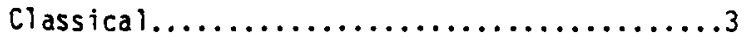 \\
\hline $3 \%$ & 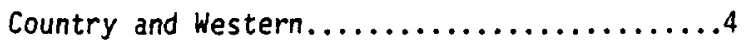 \\
\hline & other (SPECIFY): \\
\hline
\end{tabular}

21)a. What kind of music do you listen to most of ten? (READ RESPONSES)

$[3: 20]$ 
22) How many children four years of age or under are there in your household?

$[3: 21-22]$

\#. Of Children $0 \quad 76 \%$

None___ (G0.TO 23)

22)a. Do you have child car seats?

$\begin{array}{llll}{[3: 23]} & 77 \% & \text { Yes............. How many? } \\ {[3: 24]} & 23 \% & \text { No............. }\end{array}$

22)b. How often do you use a safety seat when a child is in the car?

$\begin{array}{ll}61 \% & \text { Always........... (GO T0 22-e) } \\ 22 \% & \text { Somet imes........ } \\ 17 \% & \text { Never........... (GO TO 22-e) }\end{array}$

22)c. Under what circumstances do you not use a child safety seat? (PROBE UNTIL NO OTHER REASON)

$[3: 26-27]$

45\% Short Trips Locally

22)d. Why? $43 \%$ Too Much Trouble on Short Trips

[3:28-29]

22)e. How (was/were) the safety seat(s) obtained? (Was it/Were they): (REAO RESPONSES)

$[3: 30]$

$$
\begin{array}{ll}
66 \% & \text { Purchased......... } \\
34 \% & \text { A gift.......... (GO TO 22-g) } \\
& \text { Loaned/rented....3 (GO TO 22-g) }
\end{array}
$$

22)f. What determined which one(s) you purchased?

$[3: 31-32] \quad 20 \%$ Price

22)g. Were you given written instructions or a demonstration on how to use the safety seat $(s)$ ?

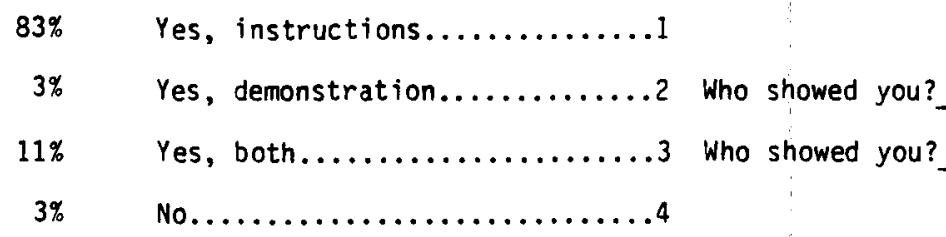


23)

To which of the following sources would you be most likely to pay attention regarding automob lle safety messages? (SHOW CARO FF) (PROBE FOR "next most likely," etc., UNTIL SOURCES ARE RANK ORDERED

\begin{tabular}{|c|c|c|c|c|c|c|c|}
\hline Meañ & & Rank & & & ank & & Mean \\
\hline 2.48 & {$[3: 35]$} & 2 & Radio & {$[3: 38]$} & 1 & Television & 1.86 \\
\hline 3.98 & {$[3: 36]$} & 4 & Magazir & ne $[3: 39]$ & 3 & Newspaper & 3.17 \\
\hline .86 & {$[3: 37]$} & 6 & Pamph le & et $[3: 40]$ & 5 & Poster & 4.63 \\
\hline
\end{tabular}

24) Where do you most of ten go to have your car serviced or repaired? (READ RESPONSES)

$[3: 41]$

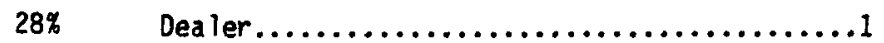

8\% Department store auto center or other

commercial service center.................

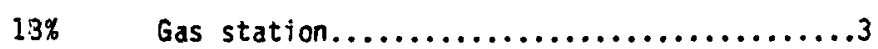

$40 \% \quad$ Independent service garage.............4

$5 \%$ Self/friend/relative.................

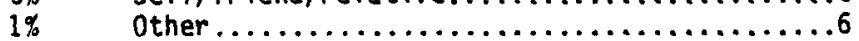

25) Can you think back to a time when you thought you should wear beits and didn't?

40\% Yes............ Why?

$[3: 43]$

$60 \%$

No...............2

26) Have you ever put a belt on and then had something happen during a trip to make you take it off?

[3:44] $36 \% \quad$ Yes............. Please explain

$[3: 45] \quad 64 \% \quad$ No.............

27) It is common knowledge that certain people have done things to the ir seat belt systems so they would not have to use them. Have you ever disconnected a safety belt system in any way so it would be easier not to use?

$24 \% \quad$ Yes............. Why?

$76 \%$

No..............2

28) Regardless of your personal opinion regarding seat belts, if you were given the job of getting people to use them more often, how would you convince them? (RECORD VERBATIM)

[3:48-49] 35\% General Comment Regarding Sa fety

23\% Show Pictures of Accidents

(G0 TO 29 IF ANSWER IS "couldn't do anything") 
28)a. Why do you think this would work? (RECORD VERBATIM)

$[3: 50-51]$

29) I'd like to ask you a few general questions which we will use to find out the types of people we are surveying in this study and a little bit about their backgrounds. (SHOW CARD G) Please tell me the letter next to the range in whtch your age falls.

$$
\begin{aligned}
& \text { A. } 15-17 \ldots \ldots .130 \% \text { D. } 35-49 \text { yrs......4 } \\
& 8 \% \text { B. } 18-24 \text { yrs...2 } 19 \% \text { E. } 50-64 \text { yrs........5 } \\
& 34 \% \text { C. } 25-34 \text { yrs...3 } 9 \% \text { F. } 65 \text { - Above.........6 } \\
& \text { Refused......8 }
\end{aligned}
$$

30) How of ten do you attend religious services? (REAO RESPONSES)

$[3: 53]$

\begin{tabular}{|c|c|c|}
\hline$[3: 54]$ & $20 \%$ & $\begin{array}{l}\text { A. B lack not of Hispanic Origin........1 } \\
\text { B. Hispanic...................... }\end{array}$ \\
\hline & $1 \%$ & C. Native American/Alaskan Native.......3 \\
\hline & $3 \%$ & D. Asian/Pacific Islander.............4 \\
\hline & $74 \%$ & E. White............... \\
\hline & $1 \%$ & F. Other (SPECIFY): \\
\hline
\end{tabular}

$\begin{array}{ll}42 \% & \text { Very often....... } \\ 25 \% & \text { Sometimes........ } \\ 32 \% & \text { Not very often....3 }\end{array}$

31) What is your race or ethnic group membership? (SHOW CARD H)

32) Considering all household members, please estimate in which range the total household income falls. Is it:

(SHOW CARD I)
$9 \%$

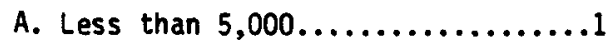
B. Between 5,000 and $14,999 \ldots \ldots \ldots 2$
C. Between 15,000 and 24,999........3
$20 \%$
D. Between 25,000 and $34,999 \ldots \ldots \ldots 4$
$11 \%$
E. Between 35,000 and $44,999 \ldots \ldots \ldots 5$
$5 \%$
F. 50,000 and over.............6
G. Refused ..................... 
33) What was the last grade of school you completed? (SHOW CARD J)
$[3: 56]$
34) About how tall are you? Inches
[3:57]
[3:58-59]
35)
If you smoke, about how many cigarettes do you smoke a day?
$\{3: 60\}$

\begin{tabular}{|c|c|c|}
\hline $12 \%$ & Less than $1 / 2$ pack............... & (GO TO 36 ) \\
\hline $9 \%$ & $1 / 2$ to less than 1 pack..........2 & $\left(\begin{array}{lll}G 0 & \text { TO } & 36\end{array}\right)$ \\
\hline $18 \%$ & 1 pack or more................ & (GO TO 36 ) \\
\hline $61 \%$ & Don't smoke cigarettes...........8 & \\
\hline
\end{tabular}

35)a. Did you ever smoke cigarettes?

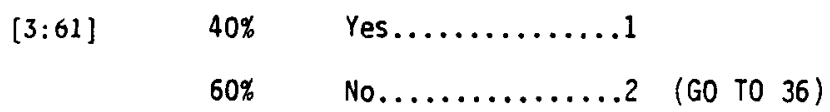

35)b. What made you stop? 56\% Not Healthy

$[3: 62-63]$

36) How of ten do you visit the dentist to have your teeth checked?

$[3: 64] \quad 49 \% \quad$ Every 6 months.........................

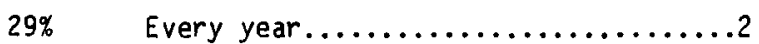

$8 \% \quad$ Every 2 years or more...............

11\% Only when something bothers me......4

37) Do you jog, cycle, swim, or engage in any constant exercise pattern?
$[3: 65]$
$55 \%$
Yes..............1
$45 \%$
No............2 (GO TO 38 )

37)a. How often during the week do you do so? Times 
38) With in the past three years, have you undertaken any other activities or taken other actions on your own to maintain or improve your health?

$\begin{array}{llll}{[3: 67]} & 60 \% & \text { Yes............. What? } \\ {[3: 68]} & 40 \% & \text { No............. (60 TO 39) }\end{array}$

38) a. What made you do this? $29 \%$ To Improve Health

$[3: 69-70]$

39) Do you agree or disagree that wearing seat belts is like other good health practices, such as brushing your teeth and having regular medical checkups?

$$
\begin{array}{ll}
80 \% & \text { Agree........... } \\
20 \% & \text { Disagree........ }
\end{array}
$$

40) About how often do you gamble during the year? Times Mean $=7.93$ (IF NEEDED, PROBE WITH EXAMPLES: LOTTERIES, HORSE RACES, OFFICE POOLS, CASINOS, BINGO, ETC.)

$[3: 72-73]$

41) We would like to find out whether people's outlook on life has any effect on how they drive. Regarding these pairs of statements, which of the two do you agree with more? (READ RESPONSES AND SHOW CARD K)

[3:74] a. I have found that what is going to

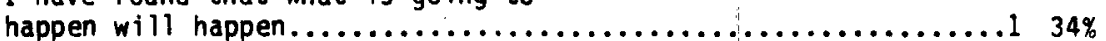
Trusting to fate has never turned out as well for me as making a decision to take a definite course of action.......2 $66 \%$

[3:75] b. When I make plans, I am almost certain

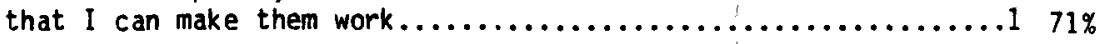
or

It is not always wise to plan too far ahead, because many things turn out to be a matter

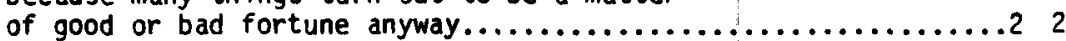

[3:76] c. In my case, getting what I want has

little or nothing to do with luck....................... $90 \%$

$$
\text { or }
$$

Many times we might just as well decide

what to do by flipping a coin........................ $8 \%$

[3:77] d. Many times I fee I that I have little influence over the things that happen to me............... $40 \%$ It is impossible for me to believe that chance or luck play an important role in my life.

[3:78] e. What happens to me is my own doing...................... $76 \%$ or Sometimes I feel that I don't have enough control over the direction my life is taking............... 21\%

[End Card Three].

$[4: 1-6] 1 D$

$[4: 7] 4$ 
42) When you make plans ahead, do you usually get to carry-out things the way you expected, or do things usually come up to make you change your plans.

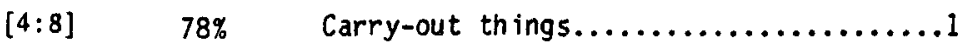

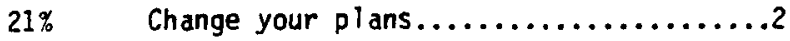

42)a. Have you usually felt pretty sure your life would work out the way you wanted to, or have there been times when you haven't been sure about it.

[4:9] $\quad 41 \% \quad$ Felt pretty sure................

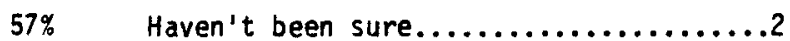

42)b. Some people feel they can run the ir lives pretty much the way they want to; others feel the problems of life are sometimes overwhe iming. How about you?

$[4: 10] \quad 72 \% \quad$ Run life the way I want............

$27 \% \quad$ Problems sometimes overwhelming......2

42)c. Do you think it's better to plan your life a good way ahead, or would you say life is too much a matter of luck to plan very far.

[4:11] $77 \% \quad$ Plan ahead........

$21 \%$ Matter of luck...2

Time ended $A M$.

PM.

$[4: 12-13]$

(THANK RESPONDENT) 


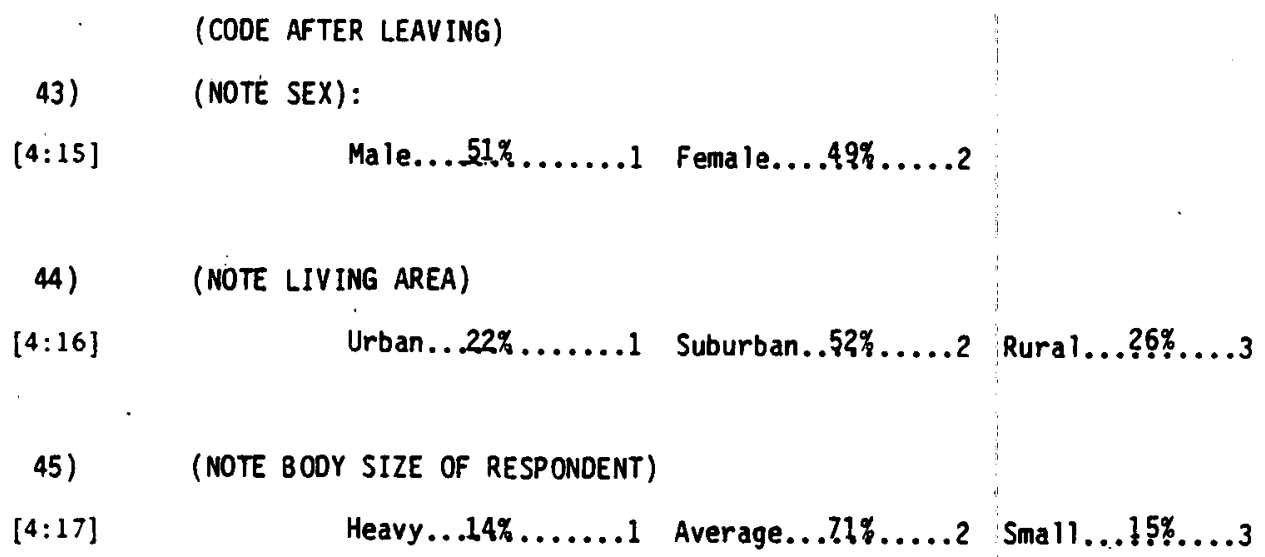


APIEHDIX C

OBSERVATIUH PrRUTUCoL.

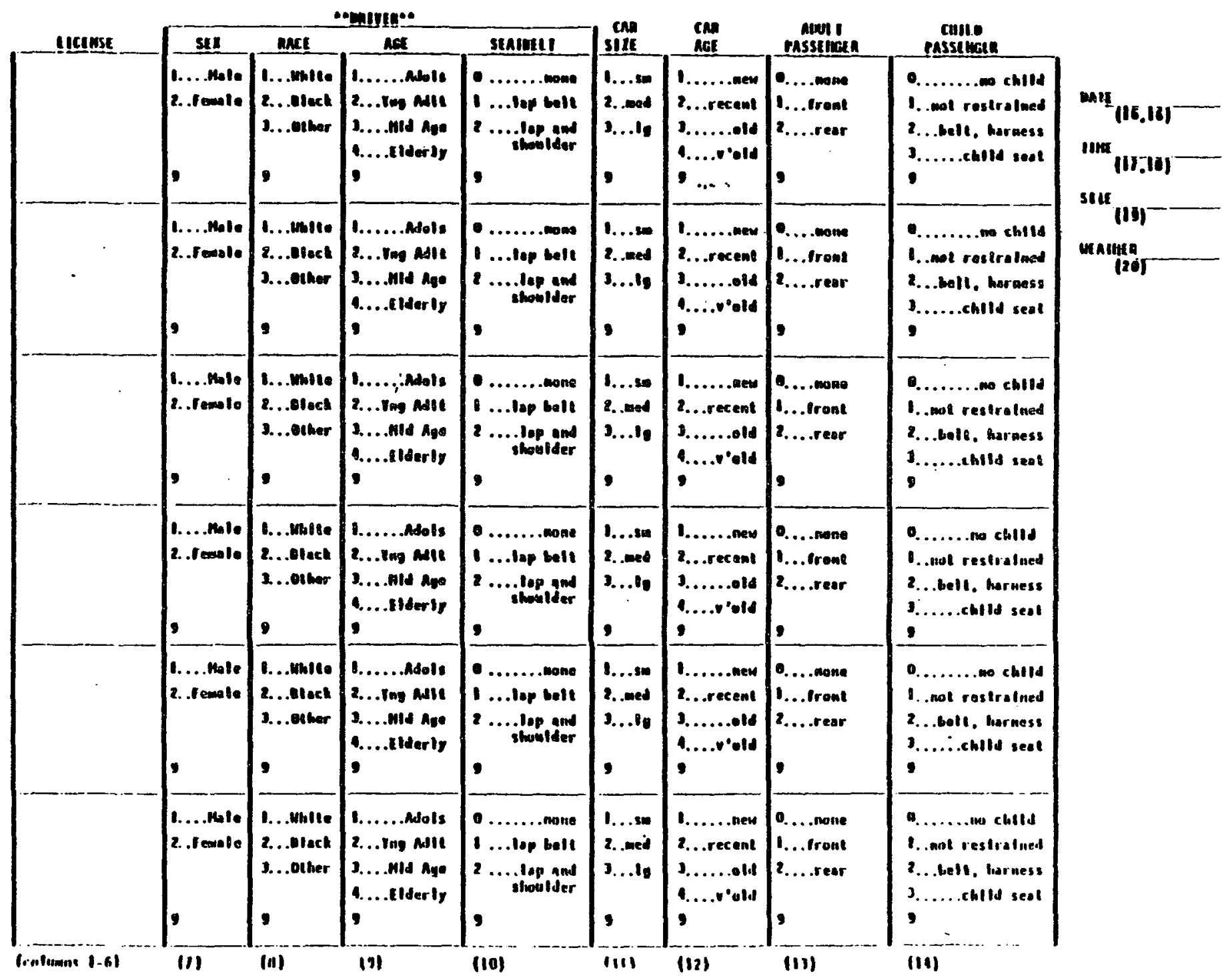

